XVII.

Aus der Königl. Psychiatrischen und Nervenklinik der Universität Kiel (Direktor: Geheimrat Professor Dr. Siemerling).

\title{
Ueber Situations-Psychosen.
}

\section{Ein Beitrag zu den transitorischen, inshesondere haftpsyehotisehen Störungen.}

Von

\author{
Dr. med. et phil. James Lewin, \\ Assistenzarzt an der psychiatrischen und Nervenklinik Leipzig; \\ vorher Kiel.
}

In ihrer Arbeit: „Die Geschichte der Haftpsychosen“ kommen Nitsehe und Wilmanns zu dem Resultat: „Der langjährige Kampf um die Frage nach einer spezifischen Haftpsychose hat sich dahin entschieden, dass die juvenilen Verblödungsprozesse nur eine charakteristische Färbung von dem Haftmilieu erhalten, und dass bei entsprechend organisierten Persönlichkeiten akute und chronische Psychosen zur Entwicklung kommen können, die denjenigen in der Freiheit unter dem Einfluss affektbetonter Erlebnisse entstandenen Störungen gleichzustellen sind. Die eigenartige Symptomatik dieser Erkrankung berechtigt uns jedoch, sie als besondere Typen zu betrachten und als eigentliche Haftpsychosen zusammenzufassen, wie wir etwa die mannigfachen eigenartigen Reaktionen und Entwicklungen nach Unfällen unter dem Sammelnamen ,traumatische Neurosen" beschreiben ...: Wenn aber nach Darlegung dieser Autoren generelle Unterschiede zwischen - dem in der Freiheit unter dem Einfluss affektbetonter Erlebnisse und in der Haft entstandenen Psychosen nicht bestehen, so wird man auch den gegensätzlichen Standpunkt gelten lassen müssen, der durch zusammenfassende Betrachtung beider Arten von Psychosen ihre gemeinsamen Eigentümlichkeiten festzustellen und sie von anderweitigen Psychosen zu differenzieren sucht. Es ist ja nicht nur der schwer Entartete, der Gewohnheitsverbrecher, wie ihn uns beispielsweise Siefiert schildert, der erkrankt. Auch der erstmalig Bestrafte, der Gelegenheits- und Affektverbrecher, der leicht Entartete kann psychotisch werden. Und wie die Gesamtheit der Entarteten eine kontinuierliche Reihe abgibt, die von der idealen Norm des gesunden Individuums bis zu den schwerst Entarteten und sozusagen schon psychotischen 
Individuen hinführt, so bilden auch die generativen Geistesstörungen in ihrer Gesamtheit eine kontinuierliche Reihe von den leichtesten Zuständen noch physiologischer Verstimmung bis zu den schwersten psychotisehen Störungen, deren Träger nicht immer gerade kriminelle Psychopathen zu sein brauchen.

Manche Autoren benutzen die gemeinsame Bezeichnung ,degeneratives Irresein“ oder „Degenerations-Psychose". Der Begriff der Degeneration bildet das grosse Sammelgefäss, in das so ziemlich alles das hineingeworfen wird, was dem Verständnis der funktionellen Psychosen Schwierigkeiten bereitet. Auf die Schwierigkeiten und Widersprüche, die in den wissenschaftlichen Formulierungen dieses Begriffes enthalten sind, soll in dieser Arbeit nicht eingegangen werden. Jedenfalls ist diese Bezeichnung, wie schon Stern hervorhebt, viel zu unbestimmt. Sie würde schliesslich alle funktionellen Psychosen umfassen müssen, da wir eigentlich überall eine degenerative Anlage in irgendwelcher Form und in allen möglichen Uebergängen annehmen. Abgesehen davoll wird aber damit der Anlage eine ätiologische Bedeutung zugeschrieben, die man - ohne sie leugnen zu dürfen - in diesem Ausmass und Umfang für viele degenerativ-psychotische Zustände bezweifeln muss. Die Beziehungen zwischen der degenerativen Anlage und der Persönlichkeit als Träger dieser Anlage kommen dabei leicht zu kurz. Wie Homburge $\mathrm{r}$ betont, ist der tief entartete Gewohnheitsverbrecher viel weniger Einzelmensch als der leicht oder spät Kriminelle. Dieser hat eine viel ausgeprägtere Individualität. Sein soziales und pathologisches Verhalten ist psychologisch durchsichtiger und verständlicher, namentlich in den Beziehnngen der Persönlichkeit zu den jeweiligen Aussenbedingungen.

Das Individum ist nieht die blosse Summe seiner krankhaften und normalen Züge; es lässt sich nicht auf eine auch noch so komplizierte ideale Formel von gesetzmässigen Verknüpfungen bringen. Die konstanten Eigentümlichkeiten, wie sie jedes Individnum aufzuweisen hat, bestimmen nicht immer und nicht ausschliesslich sein Tun und Handeln. Die gesamten bisherigen Erlebnisse haben die Individualität bilden helfen, behalten ihre Nachwirkung und können zu einer weiteren Veränderung der Individualität beitragen. „Individialität" ist auch nichts Konstantes, wenn man "sie an ihren Reaktionen zu erkennen sucht. Diese werden nämlich z. B. auch durch die derzeitige Konstellation bestimmt. Eine heitere Stimmung lkann zu einer ganz anderen Reaktion führen als Traurigkeit. Selbst wenn wir also bestimmte krankhafte Züge eines Individuums aus der Anamnese wissen, so bekommen wir damit nicht immer ansreichende Anhaltspunkte für die Beurteilung seiner krankhaften Reaktionen. Es ist ja auch bekannt, wie gerade oft Degenerierte durch ihr wechselndes Verhalten auf äusserlich ähnliche 
Reize (wiederholte Strafhaft) dem psychiatrischen Beurteiler Schwierigkeiten machen, eben weil ähnliche Bedingungen nicht zu ähnlichen Reaktionen zu führen brauchen. Um ein häufiges Beispiel zu geben: ein Individuum, das zu längerer Freiheitsstrafe verurteilt wird, erkrankt nach einer gewissen Zeit der Haft an einem paranoiden oder anderen psychotischen Symptomkomplex, der wegen seiner anfänglichen Schwere längere Irrenanstaltspflege benötigt. Schliesslich wird das Individuum als geheilt wenn auch nicht immer mit genügender Krankheitseinsicht - entlassen. Draussen begeht es eine neue Straftat und jetzt kann es auch eine längere und schwerere Freiheitsstrafe ohne psychotische Erkrankung durchhalten. Solche Erfahrungen zeigen, dass mit der Statuierung und Einteilung der psychopathischen Konstitutionen noch nicht das volle klinische Verständnis der auf ihr basierenden Psychosen erreicht ist. Es gibt nämlich, um mit Jaspers zu sprechen, neben Psychosen, die wir als krankhafte Entwicklung einer Persönlichkeit (Paranoia) und solche, die wir als Prozess, der sich gleichsam auf die Persönlichkeit aufpfropft (Dementia praecox) auffassen, noch andere Möglichkeiten, durch die wir gewisse psychotische Zustände nach ihrer psychologischen Seite charakterisieren können. Eine solehe Möglichkeit liegt da vor, wo die Psychose Ausdruck einer durch äussere Umstände bestimmten und von ihr abhängigen Reaktion ist; diese Reaktion ist nicht Symptom einer krankhaften Entwicklung, sondern nur eine krankhafte Aeusserung der Persönlichkeit, eine einmalige Reaktion, die Beantwortung eines besonderen äusseren Reizes, mit dessen Wegfall auch die Reaktion verklingt. Es ist sozusagen eine akute Insuffizienz, ein Versagen der Psyche angesichts aussergewöhnlicher Ereignisse.

Bei der Einteilung der degenerativen Individuen hebt man für gewöhnlich diejenige Reaktionstendenz heraus, die während des vergangenen Lebens am meisten hervorgetreten ist. Im Vergleich dazu erscheinen dann die übrigen pathologischen Eigenschaften als Nebenzüge. Auf diese Weise entsteht eine Reihe ineinander übergehender Typen: erethische und torpide Imbezille, Moral insanity, Hysterische, Epileptoide usw. (Wilmanns). Diese so als charakteristisch herausgehobenen Reaktionstendenzen hängen aufs innigste zusammen, so dass ein Individuum mehrere derartige Züge in sich vereinen kann. Diese brauchen aber keine dauernden zu sein. Abgesehen davon, dass sie oft ebenso einer weiteren Ausbildung wie Rückbildung fähig sind, dass sie bei gewissen Typen periodisch wechseln, können sie auch infolge äusserer Einflüsse, wie Milieuwechsel, verschwinden und andere an ihre Stelle treten; ebensogut können sie unter äusserem Druck, wie in der Haft und der militärischen Disziplin, eine Verstärkung erfahren. Bei der erhöhten Suggestibilität und Labilität des seelisehen Gleichgewichts dieser Individuen ist das nichts Auffälliges. Dieser Umstand ist aber von Wichtigkeit für die 
psychotischen Ausnahmezustände. Die Möglichkeit, das $\lesssim$ die Alter a ti 0 n der Psy"che infolge besonders wirksamer Erlebnisse im stande ist, die Reaktionstendenzdes gew öhnlichen Lebens zu verwischen, ist nicht von der Hand zu weisen." Die Möglichkeit wird zur Wahrscheinlichkeit, wenn wir sehen, wie wenig die Psychose unter Umständen mit dem anamnestisch festgestellten degenerativen Typus übereinstimmt. Ferner finden wir, dass dasselbe Individuum verschíedene Krankheitsformen durchmachen kann. „Es ist der gleiche allgemeine degenerative Boden - so erklärt es Birnbaum -, auf dem sie alle erwachsen, und daher liegt vielfach in derselben psychopathischen Person die Disposition zu verschiedenartigen degenerativen Krankheitsformen. Er bezeichnet diese Disposition als eine psychogene, die mit der psychopathischen Konstitution nicht zusammenfällt, weil die Schwere der Psychopathie kein Hinweis auf eine etwaige psychotische Erkrankung ist. Homburger spricht zur Erklärung dieser Eigentümlichkeit von einer polymorphen pathologischen Reaktivität.

Man muss bedenken, dass nicht die Anlage minderwertig ist, sondern dass sie die Persönlichkeit als Träger dieser Anlage minderwertig macht; und auch dies nur in dem Fall, in dem eine Kompensation dureh anderweitige Eigenschaften zeitweise oder danernd unterbleibt. Und die uns hier beschäftigenden Psychosen sind gerade Reaktionen der gesamten Persönlichkeit. Das unterscheidet sie von den gewöhnlich so genannten pathologischen Reaktionen, den reaktiven, depressiven, hypomanischen und Erregungszuständen, wie sie bei bestimmten Psychopathen habituell auftreten. A u s s erg e w ö hnliche, nicht habituelle Reaktionen der gesamten Persönlichkeit, weil nicht partielle degenerative Anlage, sind also die Merkmale der fragliehen Zustände. Nur bei wiederholten Rezidiven kommt es zu Uebergängen zu den habituellen Reaktionen. „Aus der polymorphen Natur der pathologischen Reaktivität ergibt sich nach Homburger, dass die Kennzeichnung eines psychopathischen Individuums nicht aus der Kenntnis einer einzigen, selbst schweren abwegigen Reaktion geschehen kann. Denn diese ist immer nur ein Einzelfall abnormen Verhaltens unter bestimmten äusseren Umständen und bei einer bestimmten psychischen Konstellation."

Fs hat nicht an Versuchen gefehlt, das noch ungelöste Problem der degenerativen Psychosen durch theoretische Erwägungen zu einem einheitlichen Formenkreis zusammenzufassen. Am weitesten scheint mir darin Alzheimer zii gehen, der in der funktionellen oder endogenen Psychose im Grunde nur ein Produkt der krankhaften Anlage, aber nicht der übrigen Persönlichkeit sieht. Birnbaum hat sich in seinem Aufsatz: „Zur Frage der psychogenen Krankheitsformen" dahin geäussert: das Erlebnis, soweit es 
ein affektiv wirksames Geschehnis ist und die persönliche Eigenart, im speziellen die psychogene Disposition bilden die grundlegenden Komponenten psychogener Krankheitszustände. Dabei sei jedoch das Erlebnis lediglich nur der auslösende Reiz, Art und Inhalt des Erlebnisses daher ohne Belang, weil alle wesentlichen Eigenschaften der Erkrankungsformen durch die persönliche Eigenart bestimmt werden. Unter der persönlichen Eigenart versteht Birnbaum aber nicht die Individualität als solche, sondern ihre wie er es nennt - psychogene Disposition; diese bezeichnet die Unfähigkeit zur natürlichen affektiven Verarbeitung der Reize. Näher charakterisiert sie sich als Abstraktionsprodukt oder Zusammenfassung ,jener der Person innewohnenden allgemeinen und speziellen pathologischen Tendenzen, die samt und sonders darauf hinwirken, dass psychotische Reaktionen auf psychotische Reize erfolgen. Als allgemeine Eigentümlichkeiten dieser Disposition nennt Birnbaum die abnorme seelische Labilität, krankhaft herabgesetzte Widerstandskraft gegen psyehische Reize, abnorme Beeinflussbarkeit nach der Richtung des Pathologischen hin." Zu solchen allgemeinen Eigentümlichkeiten, die so ziemlich allen. Formen in mehr oder weniger ausgedehntem Masse zuzuschreiben wären, würden dann speziellere Unterformen hinzukommen, also psychogene Dispositionen von bestimmter Art, welche den entsprechenden speziellen psychogenen Erkrankungsformen zugrunde liegen. (Disharmonische Seelenveranlagung bei überwertigen Ideen, abnorme Dissoziabilität dex seelischen Zusammenhänge bei psychogenen Dämmerzuständen usw.) Die Kombination verschieden gearteter psychogener Dispositionen bei derselben Person erklären das eventuell gleichzeitig oder sukzessive Auftreten verschiedenartiger Krankheitszustände, ein Beweis für deren enge Zusammengehörigkeit. - Alle anderen persönlichen Eigentümlichkeiten spielen eine ebenso untergeordnete Rolle wie der auslösende Reiz, sie färben nebensächliche Krankheitszüge. Die psychogene Disposition allein ermöglicht die Abgrenzung der psychogenen Krankheitszustände, Diese selbst entsprechen den affektiven Reaktionen der Normalen auf psychische Reize hin. Sie stellen demnach pathologische Aequivalente der natürlichen affektiven Reaktionen dar, bedingt durch die in der psychogenen Disposition liegenden Unfähigkeit $\mathrm{zu}$ normaler affektiver Verarbeitung seelischer Reize. Sie weisen fliessende Uebergänge zu den psychopathisehen Reaktionen (im engeren Sinne) auf, mit denen sie das charakteristische Missverhältnis zwischen Reiz und Reaktion gemeinsam haben und von denen sie sich nur durch ihren in abnormer Intensität und Qualität hervortretenden echt psychotischen Charakter unterscheiden lassen. Sie bilden daher des öfteren nư psychotische Steigerungen der dem abnormen Durchschnittszustande eigenen psychopathischen Reaktionen, übermäßiger Ausprägungen des psychischen Grundzustandes. 
Einen durchgehenden Unterschied erkennt also Birnbaum zwischen den psychopathischen Reaktionen und den psychogenen Krankheitszuständen nicht an. Er muss aber zugeben, dass die Psychose nicht immer als verstärkte Ausprägung des psychopathischen Grundzustandes in Erscheinung tritt, und zwar dann nicht, wenn der Habitualzustand keine sonderliche Abweichung von der Norm zeigt. Hier behilft sich Birnbaum mit der Annahme einer latenten psychogenen Disposition. - Dafür einen zwingenden Beweis zu erbringen ist nach Lage der Sache nicht möglich. Eine Berechtigung für diese Annahme besteht in dieser Allgemeinheit nicht bei dem heutigen Stande unserer Erfahrungen. Ferner ist die psychogene Disposition nichts anderes als die - ins Psychologische gewandte - degenerative Anlage; sollte sie noch etwas anderes bedeuten, so wäre sie eine überflüssig eingeführte neue Unbekannte. Die degenerative Anlage besitzt aber nicht diese Alleinherrschaft, wenigstens nicht in vielen Fällen. Unsere Erfahrungen in dieser Hinsicht seheinen noch nicht so weit gediehen zu sein, dass wir die klinischen Bilder theoretisch zu einer Einheit zusammensehweissen können. Vielleicht bestehen innerhalb dieser ganzen Gruppe doch stärkere Unterschiede, die wir klinisch beobachten können und theoretisch anerkennen müssen. Die bisherigen psychiatrischen Beobachtungen in diesem Weltkriege lehren auch, dass fürr psychogene Störungen von Kriegsteilnehmern eine besondere psyehopathische Disposition nicht notwendig ist. Hoche meint sogar, ,jeder Feldzugteilnehmer ist bei entsprechenden Erlebnissen hysteriefähig". Unter diesem Einfluss der Kriegserfahrungen hat Birnbaum seine Ansicht dahin geändert, ,dass psychische Erschïtterungen auch ohne pathologische Belastung und Veranlagung alsreichen, um eine psychogene Störung hervorzurufen; ihre Eigenart wird aus der Art der Intensität des verursachenden äusseren Reizes, bzw. der sonstigen mit dem Affektstoss gegebenen äusseren Momente erklärlich. Diese durch einen starken Affektstoss ohne dispositionelles Entgegenkommen hervorgerufenen psyehogenen Störungen sind vorzugsweise dadurch charakterisiert, dass sie pathologische Fixierungen der körperlichen und seelischen Bestandteile oder Begleiterscheinungen des Chokerlebnisses, bzw. pathologische Realisierungen desselben darstellen." Kompliziert werden diese Störungen, wenn bei bestehender Disposition endogen vorgebildete Mlechanismen hinzukommen. Birnbaum sieht nun ein Charakteristikum der psychogenen Disposition ,in der allgemeinen Tendenz zu der geschilderten Dauerfestlegung und Realisierung der körperlichen und seelischen Begleiterscheinungen der wirksamen Erlebnisse".

Im Gegensatz zu den früheren Anschaungen Birnbaum's betont Siefert fast aussschliesslich den "Kunstprodukt"-Charakter der degenerativen Haftpsychosen; ihren transitorischen Charakter in den frischen Fällen, 
wenn an Stelle des Strafanstaltsmilieus ärztliches Handeln Platz greift. Die komplizierten Bilder seien Imitationen echt psychotischer Prozesse, kenntlich an der degenerativen Grundlage, an dem merkwürdig schwankenden und von äusseren Umständen Abhängigen der Erseheinungen, der oft ungeheuerlichen Phantastik, die etwas ganz anderes als echter Grössenwahn sei, der merkwürdigen Enge persekutorischer Wahnbildungen, der künstlichen, oft bewussten Beimischung von irgendwie erlauschten Symptomen. Indessen dient dieser Standpunkt dem Verfasser zur Bestätigung seiner Ansicht, dass bei diesen schwer Kriminellen (Gewohnheitsverbrecher im Gegensatz zu Gelegenheitsverbrechern) die Psychose ebenso wie das Verbrechen das gleiche Produkt aus Milieu und Anlage sei: zwei Zweige desselben Stammes. Demgemäss definiert er die degenerativen Geistesstörungen der Haft: Produkte von Anlage und äusserer Einwirkung, im intimsten $\mathrm{Zu}$ sammenhang mit den Schädlichkeiten der Strafhaft stehend, durch Milieuwechsel in hohem Masse beeinflussbar, vorwiegend bei Gewohnheitsverbrechern im 3. Lebensjahrzehnt auftretend. Der klinische Gesichtspunkt kommt dabei neben den anderen nicht genug zur Geltung; allgemein hypothetische Betrachtungen sind eingestreut und erzeugen Gruppierungen, die Zusammengehöriges trennen und Getrenntes unter einen Hut bringen. Dadurch verliert aber die wertvolle Arbeit nicht ihre Bedeutung für die Kenntnis der Gewohnheitsverbrecher.

Den mehr klinischen Standpunkt vertritt Bonhöffer, der deswegen von psychotischen Zustandsbildern spricht, die lediglich die Steigerung einer bestimmten affektiven Anlage darstellen (reaktive, depressive und manische Erregung, paranoische Prozesse auf dem Boden überwertiger Ideen); von diesen trennt er eine 2. Gruppe psychogener Erkrankungen, in denen das psychotische Bild der vorhandenen ursprünglichen psychopathischen Konstitutionen selbständiger gegenübertritt (Dämmerzustände, affektepileptische Erregungen bei instabilen Degenerierten, paranoisch-halluzinatorische Psychose im Gefüngnis und die akuten haftpsychotischen Komplexe).

Die gewöhnlichen pathologischen Reaktionen verdanken also bestimmten krankhaften Zügen ihre Entstehung; die hier in Frage stehenden Zustände sind aber sozusagen Abwehrreaktionen der gesamten Persönlichkeit, bei denen wohl die degenerative Anlage eine wichtige Rolle spielen kann, aber nicht ausschliesslich. Es soll die Bedeutung der degenerativen Anlage nicht bestritten werden; es müssen aber auch die anderweitigen Faktoren zu ihrem Rechte kommen. Zu diesen anderweitigen Faktoren rechne ich die individuellen Lebensschicksale oder Vergangenheit und alles das, was die sonstige individuelle Eigenart charakterisiert (Schicksal und Lebensführung); ferner die gegenwärtige psychophysische Konstellation (Stimmung, Milieueinfluss, nervöse Ersehöpfung, Alkohol usw.), dann die Art und Weise des 
einwirkenden Reizes. Diese Faktoren insgesamt bedingen die individuelle Reaktion, wie wir sie der Kürze wegen bezeichnen können. Darunter soll nun nicht etwa verstanden werden, was gesetzmässig bestimmten Individualitätstypen als Merkmal zukommt - dieses Problem steht ausserhalb einer klinischen Betrachtung -, sondern die jeweilige Einstellung auf einen objektiven, das heisst auch für andere Individuen gleichen Reizkomplex, eine Einstellung, die eben durch Anlage, Vergangenheit, persönliche Eigenart, gegenwärtige psychophysische Konstellation und die Art des Reizes mit bedingt wird, somit also zumeist eine individuelle Note erhält.

Es soll nicht geleugnet werden, dass ein Rezidivieren derartiger $\mathrm{Zu}$ stände ihre Reproduktion derart erleichtert, dass das äussere Moment an Bedeutung verliert und eventuell zur Rolle des äusseren Anstosses herabsinken kann. Ob die dann fast zur Gewohnheit herabgesunkene Realktion noch der ursprünglichen gleicht, erseheint fraglich, wenn wir bedenken, wie Simulation und hysterische Automatismen dabei mitwirken können, worauf wir noch zurückkommen werden. Es ist schliesslich auch nicht notwendig, dass das äussere Ereıgnis ein einmaliges aussergewöhnliches Geschehen darstellt. Eine Summation schädlicher Reize kann zu einem ähnlichen Affekt führen, sowohl in der Freiheit wie in der Haft, aber auch dann ist der ausschlaggebende Faktor meist ein stärker wirksames Ereignis, wie z. B. disziplinarische Bestrafung des inhaftierten Individuums, vereitelte Heiratshoffnung eines alternden Mädchens. Dass selbstverständlich die körperliche und speziell nervöse Widerstandskraft in diesem Sinne ungünstıg einwirkt, sei nur der Vollständigkeit wegen erwähnt, ist auch bereits im Begriff der psychophysischen Konstellation mit ausgedrückt. Welche Rolle gerade dieser Faktor in der Symptombildung der Kriegspsychosen spielt, geht aus der darüber bestehenden Literatur hervor.

Auch die Bedeutung des auslösenden Reizes ist nicht zu unterschätzen. Dies erkennt man am besten an den Zuständen von Angst- und Schrecklähmung, Verwirrtheit, die bei sonst ganz normalen Individuen unter dem Einfluss besonders starker affektbetonter Erlebnisse vorübergehend auftreten können, wie bei Todesnachrichten, Feuersbrunst, Examen usw. Zustände emotioneller Stupidität, wo bei erhaltener Auffassungsfähigkeit eine völlige motorische und emotionelle Lähmung an gewisse stuporöse Bilder erinnern (Jung). Von eventuell noch stärker hervortretenden Störungen bei katastrophalen Ereignissen wie Erdbeben (Stierlin) und Krieg sehen wir hier $a b$.

Wie hier eine psychische Leere oder Verwirrtheit eine gewisse Analogie zu den klinischen Bildern eines stuporösen oder amentiaartigen Komplexes bildet, so finden wir ein andermal Zustände, in denen das Individuum einer Sehrecken und Entsetzen erregenden Situation instinktiv dadurch zu ent- 
fliehen sucht, dass ganz andere szenische Bilder (z. B. Jugenderinnerungen) an seinem geistigen Auge vorüberziehen. Bekannt sind diese Zustände in Fällen von Todesgefahr, z. B. beim Ertrinken. Erzeugt im vorigen Falle die Störung im Ablauf des psychischen Gesehehens eine Lähmung, eine Unfähigkeit, sich von der affektiven Wirkung der Situation zu befreien - wir wollen kurz von Situationsfixierung sprechen, die sich im Wesen nicht von der Affektfixierung Bonhöffer's unterscheidet, aber alle Intensitätsgrade zusammenfasst - so produziert sie im zweiten Falle eine Assoziationsreihe, die wohl psychologisch, $d . h$. aus einem affektiv und assoziativ wirksamen Zusammenhang verständlich zu machen ist, aber eigentlich an sich zu dem äusseren Vorgang keinerlei auffindbare Beziehungen hat; hier könnte man von einer Situationsverschiebung sprechen. Welche Reaktion nun gerade eintritt, scheint von verschiedenen Faktoren abzuhängen, darunter auch dem äusseren Ereignis selbst und dem zufälligen Zustande des Individuums, d. h. der psychophysischen Konstellation. Wahrscheinlich kommt aber auch eine persönliche Eigenart in Frage (wie wir gerade bei den durch die Situationsverschiebungen ausgezeichneten Situationspsychosen noch sehen werden). Diese beiden Reaktionen der Situationsfixierung und Situationsverschiebung sind auch für das psychologische Verständnis gewisser, bald zu besprechender psychotischer Zustände ron Bedeutung. - So können also wirksame Erlebnisse auch bei gesunden Individuen eine Störung im Ablauf des psychischen Geschehens hervorbringen, die, wenn auch kurzdauernd und geringgradig, eine gewisse Aehnlichkeit mit ausgesprochen psyehotischen Bildern aufweisen. Wenn nun - nach Birnbaum - die psychogenen Krankheitszustände den affektiven Reaktionen der Normalen entsprechen, bzw. deren Aequivalente sein sollen, so ist dem hinzuzufügen, dass diese affektive Reaktion der Gesunden bereits unter Umständen einen pathologisehen Charakter tragen können. Hier ist das Erlebnis das wesentlich ätiologische Moment; mit dem Wegfall des äusseren Reizes, bzw. auch schon vorher, hört die psychische Störung mehr oder weniger rasch auf. Anders kann sich der Verlauf gestalten, wenn Eigenschaften und Zustände des Individuums eine weitere ungünstige Steigerung der Störung herbeiführen, wie z. B. bei Debilen eine erschwerte Auffassung und Verarbeitung die Fassungslosigkeit verstärkt, bei anderen erhöhte Affekterregbarkeit und Labilität des psychischen Gleichgewichts eine Spaltung des Bewusstseins begünstigen. Dann werden aus den rasch vorübergehenden Reaktionen der Norm länger andauernde, protrahierte Zustände. Hier hätten wir es also mit einer Komplikation ätiologischer Faktoren zu tun, unter denen neben dem Ereignis selbst psychische Artung und derzeitige Konstellation von Bedeutung sind. Wo die gewöhnlichen pathologischen Züge besonders stark in spezifischen Reaktionstendenzen zur Geltung kommen, kann auch der psychotische 
Zustand häufig als weitere Steigerung der pathologischen Reaktion erscheinen. Konstitutionelle Erregungs- und Verstimmungszustände, pathologische Lügenhaftigkeit und hysterischer Habitus vermögen unter diesen Umständen den psychogenein Erkrankungen in schwächerem oder stärkerem Grade ihren Stempel aufzudrücken, so dass man sie sogar als Exazerbationen des Charakters bezeichnen kann. Sie können es, aber sie brauchen es nicht, und wo sie es tun - am häufigsten bei den degenerativen Sträflingen in der Detention - geben sie oft nicht die hinreichende Erklärung für die Störung ab, da letztere erfahrungsgemäss eigentlich nur in der Haft, aber nicht in der Freiheit auftritt. Wie die Bestimmung dieser psychogenen Erkrankung überhaupt als Exazerbationen des Habitualzustandes dem Umfang nach einerseits zu eng ist - denn sie trifft nicht für alle Fälle zu, - ist sie andererseits inhaltlich auch zu weit, demn nicht alle Exazerbationen sind schon Psychosen, sonst müsste man hysterische Anfälle, Erregungszustände, wenn sie nur bei einem Individuum seltener auftreten, als Psychosen bezeichnen. - Aber auch in den Fällen, in denen die Exazerbation im psychotischen Bilde deutlich hervortritt, bleibt oft die Reaktion doch noch aussergewöhnlich, da die habituelle Reaktion bedeutend schwächer und weniger kompliziert ist.

„Generell sind wir also - so urteilt Stern - weit davon entfernt, schon jetzt in der Form die Weiterentwicklung und pathologische Steigerung der Psychosen bestimmter konstitutioneller Abweichungen zu erkemnen. Häufig beobachtet man zwar in erklärlicher Weise, dass gerade bei besonders reizbaren Personen sich an den Affektchok ein schwerer Tobsuchtszustand anschliesst. Warum aber hierauf in dem einen Fall ein kurzer Stupor, in dem anderen ein Ganserzustand, in dem dritten ein langdauerndes katatonieähnliches Krankheitsbild folgt, kanu aus der Konstitution nicht erschlossen werden. Ebensowenig ist dies natïrlich bei den Personen möglich, welche während zweier auseinanderliegender Erkrankungen an ganz differenten Formen psychischer Störung litten."

Dagegen besteht - nach demselben Autor - eine gewisse Proportionalität zwischen Schwere der psychopathischen Veranlagung einerseits, Dauer, Intensität und Disposition zu Rezidiven andererseits. Namentlich eine debile Grundlage scheint hier wenig günstig zu wirken. Diejenigen Fälle, in denen die psychopathische Grundlage entweder nicht manifest oder nur wenig ausgeprägt war, erkrankten sämtlich an kurzdauernden, meist auch nur leichten Psychosen und erlitten keine ausgesprochenen psychotischen Rezidive, umgekehrt zeigten sich langanhaltende schwere und zum Rezidivieren neigende Psychosen gerade bei Personen, die starke psyehische Anzeichen der Entartung tragen. Die Gewohnheitsverbrecher - auch wenn die Anamnese nicht genügende Anhaltspunkte für sonstige psychische Anomalien botsollen sich darin in der gleichen Weise wie schwere Psychopathen verhalten. 
Nach alledem erweist sich die Einteilung der Psychopathien nach ihren Hauptrichtungen, also nach inhaltlichen Merkmalen, für psychiatrische: Zwecke als nicht ausreichend. Um der Mannigfaltigkeit der hierher gehörigen Erscheinungen gerecht zu werden und spezieller, den Situationspsychosen ihre Stelle anweisen zu können, wird man eine andere Einteilung versuchen müssen, unter der Voraussetzung, dass es sich bei den überall stattfindenden Uebergängen natürlich nicht um scharf begrenzte Einteilungen, sondern nur um Typen oder Gruppierungen handeln kann. So könnte man mehr ein allgemein formales Moment, das der pathologischen Reaktivität, als Einteilungsgrund nehmen und bekäme 3 Gruppen: die endogenen, die reaktiven und die Situationstypen. Bei den endogenen Typen entsteht die Psychose rein von innen heraus, äussere Momente spielen keine oder nur eine untergeordnete auslösende Rolle; so gewisse Fugueszustände, periodisch auftretende Verstimmungen, gewisse paranoische Bilder bei paranoiden Charakteren (Vorstufen des manisch-depressiven Irreseins und der Paranoia). Bei der 2. Gruppe, die die Mitte zwischen den beiden anderen hält, sind die psychotischen Zustände deutliche Reaktionen auf äussere Reize, wie reaktive Verstimmung, reaktive tobsüchtige Erregungszustände, manche querulatorisch-paranoische Zustände in der Haftt und bei vermeintlichen zivilrechtlichen Benachteiligungen, ferner viele der Hysterie zugezählten Formen. Bei der 3. Gruppe, dem Situationstyp, spielt das auslösende Ereignis eine dominierende Rolle, derart, dass die ganze Psychose nur als eine sich an das auslösende Ereignis anschliessende, über kurz oder lang wieder vorübergehende Episode im Leben des Individuums erscheint. Im allgemeinen wird diese Gruppe die leichte Form der degenerativen Anlage aufweisen, wenn wir auch wissen, dass die Schwere der psychopathischen Konstitution mit der Tendenz zu psychotischen Exkrankungen nicht immer parallel geht. Ausserdem können alle diese - auch die endogenen Formen - am auffallendsten wohl die depressiven Zustände unter dem Druck der Haft eine vorübergehende Verschlimmerung erfahren, was den Sachverhalt kompliziert. Diese Einteilung wird sehliesslich durchbrochen von denjenigen schwer degenerierten Kriminellen, die einerseits endogene periodische Verstimmung oder triebartige Zustände aufweisen, auf denen sich tobsüchtige oder ängstlichdelirante Erscheinungen aufbauen können, die aber andererseits zu einem bestimmten Zeitpunkt, namentlich in einer durch den Druck der Haft besonders gekennzeichneten Perode andere Störungen aufweisen können: phantastischkonfabulatorische nach Art der Hysterischen, Querulieren, pathologische Einfälle usw., die im Gegensatz zu den ersteren nur episodisch auftreten und. mit dem Aufhören der Haft schwinden. Neben dem bereits von Siefert betonten "Kunstprodukt"-Charakter spielen der Krankheitswunsch und eventuelle Simulation eine häufige Rolle, worauf wir noch zurückkommen; 
daneben ist aber auch der Einfluss des chronischen Alkoholismus auf die Entstehung von Sinnestäuschungen und Wahnideen gebührend zu berücksichtigen. - Die Verschiedenheit der Genese erklärt die Kompliziertheit dei psychotischen Komplexe, die deshalb nicht als eine einheitliche Psychose bei einem derartigen Individuum zusammengefasst werden können. Nur unter der Berücksichtigung der gesamten Persönlichkeit und ihrer Lebensschicksale gelingt es, die verschiedene Wertigkeit der eventuell bei demselben Individuum auftretenden jeweiligen Symptomkomplexe zu eruieren. Zugleich bemerkt man, dass die degenerative Anlage dabei nicht immer die gleiche Rolle spielt, das eine Mal gibt die endogene Anlage eine genügende Aetiologie, das andere Mal kommen noch andere Faktoren in Frage. So kann das Schicksal derartiger Persönlichkeiten dem Psychiater ein buntes Bild liefern, wie z. B. in der Kasuistik Siefert's der erste Fall. - Homburger ist eigentlich der erste gewesen, der sich nicht nur bewusst auf den Standpunkt gestellt hat, die ganze Lebensgeschichte des Individuums ist für die Beurteilung und Diagnose massgebend, sondern der dies auch durch die Verfolgung der Kirnschen Fälle durehgetührt hat. Er kommt dabei zu dem Resultat, dass auch wir als Folgerung unserer Ausführung betrachten dürfen: „Die Tatsache, dass sozial nicht schwer Entartete in prinzipiell der gleichen Weise, wem auch an den leichteren Formen und Graden degenerativer Geistesstörung in der Haft erkranken, wie Gewohnheitsdiebe und gemeingefährliche Atfektverbrecher, diese Tatsache allein genügt, um darzutun, dass die haftpsychotische Erkrankung nicht schon an sich einen Rückschluss auf eine schwere Entartung in sozialer und forensischer Hinsicht gestattet und eine prognostische Bedeutung nach dieser Richtung beanspruchen kann." Unter entsprechender Würdigung der Individualität in ihrer Bedeutung für die psychotischen Zustände meint Homburger, die Haftpsychose kann unter Umständen dauernd vorhandene, aber latente Züge beleuchten. Die Anlage ist vielseitig eben auch in pathologischer Hinsicht. Wie nun in der Freiheit bei den leicht Kriminellen und später wieder sozial gewordenen Typen sich die Besonderheit des einzelnen bewahrt, so vermag auch die Haft die Unterschiede der psychischen Individuen nicht auszulöschen, wenn schon auch sie gleich krank machenden Einflüssen im allgemeinen der nivellierenden Wirkungen nicht entbehrt. Es hängt dies nach Homburger damit zusammen, dass die pathologisch und sozial schwer Entarteten wohl typische, sozusagen Artmerkmale zeigen, aber viel weniger die Zeichen einer ausgeprägten Indıvidualität, wie dies bei anderen der Fall ist. Diese Ueberlegung müssen schliesslich entgegen den Ansichten Wilmann's und Nitsche's zu der - hier nicht zu erörternden - Frage führen, ob es zweckmässig ist, den Sammelnamen der Haftpsychose für so verschiedenartige Zustände beizubehalten, denen die Haft wohl ihr Kolorit verleihen, die sie aber nicht in ihrer Wesensart bestimmen 
kann. Trotz Uebereinstimmung im Zustandsbild, Verlauf und Ausgang kann die Pathogenese eine verschiedene sein. Man wird daher vielleicht besser tun, an Stelle des uns bisher zur Orientierung dienenden einseitigen Einteilungsprinzipes nach der pathologischen Reaktivität einen anderen umfassenderen Gesichtspunkt zu setzen, der den ätiologisch-klinischen Bedürfnissen eher gerecht wird. Der Einteilungsgrund kann dann nur auf der Beziehung der psychotischen Störung zur Individualität überhaupt basieren. Die psychotische Störung ist demnach entweder I. eine Intensitätssteigerung des sonstigen pathologischen Habitualzustandes (z. B. Gefängnis- oder Zuchthausknall bei einem auch sonst zu explosionsartigen Zuständen neigenIndividuum oder konstitutionellen Erregten), oder sie ist II. nur eine Episode im Leben des Individuums. Schliesslich kann es sich III. um eine pathologische Weiterentwicklung der Persönlichkeit durch die Ungunst der Umstände handeln. (Rüdin hat derartige paranoide und querulatorische Bilder beschrieben, die er bei zu lebenslänglicher Zuchthausstrafe Verurteilten beobachtet hat. Gerade diese Gruppe harrt jedoch noch der weiteren Erforschung.).

Auch hier findet man natürlich überall Uebergänge. Die Entscheidung und Rubrizierung kann unter Umständen schwierig werden. So wenn sich bei einem leicht Hypomanischen als Folge seines pathologischen Selbstgefühls in der Haft Beeinträchtigungs- und Grössenideen entwickeln, die später wieder schwinden, erscheint das paranoische Bild als Episode; im Grunde ist es aber nur ein sekundäres Produkt einer von Haus aus krankhaften Persönlichkeit. Die Schwierigkeit entsteht hier dadurch, dass der Begriff der Intensitätssteigerung nicht im engen Wortsinne zu nehmen ist. Wie das letzte Beispiel zeigt, kann das Krankheitsbild auch qualitative Unterschiede gegenüber der krankhaften Anlage zeigen. Es kommt dann auf den Nachweis des psychogenetischen Zusammenhangs an. Wo ein solcher Zusammenhang nicht statthat oder die Erscheinungen nicht ausreichend erklärt - und das findet man häufig bei leicht oder gar nicht nachweislich Degenerierten - sprechen wir von "Situationspsychosen". Bis. zu einem gewissen Grade rilt dies aber auch von manchen schwer Entarteten, die wir unter den Gewohnheitsverbrechern finden. Eine transitorische Haftstörung, deren Erscheinung durch die krankhafte Artung allein nicht verständlich sind, werden wir zu den Situationspsychosen rechnen dürfen.

Wiederholt hat man darauf hingewiesen (Stern, Michaelis), je stärker die degenerative Anlage, um so geringer braucht die auslösende Ursache zu sein; ausserdem gibt diese den resultierenden Krankheitsbildern ihre Prägung, ,so dass besonders noch unter Mitwirkung schädigender somatischer Momente die Erkenntnis der exogenen reaktiven Entstehung und die Abgrenzung von bloss ausgelösten, nach akuter Steigerung schleichend ver- 
laufenden Psychosen im Sinne der Dementia praecox und der Paranoia äusserst erschwert wird" (Michaelis). Hier wird eine sichere Diagnosenstellung nur möglich sein, wenn man die individuelle Lebensgeschichte genauer kennt; sie allein gestattet uns die endgültige Beurteilung der Beziehung zwischen Persönlichkeit und Psychose, die eine so grosse Bedeutung für eine exakte Diagnosenstellung hat.

Nachdem wir den Situationspsychosen ihre Stellung im Bereich der degenerativen Geistesstörung angewiesen haben, köınen wir uns zu näherer Betrachtung und Einteilung jetzt diesen selbst zuwenden. Wir betrachteten sie bisher psychologisch als die Einstellung auf einen Reizkomplex, wobei wir be1 der Einstellung neben der Art des Reizes drei Faktoren wesentlich unterschieden: "degenerative Anlage, individuelle Lebensschicksale und gleichzeitige psychophysische Konstellation; der zweite Faktor enthält sozusagen die mehr persönlichen Züge, soweit sie ausserhalb der psychopathischen Konstitution als normale zu gelten haben; der dritte Faktor die mehr zufä̈lligen, in dem gegenwärtigen Zeitpunkt gerade vorhandenen Erscheinungen, wie Stimmungslage, vorherrschende Wunschrichtung, Ernährungszustand usw. Der Begriff der Konstellation, der früher bei den traumatischen Neurosen, jetzt auch bei den Kriegspsychosen von Bedeutung ist, wird sonst nur im engeren psychologischen. Sinne verwandt. So spricht Schuster von der psychischen Konstellation im Moment des Unfalls: Aufmerksamkeit, Erwartung usw. Wollenberg spricht von der momentanen psychischen nervösen Einstellung durch Erschöpfung, Entbehrung und insbesondere durch aufregende Erlebnisse kurz vor dem Ereignis. Er fasst also den Begriff nicht mehr in dem engen psychologischen Sinne. - Wo keine stärkeren somatischen Schädigungen, wie Hirnerschütterung usw. vorliegen, wird man schwerlich einen rein somatischen Faktor von dem psychischen abtrennen können. Gerade hier ist die Beziehung zwischen ,psychisch" und ,physisch" so innig, die psychophysische Einheit so ausgeprägt, dass jede Trennung und Betonung eines Faktors einseitig wäre.

Die Einstellung auf den Reizkomplex ergibt nun das, was wir als Situation bezeichnen. Bedeutet doch diese nichts anderes als die bestimmte Art und Weise, in der ein Subjekt sich zu einem objektiven Reizkomplex in Beziehung gesetzt hat. So gefasst enthält der Begriff der Situation also all die ätiologischen Faktoren in sich, die für die Entstehung der Krankheit von Wichtigkeit sein können. Verschiedene Situationsformen würden dementsprechend verschiedene Stellungnahmen bedenten und eventuell zur Einteilung und Differenzierung der hierher gehörenden Zustände dienen können. Durch die Herausarbeitung dieser Form erhalten wir also einen gewissen Anhaltspunkt für die diagnostische Beurteilung. Was bei weiterer Analyse auf die degenerative Anlage, was auf die psychophysische Konstellation 
zurückzuführen ist, dies zu entscheiden wird oft nicht möglich sein. Haben wir jedoch die Simulation als reaktives Hauptmoment in Rechnung gestellt, so werden wir zu einem anderen Urteil kommen, als wenn wir eine Angstund Schrecklähmung vor uns haben. Es ist dies ja nicht neu, nur ist es nicht immer genügend zur Geltung gekommen.

Die von Siemerling und Stern herrührende Bezeichnung der Situationspsychosen erscheint daher für diese Krankheitsgruppe berechtigt. Allerdings fassen wir den Begriff etwas weiter und mehr im psychologischen Sinne. Stern versteht unter der Situation nur die äusseren Verhältnisse, soweit sie psychogene Wirkungen enthalten: ,Ein solcher ätiologischer Faktor ist z. B. eine die Interessen des Individuums bedrohende oder schädigende Situation, welche aus verschiedenen Gründen, namentlich bei labilen Personen krankmachend wirken kann. Namentlich der Begriff der hysterischen Situationspsychosen erscheint mir, auf die Dämmer- und Stuporzustände angewandt, passend, da er sowohl die hysterische Genese, die Verwandtschaft oder gar vereinzelt auch die symptomatologische Uebereinstimmung mit hysterischen Psychosen auf dem Boden andersartiger psychischer Schädigungen, als-auch die engen Beziehungen zu anderen transitorischen, nicht hysterischen Haftkomplexen in seinem Wortlaut ausdrückt. Gerade dieser letzte Punkt hat für unsere Betrachtung eine gewisse Wichtigkeit, insofern es uns darum zu tun ist, die hierher gehörigen transitorischen Komplexe unter einen einheitlichen klinisehen Gesichtspunkt zu bringen, der uns zugleich ein Verständnis der mannigfaltigen Formen eröffnen soll. Mit dem Begriff der Situationspsychosen wollen wir aber noch mehr gewinnen: aus dem Gebiet der bisher als degenerative Haftpsychosen bezeichneten Zuständen können wir einen bestimmten Teil von Krankheitsbildern herausheben und hier einreihen. Zudem gibt es auch ausserhalb der Haft ähnliche psychotische Bilder, die ähnlichen Situationen ihre Entstehung verdanken: so kann die Furcht vor der Verhaftung bzw. ungerechter Bestrafung dieselben Wirkungen hervorbringen. Aber auch andere Situationen, die mit gerichtlichen Dingen nichts ru tun haben, wie überhaupt schliesslich alle stark affektbetonten Ereignisse können derartíge Zustände zeitigen. Der Weltkrieg wird uns auch hier weitere Erfahrungen an die Hand geben.

Man könnte nun einwenden, dass wir nur eine andere Bezeichnung für das gewählt hätten, was man bisher als hysterische Psychosen gekennzeichnet hat. Demgegenüber - wir wollen uns kurz fassen, um nicht Altbekanntes ausführlich zu wiederholen - ist zuzugeben. dass hysterische Psychosen auch unter den Situationspsychosen vorkommen; damit ist jedoch nicht gesagt, dass alle Situationspsychosen der Hysterie zuzurechnen sind. Nur wer „hysterisch" mit „psychogen" identifiziert, könnte dies tun; dann würde der Ausdruck hysterische Geistesstörung promiscue mit psychogener ge- 
braucht werden können und eine Gruppe bezeichnen, über deren L'mgrenzung und Einteilung damit noch nichts weiteres gesagt wäre. Um so eher hätten wir ein. Recht, diese Gruppe näher einzuteilen und zu sondern. So würden die reaktiven Aeusserungen eines Hysterikers, soweit es sich um vorübergehende stärkere Aeusserungen eines habituellen Zustandes handelt, die Anfälle, Verstimmungs- und Erregungszustände nicht zu den Situationspsychosen zu rechnen seien. - Die meisten Autoren neigen dahin, nur dann von hysterischen Psychosen zu sprechen, wo ein hysterischer Charakter, d. h. eine durch ihre Aeusserung charakteristische krankhafte Wesenseigentümlichkeit vorliegt. Nun können aber hänfig hysterische Antezedenzien völlig fehlen bei einer Psychose, die nach hysterischem Typus verläuft (Stern). Umgekehrt können die psychotischen Ausnahmezustände bei Hysterischen derart sein, dass es zweifelhaft erscheinen muss, ob wir bei der Psychose den gleichen Mechanismus haben, den wir bei der Hysterie voraussetzen. Ferner ist die Einheitlichleit des hysterischen Symptomkomplexes, der bei den verschiedensten Krankheiten vorkommen kann, nicht sicher. Zum mindesten weist gerade das Vorkommen dieses Syndrom bei ganz differenten organischen und funktionellen Erkrankungen auf die Möglichkeit hin, dass nicht einer, sondern verschiedene uns unbekannte Mechanismen den hysterischen Symptomkomplex zu erzengen vermögen.

Wenn Stuporen, Ganser- und Dämmerzustände gerade als hysterische Psychosen in Anspruch genommen werden, so geschieht es allerdings nicht nur deswegen, weil Hysterische daran erkranken - auch Nichthysterische können es -, sondern weil diese Zustände häufig unverkennbar hysterische Züge zeigen: theatralisch-demonstratives Gebahren, Uebertreibung, starke Beeinflussbarkeit, Stigmata usw. Können wir nun von einem hysterischen Situationstyp sprechen, der sich nicht nur auf einer spezifischen, sondern auf jeder anderen krankhaften Veranlagung und auch bei mehr oder weniger normalen Persönlichkeiten zeigen kann, wie Wilmanns es von seinen hysterischen Symptomen, die er als Typus, aber nicht als eigentliche Krankheitsgruppe betrachtet, annimmt? Die klinische Beobachtung zeigt nun in solchen Fällen, dass die Individuen in der Tat eine bestimmte Art der Stellungnahme bzw. des Situationsmässigen erkennen lassen. Die Situation hat sich nämlich für sie versehoben. An Stelle der adäquaten Auffassung des unlustbetonten Reizkomplexes tritt meist eine als Wunscherfüllung zu deutende Szenerie, oder - vielleicht infolge einer gewissen Perversion des Gefühlslebens - eine Ausmalung und Weiterführen des ursprünglichen Ereignisses zu einer katastrophalen oder tragödienhaften Szenerie; zuweilen kann auch zugleich beides eintreten als Folge der für Hysterie charakteristischen $\mathbf{A b}$ kehr von der Wirklichkeit und Flucht in eine ideale Welt. Diese Art der Situationsverkennung, die zugleich infolge ihres Zusammenhangs mit der 
eigentlichen Wirklichkeit auch die ursprünglich adäquate - aber oft aus dem Bewusstsein nach Möglichkeit verdrängte - Auffassung des Sachverhalts voraussetzt, ist dasjenige Moment an den hysterischen Situationspsychosen, das auf den Beobachter den Eindruck des Hysterischen macht, ein Eindruck, der zuweilen nur gefühlsmässig ist. Wir können daher mit Recht von einer hysterischen Situationsverschiebung sprechen; wie diese zustande kommt, das gehört in den Bereich der Theorien über Hysterie. Doch lässt sich vielleicht eine Vermutung hier kurz skizzieren: es scheint, als ob bei vielen Individuen besonders starke Affekte spezifische Wirkungen zu äussern vermögen, die bei der Störung des seelischen Gleichgewichts als akute Insuffizienzerscheinung unter der Form der Situationsverschiebung hervortritt. Es vermag also hier der Affekt eine Abspaltung im Bewusstsein zu erzeugen. Dabei möchte ich annehmen, dass diese Erscheinung an sich nicht viel mehr als eine individuelle Tendenz bedeutet und bei sonst nicht hysterischen Individuen nur mit Kombination anderer Faktoren zur Psychose führt. Eine gewisse Analogie findet sich dafür auch im normalen Seelenleben, wenn bei unlustbetonten Situationen die Erinnerung an die goldenen Jugendtage wach wird und wir uns förmlich in unsere Kindheit versetzt fühlen. Ist es nicht auch eigentümlich, dass gerade der Puerilismus, die Verkindlichung des ganzen Benehmens, bei hyster'schen Situationspsychosen so häufig vorkommt?

Wie weit wir übrigens davon entfernt sind, die dabei mitspielenden psychischen Vorgänge zu verstehen, darauf hat neuerdings Binswanger wieder mit vollem Nachdruck hirgericscr. Weder aktuelle, bzw. latente Vorstellungen noch Emotionen kömnen die Entstehung der Krankbeitsfälle erklären; die psychischen Vorgänge sind viel verwickelter, doch lässt sich vielieicht - negativ - zur Abgrenzung gegen andere psychogene Störungen sagen: die lysterische Situationspsychose ist nicht unmittelbares Produkt des einwirkenden Ereignisses, wie bei den rein affektiv bedingten emotionellen Situationspsychosen, sondern Produkt einer krankhaften, uns aber unbekannten psychischen Verarbeitung. Mit den Schlagworten thymogen und ideagen, die uns die Genese vermittelst eines Affektes oder einer ententsprechenden Vorstellung verständlich machen sollen, ist es nicht getan. Wenn auch die Hysterie als eine Gruppe der Psychogenie mit anderen psychogenen Zuständen verwandt ist und sich nicht immer scharf trennen lassen wird, wird man doch bedenken müssen, dass die hysterischen Erscheinungen ihrer Psychogenese nach für uns unverständlich, weil nicht einfühlbar sind. Sie stellen Arten des Erlebens, Verarbeitens und Reagierens dar, die dem gewöhnlichen Seelenleben fremd sind. Wir kennen beim Hysterischen den Reiz und Reaktion, das Anfangsglied und das Endprodukt. Die Mittelglieder konstruieren wir uns - wie man wohl sagen kann - meist in fraglicher Weise. Denn dass sich ein Affekt oder eine Vorstellung bzw. Wunsch 
in eine entsprechende körperliche Störung, bzw. einen psychotischen Zustand auf dem Wege der Autosuggestion umsetzen soll, ist die unvollständige Umschreibung eines „,post hoc, ergo propter hoc"; die Zwischenglieder bleiben uns unbekannt. Ausserdem stempeln wir den psychischen Zusammenhang zu einem kausalen, indem wir uns den Affekt oder die affektbetonte Vorstellung mehr nach Art der materiellen Ursache wirkend denken. Man interpretiert so die Hysterie als eine Art unbewusste oder unterbewusste Gefüblslogik. Bei den monosymptomatischen hysterischen Erscheinungen stösst diese Interpretation - wie bereits Binswanger hinweist - auf unlösliche Schwierigkeiten, obwohl doch gerade hier die Hysterie sozusagen in statu nascendi sich befindet und oft nicht weitersehreitet. Bei so komplizierten E:scheinungen, wie hysterische Psychosen es sind, werden wir mit derartigen Interpretationen erst recht vorsichtig sein müssen. Wie können wir uns z. B. den Krankheitswunsch, die Flucht vor der Wirklichkeit, in einem Falle wirksam denken, in dem die Psychose sich als Ausdruck der stärksten Angst und der schlimmsten Halluzinationen kundgibt?

Begnügen wir uns also mit dem negativen Kriterium: die hysterische Situationsverschiebung ist Produkt einer ihrem Wesen nach. zwar unbekannten, jedoch als spezifisch anzusehenden psychischen Verarbeitung.

Massgebend für die Beurteilung des Krankheitsbildes sind dabei nicht nur die Symptome, die bei den verschiedenen Gruppen übereinstimmen können: selbst so im Vordergrunde stehende Erscheinungen wie Vorbeireden und Stupor genügen nicht. Sie haben keine einheitliche Genese, so kann z. B. der Stupor ebenso Ausdruck einer Abulie sein, wie einer Schrecklähmung oder starken Angst. Sie sind also nicht primäre, sondern Ausdruck oder Folge bestimmter psychopathologischer Vorgänge. Wie stark diese letzteren sich in jenen manifestieren, das kann zum Teil auf individuell basierenden Eigenschaften beruhen. Manche Individuen bekommen unter Umständen eher einen äusserlich stupurösen Zustand als andere; die innere Hemmung bzw. Lähmung setzt sich dann leichter in eine motorische Akinese um, ohne dass deshalb die psychotischen Grunderscheinungen stärker zu differieren brauchen. Es können also derartige Phänomene die richtige Bewertung nur im Zusammenhang mit den übrigen Symptomen gewinnen. Aber das genügt noch nicht. Es ist ein Charakteristikum der psychogenen Krankheitsformen, dass sie äusserst mannigfaltig sind, dass äusserlich verschiedene Symptombilder noch kein Beweis für differente Krankheitsformen sind, und umgekehrt hinter demselben Symptombild eventuell sich verschiedene Krankheitsformen verbergen können. Diese Eigentümlichkeit liegt im Charakter der Psychogenie als solcher, die der Individualität nicht nur in den Einzelsymptomen, sondern auch im ganzen Symptomkomplex einen weiten Spielraum gibt in der Ausdrucksform und der Darstellung der Erlebnisse. „Wie die 
Normalen auf den gleichen Reiz verschieden reagieren und der eine auf einen psychischen Schmerz mit Jammern und Wehklagen, der andere mit starrem Schweigen antwortet, so sehen wir den Entarteten, je nach seiner Verañlagung, auf eine psychische Schädigung hin beispielsweise in Tobsucht oder Stupor verfallen. Aeusserlich verschiedene Bilder können demnach einen gleichen psychopathologischen Ursprung haben und in ihrem Wesen gleichwertig sein" (Wilmanns).

Auch von diesem Gesichtspunkt aus erkennen wir die Bedeutung, die der Einstellung zukommt; sie erst gibt den jeweiligen Symptomen ihre nosologische Einheit.

Nach alledem sind wir berechtigt, die hysterischen Situationspsychosen vom hysterischen Charakter als solchem zu trennen: dieser bedeutet eine angeborene oder erworbene minderwertige Anlage, die alle möglichen Grade, Spielarten und Uebergänge zu den Phantasten, eretischen Imbezillen usw. umfasst (Bonhöffer); unter einer hysterischen Situationspsychose katexochen verstehen wir eine psychotische Episode, die in ihrer Pathogenese mit dem Wesen und der Erscheinungsform der klassischen Hysterie eine gewisse Verwandtschaft zeigt. Auch Stern, der im Stupor eine besonders häufige und in gewissem Masse auch typische Erscheinungsform der Situationspsychosen sieht, während die Ganserzustände, namentlich mit Reminiszenzdelirien, eine symptomatische Aehnlichkeit mit dem hysterischen Typ der Geistesstörung haben, betont die ätiologische Differenz in beiden Fällen. „Auf der einen Seite handelt es sich um transitorische Erkrankungen, die bei den verschiedensten Arten der Psychopathie auftreten, auf bestimmte Situationen sich beschränken, in den verschiedensten Formen sich repräsentieren, und eine unleugbare Verwandtschaft zu anderen transitorischen Haftpsychosen zeigen, auf der auderen Seite handelt es sich meist nur um psychische Episoden oder Paroxysmen von Individuen, die in der Regel doch auch ausserhalb der Psychose für lange Zeit oder von Jugend an körperliche Stigmen der Hysterie bieten.

Diesen eigentlichen hysterischen Situationspsychosen gliedern wir diejenigen psychotischen Episoden an, die wir bei Hysterikern und ähnlichen Charakteren finden und die zugleich ähnliche Bilder, jedoch mit gewissen Unterschieden aufweisen, worauf wir noch zurückkommen. Natürlich bestehen auch Uebergänge zwischen beiden, wie ja auch ein hysterischer Charakter geringgradig oder stärker ausgeprägt sein kann. Die Hysterie kann ja auch bei anderen Zuständen eine gewisse Rolle spielen, in denen wir gewisse Symptome auf die hysterische Grundlage zurückführen. Um nun die Unterschiede der hysterischen Situationspsychosen von den übrigen näher zu beleuchten, werden wir diese letzteren jetzt mit heranzuziehen haben.

In erster Linie kommen da solche Formen in Betracht, bei denen die 
Individuen gleichsam mit der Situation nicht fertig werden und ihr unterliegen, wobei es zur Situationsfixierung kommt: die Fälle von Angst und Schrecklähmung, Ratlosigkeit und Verwirrtheit; teilweise stupuröse, teilweise amentiaartige Zustandsbilder, ebenso auch Dämmerphasen; ferner stärkere Depressionen mit Halluzinationen und eventuell Beeinträchtigungsideen. Die Unerträglichkeit der Situationen kann jedoch in anderen Fällen unmittelbar oder nach Ueberwindung des lähmenden Entsetzens zur motorischen Entladung führen: es treten tobsüchtige Erregungszustände mit sinnlosem Zerstörungstrieb auf, die dem Individuum sonst fremd sind. Das treibende, mehr oder weniger bewusste Motiv dabei ist, der Situation ein Ende zu machen, sich ihrer zu erwehren. Diese Zustände von Erregung und Hemmung treten oft sukzessive auf. Bei den hysterischen Formen, die ihnen äusserlich ähnlich sein können, haben wir eine Abkehr von der eigentlichen Situation, sei es auch nur, dass das Individuum sich eine ähnliche schafft, die es mit allen möglichen Schrecknissen ausmalt; dies zum Teil als Folge der nicht völlig geglückten Verdrängung aus dem Bewusstsein. Bei den rein emotionellen Formen - we wir dies zum Unterschied von den hysterischen bezeichnen wollen - ist die ursprüngliche und zugleich bleibende Situationsform die psychsche Lähmung, die Situationsfixierung; die szenische, ins Phantastische gehende Ausmalung des Hysterischen unterbleibt. Ein weiterer unterscheidender Faktor ist die abnorme Beeinflussung aller Symptome durch äussere Faktoren: als Folge der erhöhten Fremd- und Autosuggestibilität bei den hysterischen Formen. Dieser Unterschied ist aber nicht durchgehend, gerade die hysterischen Situationspsychosen bei Nichthysterischen zeigen oft eine geringe Beeinflussbarkeit.

Die Aehnlichkeit zwischen den emotionellen und den hysterischen Formen sind mehr äusserlicher Natur. Jene sind von verschiedenen Autoren beschrieben worden, so von Kirn unter den Bezeichnungen der Melancholia simplex, hypochondrica, stupida und vorzüglich der akuten halluzinatorischen Melancholie und akuten Paranoia. Bilder, die trotz der etwas untereinander versehiedenen Symptomatik hierher zu rechnen wären: sie haben nicht nur den kurzen Verlauf von Wochen bis wenigen Monaten und den Ausgang in Genesung ohne Defekt gemeinsam, sondern auch die psychische Einstellung, die Situationsfixierung. Bei der Melancholie geht dem Ausbruch der Sinnestäuschung eine depressive Verstimmung unter körperlicher Reduktion, wie Abmagerung, Anämie, Verdauungsstörung, voraus, während bei der akuten Paranoia die Halluzinationen direkt aus dem Kern des Bewusstseins hervorgehen; differenzialdiagnostiseh gegenüber der chronischen Paranoia tritt zu dem akuten Beginn noch die unscharfe Abgrenzung und mangelhafte Systematisierung der Wahnideen. Homburger hat bekanntlich die Fälle Kirn's weiter verfolgt und seine diagnostischen Irrtümer richtiggestellt. 
Nach ihm handelt es sich bei der akuten Paranoia um ein Zustandsbild von ubiquitärem Vorkommen sowohl bei organischen Psychosen wie degenerativen Geisteszuständen. Im letzteren Falle - soweit nicht Fehldiagnosen, namentlich Dementia praecox in Betracht kam - sind es ganz vorübergehende Wahngebilde auf degenerativer Grundlage in Angliederung an einen Haftkomplex. Die akute halluzinatorische Melancholie ist nach Kirn die charakteristische Psychose der Einzelhaft, besonders der Affektverbrecher und Erstbestraften.

Eigentlich paranoide Formen gehören unserer Gruppe nicht an; hier sind die paranoiden Ideen die Folgen der Halluzinationen; auch pflegt einè verschiedengradige Bewusstseinstrübung nicht zu fehlen. Zudem sind es meist die Untersuchungsgefangenen und kurzfristig Bestraften, die derart erkranken. Als Beisipel möchte ich einen von Kirn irrtümlich diagnostizierten Fall erwähnen. Kirn rechnet ihn zum Verbrecherwahnsinn, den er als Unterform der Paranoia chronica rubriziert: weitere Entwicklung des sittlichen Schwachsinns, zumeist als Uebergang der psychischen Degeneration in chronischen Wahnsinn (Fixierung und Systematisierung der Wahnideen). Es handelt sich um einen schweren Gewohnheitsverbrecher; von den 40 Jahren seit seiner ersten Bestrafung hat er höchstens 7 Jahre in der Freiheit gelebt und nie mehr als 2 Jahre hintereinander. Er war sehr reizbar und gewalttätig, erkrankte auch zweimal (1875 und 1880) unter dem Bilde der Tobsucht im Gefängnis. Später (1882) bekam er während einer erneuten Gefängnisstrafe einen akuten halluzinatorischen Verfolgungskomplex, ,,mit Gehörs- und Gesichtshalluzinationen und aus diesen abgeleiteten Wahnvorstellungen (er sieht und hört namentlich altäglich den - von ihm bestohlenen - Bürgermeister seiner Heimat, der ihn auf alle denkbare Weise quält, mit dem Tode bedroht), zeitweise Nahrungsverweigerung; intensive Angstzustände, Anfälle lebhaftester Aufregungen mit feindlichen und zerstörenden Handlungen". Wurde nach Mlenau überführt, verblieb dort mehrere Jahre. Wie aus den von Homburger veröffentlichten Akten über diesen Fall hervorgeht, hielt Kirn ihn ursprünglich für einen heilbaren. Nach späteren Berichten der Anstalt Illenau war er dort zeitweise ruhig, zeitweise tobsüchtige Erregungszustände, in denen auch der frühere halluzinatorische Haftkomplex wieder auflebte. Bis 1887 entwich er mehrere Male, beging dabei ein newes Vergehen. Die Halluzinationen und Angstdelirien hörten schliesslich auf, die Gereiztheitszustände wurden milder. Bis 1891 vagierte er dann umher, wurde wegen Diebstahls in Freiburg wieder verhaftet, wobei er sich blindwütend rasend benahm. In der Klinik verlegte er sich auf Simulationsversuche und phantastieche Produktionen; brachte auch die Sache mit dem Bürgermeister wieder vor. Das Gutachten erkannte auf Simulation; 4 Jahre Zuchthaus. Verbüsste seine Strafe auf der Irren- 
abteilung, da er im Gefängnis immer zu toben anfing. Auch bei späteren Gefängnis- und Zuchthausstrafen wegen Diebstahls zeigte sich seine tobsüchtige Erregung. Doch konnte er schliesslich seine Strafen. ordnungsgemäss verbüssen. Symptome der Verblödung oder katatonisehe Krankheitszeichen sind nirgends beobachtet worden.

Wir haben es hier also mit einem Grewohnheitsverbrecher zu tun, der ausgezeichnet ist durch die Neigung zu explosionsartigen Ausbrüchen, wozil die Inhaftierung immer neuen Anlass gibt, also eine Intensitätssteigerung der degenerativen Anlage. Dieser Mann erkrankt auf einmal an einem halluzinatorischen Verfolgungswahn im Gefängnis. Bei Versetzung in die Irrenanstalt liess die Störung nach einigen Monaten nach; flackerte aber anscheinend des öfteren dort bei Erregungszuständen wieder auf. Allerdings geht aus dem Bericht nicht mit Sicherheit hervor, ob das wirklich noch die Reste des halluzinatorischen Haftkomplexes waren oder nur affektive Entgleisungen. Jedenfalls benutzte er diese Erscheinung später für Simulationsversuche. - Der haftpsychotisehe Zustand ist hier ein Ereignis, das sich aus dem übrigen pathologischen Verhalten des Gewohnheitsverbreeheers besonders heraushebt und durch die degenerative Anlage jedenfalls nicht ausreichend erklärt wird, wie etwa die wiederholt aufgetretenen tobsüchtigen Erregungen. Allerdings lassen sich dỉ näheren Umstände, die zur Haftpsychose geführt haben, nicht mehr eruieren.

Auch Reich beschreibt in seiner Arbeit: „Über akute Seelenstörung in der Gefangenschaft" einige Fälle unter dem Bilde motorischer Tobsucht, ängstlicher Erregung und Hemmung, die hierher zu rechnen wären; andere, die er ebenso rubriziert, würden wir heute anders diagnostizieren. Ich lasse die treffliche allgemeine Charakteristik Reich's hier folgen: „Schon in den ersten Stunden oder Tagen nach der Einsperrung oder bald nach einer heftigen Gemütserschütterung (durch Verhör, Konfrontation, Geständnis, Furcht) tritt eine Art psychische Erstarrung ein, der Gefangene wird still, wortkarg, in Hinbrüten versunken, er beobachtet wenig mehr, was um ihn vorgeht; bewegungslos bleibt er auf demselben Flecke, das Gesicht erhält einen staunenden Ausdruck, der Blick ist starr, gläsern, glotzend, abwesend, ohne einen bestimmten Gegenstand zu fixieren; macht er Bewegungen, so sind sie zögernd, unsicher, wie bei einem Betrunkenen; es treten Schwindel und auraartige Empfindungen auf, heftige Angst bemächtigt sich des Menschen, welche mit der ganzen Gewalt eines heftigen Affekts alle anderen Vorstellungen und Empfindungen verdrängt und das Gemüt beherrscht. Das Bewusstsein trübt sich mehr und mehr. Es kommt jetzt der Zeitpunkt, wo Illusionen und Halluzinationen oft plötzlich auftauchen. Die Verwandlung der ganzen Empfindungsweise, das Ueberwältigende und Beherrschende der veränderten neuen Stimmung kommt als eine fremde feindliche Macht 
dem Kranken zum Bewusstsein, die Vorstellungen, von unbekannten bösen Mächten, von Geistern, Dämonen, vom Teufel verfolgt und besessen zu sein, drängen sich mit zwingender Gewalt dem Bewusstsein auf, das im Zwang des Affekts keines Widerstandes, keines objektiv richtigen Urteils mehr fähig ist. Nun strömen auch von der Peripherie allerlei sensible und motorische abnorme Empfindungen zu - Neuralgien, insbesondere heftige Präkordial- und Interkostalneuralgien, konvulsivisehe Zuckungen der willkürlichen Muskeln und Krämpfe der unwillkürlichen, welche vereint mit den Sinnestäuschungen überwältigend die Angst steigern, Wahnvorstellungen entzünden, das Bewusstsein in wildem Sturm mit sich fortreissen und nun in reflektorischem Wege die Entladung des ganzen motorischen Apparats auslösen. Nun kommt Bewegung in die starre Szene. Der Kranke lärmt, tobt, schreit, rennt sinnlos herum, zerstört und vernichtet, was sich im Wege findet. Damit hat die Krankheit ihren Höhepunkt erreicht, das ist auch in der Regel der Moment, welcher die Versetzung des Kranken aus dem Gefängnis in die Anstalt nötig macht." Der Uebergang in Genesung geht unter allmählicher langsamer oder rascherer Klärung des Bewusstseins vor sich, wozu die Milieuveränderung wirksam beiträgt. Oder es tritt erst eine heitere reaktive Stimmung ein, bzw. es verbleibt eine gewisse Reizbarkeit und Verstimmung. Andere wenige Fälle sollen nach der Meinung Reich's in sekundäre psychische Schwächezustände übergehen.

Als ätiologisches Moment gilt ihm der heftige Affekt und dessen durch die Haft gehemmte Ausgleichung und Lösung. „So reiht sich die in Gefangenschaft auftretende akute Psychose, wenn auch dem äusserlichen Boden nach, dem sie entspross, scheinbar eigentümlich, nach ihrem inneren Wesen und klinischen Bilde in jene grosse Gruppe psychisch anormaler Prozesse ein, welche sich aus Affekten und affektartigen Zuständen entwickeln." Es sind namentlich zwei Kategorien von Affekten: Schrecken, Furcht, Angst Aerger, Zorn. „In der Einsamkeit des Gefängnisses findet der depressive Affekt keine Ableitung, keine Ausgleichung. Infolge des fehlenden Ausgleichs übersteigt der Affekt die Schwelle der Gesundheit, führt zur krankhaften Erregung des Gemüts und zur wirklichen Geistesstörung . . . Bei einem geistig und körperlich vollkommen gesunden Menschen wird dieser Affekt eine ungleich grössere Intensität und tiefer in das Gemütsleben einschneidende Wirkung zur Hervorbringung der Geistesstörung besitzen, als bei dem geistesbeschränkten, hereditär, psychisch oder somatisch prädisponierten Individuum."

Skliar beschreibt in seinem Aufsatz über akute Gefängnispsychosen gleichfalls hierher zu zählende Bilder. Nach ihm treten in der Untersuchungshaft, wenn sie zugleich Einzelhaft ist, transitorisch-psychotische Zustände auf, die infolge der ängstlich deliranten Erregung mit Halluzinationen und 
Verfolgungsideen auch Unorientiertheit als Unterarten der Amentia aufzufassen seien. Würde die Haft fortbestehen, so soll statt Heilung eine Verblödungspsychose (?) entstehen. (Ein Beweis für diese Behauptung wird nicht gegeben.) In dieser Art erkranken nicht nur prädisponierte, sondern wenn auch selten - völlig gesunde und erblich nicht belastete Menschen. Die Haft sei die Ursache der Psychosen, die durch die geringen Gelegenheitsursachen des freien Lebens nicht entstanden wären.

Wilmanns beschreibt folgenden dahingehörigen Typ: „Es sind kurzdauernde Störungen, wie sie sich anscheinend aus hypnagogen Halluzinationen heraus entwickeln. Die Kranken, meist junge, schwach begabte und zum erstenmal mit dem Gesetz in Konflikt geratene Personen träumten zum Teil schon früher sehr lebhaft, sprachen und weinten auch sonst im Schlafe. Die Verhaftung, die Verhöre machten einen tiefen Eindruck auf sie; sie sind in starker innerer Erregung, essen wenig, schlafen schlecht und träumen sehr lebhaft. Eines Nachts werden sie ängstlich, schrecken oft und plötzlich auf, hören allerlei verdächtige Geräusche, der Ofen knattert eigentümlich, es klopft an den Wänden, sie hören Musik und Glockenläuten, ihren Namen rufen, die Stimme des Vaters auf dem Gange. Allmählich nehmen die Sinnestäuschungen bestimmtere Gestalt an; ein sexuell Perverser hört seine Frau vorwurfsvoll sagen: ,Wenn du so was getan hast, hättest du mich nicht heiraten sollen'; ein anderer die Stimme seiner Mutter: :Ich lkann jetzt nicht mehr leben, ich muss vor Kummer sterben'; ein dritter die Stimmen der Aufseher vor der Zelle: ,Jetzt liegt er im Bett'; ,Wir bringen ihn um' usw. Die Kranken fühlen sich beengt, haben heftige Präkordialangst, können keine Luft holen, sie merken, dass eine Wolke in die Zelle schwebt, dass sie sich mit Schwefeldampf füllt. Bisweilen treten auch plastische Gesichtstäuschungen ein: der Gefangene sieht, wie seine Mutter wie lebend an sein Bett tritt, wie ihm der Vater die Hand aus dem Sarge reicht, hässliche Tiere, Vögel und Schlangen drängen auf ihn ein, der sich vor Angst nicht zu rühren wagt. Die Störungen sind nachts am heftigsten. Tagsüber legt sich die ängstliche Erregung. Die Kranken sind aber scheu, furchtsam, bisweilen etwas traumhaft benommen und klagen über Kopischmerzen, Schwindel und Ohrensausen. Den nächtlichen Erlebnissen stehen sie zunächst oft einsichtig gegenüber, oder aber sie halten an ihrer Realität fest, um so mehr, als sie eine gewisse subjektive Wahrscheinlichkeit besitzen. Bringt man die Kranken rechtzeitig in ein anderes Milieu, so werden sie in kurzer Zeit bei starker Zunahme des meist sehr gesunkenen Körpergewichts völlig einsichtig. Wird die Haft nicht aufgehoben, dann scheinen diese leichten Störungen die Finleitung für schwerere geben zu können."

$E_{s}$ sind Steigerungen, die stark an das Bild des Alkoholwahnsinns erinnern; charakterisiert durch das Vorherrschen von massenhaften, äusserst 
plastischen Halluzinationen, vorzüglich des Gehörs, weniger des Gesichts, bei voller Besonnenheit, lebhaftesten, ängstlich gereiztem Affekt. Die Halluzinationen beziehen sich dabei entweder auf die Person selbst oder auf die Nahestehenden und lassen die Beziehung zu dem affektiven Erlebnis nicht verkennen.

Gerade auch Wilmanns betont, wie bei sonst gesunden Individuen die Haft Störungen erwecken kann, die an das Psychotische grenzen. Neben nervösen Beschwerden, Reizbarkeit und Gemütsdepression wird das Auftreten von Halluzinationen und Mlusionen durch die Einzelhaft sehr begünstigt. Die halluzinatorische Färbung der Störung in der Untersuchungshaft werden wir also oft auf das Milieu zurückführen können. Aber auch hier tritt als wesentlich dasjenige Moment hervor, das wir als eharakteristisch für die ganze Gruppe anzusehen haben: die Situationsfixierung. Die Simnestäuschungen, sobald sie bestimmtere Gestalt angenommen haben, gehen und beziehen sich auf das Erlebnis mit seinen Begleit- und Folgeerseheinungen, dessen die Psyche nicht Herr geworden ist.

Als Musterbeispiel für die Analyse einer emotionellen Situationspsychose möchte ich den Fall von Michaelis anführen: es handelt sich um einen Kriegsteilnehmer, der ausser einer leichten Verwundung und geringen Erschöpfung keine belastenden anamnestischen Daten aufwies; keine degenerative Anlage; nur eine als physiologisch anzusehende Enge und Beschränktheit des Gesichtskreises, die gesteigert sind durch die äusseren Einflüsse des Milieus (ein Bauer, der ausser seiner Militärzeit nie von seinem Heimatflecken fortgekommen war). „Aus dieser einförmigen Stille hat ihn der Krieg plötzlich herausgerissen. Die erste Erregung äusserte sich darin, dass, während er früher stets traumlos geschlafen hatte, er jetzt jede Nacht vom Erlebnis des Tages träumte. Als dann mit der Verwundung (Weichteilschuss) im Lazarett wieder plötzliche Stille eintritt, wird er psychotisch: das so entgegengesetzte, gleichsam überlebensgrosse Ereignis des Krieges hat sein psychisches Gleichgewicht erschüttert und als Reaktion die psychische Erkrankung hervorgerufen. Beginn mit Apathie und Abulie. Auf der Höhe finden sich psychomotorisch die katatonen Zeichen der Katalepsie und des Negativismus; ausserdem Zeichen von Verwirrtheit, wahnhafte Verkennung der Umgebung, Sinnestäuschungen. Die Fixierbarkeit ist fast aufgehoben; Desorientierung über Zeit, Ort und die letzten Erlebnisse, tiefe Störung der Auffassung und Verwertbarkeit jeglieher Eindrücke. Während die einfachen Wahrnehmungsfunktionen und die mechanischen Gedächtnisleistungen gut sind, ist jede andere geistige Tätigkeit, die eine Verknüpfung mehrerer Eindrücke fordert, äusserst gering; nur die allereinfachsten Fragen werden beantwortet. “ Das Bewusstsein scheint nur ein Gemisch weniger sich durchkreuzender Antriebe: ausgesprochene Ambivalenz. Die Bewusstseinsinhalte treten gleichzeitig mit 
positiven und negativen Vorzeichen auf; ohne Korrektur und Wahl werden direkt entgegengesetzte Gedankeninhalte anstandslos nebeneinander gesetzt. Mehrfach Verdichtung und Verquickung zweier Ideen, wie sie Bleuler für die Spaltung der Dementia praecox beschreibt. „Häufig Vorbeireden, aber meist nicht im Sinne des von Ganser beschriebenen Typus der unsinnigen Antwort, sondern anderer Genese: Ausdruck eines ganz bestimmten Komplexes, der so stark in Bereitschaft ist, dass er bei den verschiedensten Ereignissen ohne erkennbare inhaltliche Beziehung zur Frage assoziiert wird." Dieser Kriegskomplex (Schützengrabenerlebnisse, die auch stark halluziniert werden) steht beherrschend im Mittelpunkt der Störung; durch ihn wird trotz der tiefen Spaltung das Bewusstsein gleichsam zusammengehalten und der einheitliche Charakter des Bildes bewahrt (wir würden es als Situationsfixierung bezeichnen). Der Komplex entstammt dem emotiellen Erlebnis der Psyche. Zuerst schwinden nach 14 Tagen die katatonen Zeichen; die Sperrung lässt nach. Eine Woche später verliert der Kriegskomplex stärker an Intensität; die Orientierung gelingt zum Teil, wenn auch noch die wirkliche Situation unerkannt bleibt; Ambivalenz und Sperrung zeigen sich noch in den schriftlichen Aeusserungen. Nach weiteren 14 Tagen sehwindet der Kriegskomplex ganz; Patient gelangt zur völligen Orientierung.

Eine leichte Hemmung hält dann noch etwa einen Monat an, bis völlige Krankheitseinsicht eintritt und damit die Genesung. - Mit Dominieren des Komplexes ist die Störung am stärksten, mit seinem Schwinden tritt Rückbildung aller Erscheinungen ein; damit sei der exogene reaktive Charakter der Psychose festgelegt, die psychische, emotive Genese des Krankheitsbildes erwiesen. Aber Verfasser glaubt auch, die Forderung der Erkenntnis der Bedingtheit gerade dieser Reaktion in der individuellen Anlage erfüllt zu haben. Das geringe geistige Niveau, eine teils angeborene, teils milieubedingte Beschränktheit, mache das Individuum auch in gesunden Tagen zu jedweder grösseren synthetischen Leistung unfähig. Von diesem niedrigen Niveau aus führen nun kontínuierliche Cebergänge zu dem-Stadium stärkster Störung, das den Höhepunkt der Reaktion charakterisiert. Die verschiedenen Stadien rückwärts verfolgt, zeigen, ,wie die synthetische Fähigkeit immer mehr abnimmt oder, um einen anderen psychologischen Ausdruck zu brauchen, wie die Aktverbindungen immer tiefer herabgesetzt sind bis zu jenem Zustande, wo das Bewusstsein völlig zerstückelt nur ein Gemisch verschiedenster Antriebe ist, das durch den auslösenden Kriegskomplex beherrscht wird ... Die dunkel und rätselhaft scheinende Störung des Bewusstseins wird so dem Verständnis durch den Nachweis kontinuierlicher Verbindung mit dem individuellen Grundzustand nahegerückt." Differenzialdiagnostisch kamen Dementia praecox und Hysterie in Betracht. Die symptomatische Verwandtschaft $\mathrm{zu}$ der ersteren ,,ist durch die klinisch-analytische Beobachtung als 
rein äusserlich enthüllt, und damit ein neuer Beweis für die Unzulänglichkeit rein symptomatischer Betrachtungsweise gegeben". Negativismus, Katalepsie und eine der Spaltung ähnliche Bewusstseinsstörung, wie Sperrung, Ambivalenz, Neologismen, Verquickung zweier Ideen, Vorbeireden sind hier bedingt durch das psychische Trauma. Zwei genetisch völlig verschiedene Phänomene: Tährend bei der Spaltung der Dementia praecox in überraschendem Wechsel einfachste Aufgaben nicht gelöst, kompliziertere dagegen verstanden und ausgeführt werden, zeigt sich hier eine allmähliche Aufhellung des Bewusstseinszustandes mit kontinuierlicher Besserung der synthetischen Leistungen. Dieser gesetzmässigen Geschlossenheit steht bei der Dementia praecox der Charakter des Bizarren, unverständlich Sprunghaften gegenüber. Orientierung und Auf fassung ist dafür meist hier nicht gestört, auch das Gedächtnis in viel geringerem Grade. Gegenüber der Hysterie (i. e. Psychogenie in Sinne Sommer's) finden sich - abgesehen von dem Fehlen körperlicher Reiz- und Lähmungserscheinungen - statt der Beeinflussbarkeit unzulängliche Starre, statt Labilität allmählicher steter Fortschritt, statt erhöhter übertriebener Affektreaktion geringe Ansprechbarkeit des Affekts. Auch das Vorbeireden hat, wie schon hervorgehoben, eine andere Genese. Sonstige ätiologische Faktoren, wie exogene Schädlichkeit somatischer Art, und endogene psychopathische Konstitution fehlen; nur die psychische Reaktion und Genese stehen ausser Zweifel. Es liege nicht der geringste Hinweis vor, die Anlage als eine degenerative hinzustellen, gerade das Fehlen einer solchen mache den Fall so überaus klar und typiseh.

Dieser vortrefflichen Analyse ist - nach unseren bisherigen Ausführungen - kaum etwas hinzuzufügen. Es zeigt sich jedenfalls zur Genüge, welche Einsichten uns die rein psychologische Analyse auf Grund guter klinischer Beobachtung geben kann. Ob die hier angegebenen differenziellen Zeichen allgemein für die ganze Gruppe zu gelten hätten, ist von sekundärer Bedeutung. Geht doch aus Michaelis' Ausführung indirekt hervor, dass nicht die Symptome, sondern die individuelle Reaktion das Massgebende ist.

Es kommt hier auch nicht darauf an, wie weit man im einzelnen den Folgerungen des Verfassers zustimmen will. Das Pinzipielle wird man anerkennen müssen und zu der Einsicht gelangen, dass unsere bisherige Kasuistik in dieser Hinsicht nur wenig bietet; die Literatur ist daher für unsere Zwecke nicht in dem wünschenswerten Masse heranzuziehen, weil gerade die grösseren Arbeiten die Krankengeschichten nur summarisch wiedergeben. Freilich muss zugegeben werden, dass eine derartige Analyse nur bei eingehendster Exploration zu erreichen ist, und diese ist oft erschwert, oft überhaupt nicht möglich; gerade den so wichtigen und häufigen stupurösen Zuständen kann man infolge ihres gewollten oder ungewollten Negativismus in vielen Fällen nicht beikommen. Die Diagnose hysterischer Stupor auf Grund 
hysterischer Stigmen und Antezedenzien ist da die Wahrscheinlichkeitsdiagnose, die an Sicherheit etwas gewinnt, wenn starke Beeinflussbarkeit durch äussere Umstände und Oberflächlichkeit mit promptem Wechsel in den Erscheinungen durch äussere Massnahmen, wie Faradisieren, hinzutreten.

Für die meisten Fälle haben wir jedoch ausreichende Kriterien gewonnen, um sie von dem hysterischen Typ abzutrennen. Ob die depressive Verstimmung die hervorstechendste Erscheinung bildet oder Stupor, ängstliche Erregung, Halluzinationen, die sich bis zum Delirium steigern können, ob schliesslich Wahnideen, meist als Folge der Halluzinationen, stärker hervortreten, sie alle sind Produkte einer ihrem Wesen nach gleichartigen, durch starke Affekte hervorgerufene seelische Gleichgewichtsstörungen, die durch die spezifischen Einflüsse der Haft noch stärker hervortreten. Das, was w.r als Situationsfixierung charakterisierten, äussert sich vor allem darin, dass der reaktiv ansgelöste Affektzustand - wie schon Reich gesehen hat überwertig wird, dass er nicht nur anhält, sondern sich sozusagen über alle psychischen Erlebnisse ausbreitet und ihnen ihren Inhalt liefert. Dabei ist es als charakteristisch gegenüber den hysterischen Formen anzusehen, dass die Ausgestaltung, die die traumatische Affäre noch etwa in der Psyche erhält, sozusagen nicht das Mass des Physiologischen übersehreitet, nicht die phantastisch übertriebenen und abenteuerlichen Formen der hysterischen Dämmerzustände annimmt. Der Kranke sieht vielleicht die tote Mutter, die ihm Vorwürfe macht usw.; aber all die psychotischen Erlebnisse sind aus einem normalen Seelenleben heraus zu interpretieren, weil ihnen die assoziativen Zusammenhänge des gewöhnlichen Lebens zugrunde liegen: Angst vor der Strafe und den Behörden, Scham vor den Angehörigen, Rene und Selbstvorwürfe usw. - Es bestehen keine Anhaltspunkte, für die Gruppe der emotionellen Situationspsychosen besonders endogen vorgebildete pathologische Mechanismen anzunehmen; vielmehr sind sie aus den jeweiligen Umständen heraus verständlich, weshalb auch eine psychopathische Konstitution fehlen kann. Es sind wohl pathologische Affektwirkungen, weil sie das physiologische Mass überschreiten, aber keine spezifischen, d.h. solche, die einen speziellen Mechanismus zu ihrer Erklärung fordern, wie das bei der nächsten Gruppe, dem hysterischen Typ, der Fall sein kann.

Wir hatten bereits oben den Begriff der hysterischen Situationspsychose erläutert und als wesentliches Moment die Situationsverschiebung kennen gelernt. Dieser Typ entbehrt nun allerdings der Einheitlichkeit der vorigen Gruppe. Wir mussten nämlich die hierher gehörigen Fälle danach trennen, ob und wieweit ein Krankheitswunsch oder gar die Simulation von Krankheitssymptomen bei einem hysterischen oder verwandten Charakter mit- 
spricht; es sind dies Momente, die ätiologisch betrachtet, der psychophysischen Konstellation zuzurechnen sind. Keineswegs erscheint es nun erwiesen und wird auch von vielen Autoren verneint, dass bei hysterischen Störungen der Wunsch oder gar die Simulation immer mitspricht. Stern meint zwar, dass nur in einzelnen Fällen besonders starke Affekte allein die hysterischen Situationspsychosen hervorrufen; bei Gewohnheitsverbrechern und sonstigen wiederholt bestraften Individuen wird man meistens - nach Stern - mit Recht keine besonders heftige Affektwirkung annehmen können. Symptomatisch zeigen sich nämlich sonst Unterschiede gerade bei den Haftkomplexen. Ein Wechsel der Symptome, eine erhöhte Beeinflussbarkeit spricht für die Beteiligung eines Krankheitswunsches; allerdings scheint ein einheitliches Krankheitsgepräge nicht immer der Beweis für das Gegenteil zu sein, namentlich bei Dämmerzuständen, die nach Wilmanns öfter aus der Simulation heraus sich entwickeln sollen. Auch Stäussler nimmt für seine unter dem Bilde des Puerilismus beschriebenen Dämmerzustände einen Krankheitswunsch als wirksam an. Indes kann man doch Fälle beobachten, in denen man einen derartigen Nachweis nicht zu führen vermag, und die auch dem unbefangenen Beobachter keinen derartigen Eindruck machen. Es sind das gerade diejenigen Individuen, die keine oder wenige hysterische Antezedenzien aufweisen und bei denen eine starke Affektwirkung ätiologisch die Hauptrolle spielt. Stupor, Dämmerzustände mit oder ohne Gansersymptome, Delirien, eventuell in gegenseitiger Kombination und mit Uebergängen sind die häufigsten hier anzutreffenden Bilder. Dabei ist zu bemerken, dass nicht nur das Vorherrschen eines affektbetonten Komplexes zu konstatieren ist, sondern in den ausgesprochenen Fällen eine Situationsverschiebung; das Individuum durchlebt eine pathologisch - veränderte Situation.

Den stärksten Grad der Situationsverschiebung zeigen die von Sträussler unter dem Bilde des Puerilismus beschriebenen Dämmerzustände, wo „,das Nichtwissenwollen sich nicht auf die strafbare Handlung und das Nächstliegende beschränkt, sondern weitere Kreise zieht, der Kranke willvon der gesamten Gegenwart mit all dem Ungemach, welches sie birgt, nichts wissen, er will weit, weit weg, er flüchtet sich seinem gegenwärtigen Bewusstsein gegenüber in die Kindheit zu Vater und Mutter. Die Flucht aus der peinlichen, unglückseligen Gegenwart und dem gegenwärtigen Bewusstsein kommt aber nicht einer wirklichen, in allen Einzelheiten durchgeführten Rückversetzung in die Kindheitsjahre gleich; angenehme Vorstellungskomplexe aus späterer Zeit bleiben meist erhalten. Es ist also weder eine vollständige retrograde Amnesie, noch eine vollständige Wiederherstellung des kindlichen Zustandes, eine Regression der Persönlichkeit im strengen Sinne des Wortes." Dies die Auffassung Sträussler's. Häufiger sind die 
nicht so weit gehenden Zustände von Moria, kindlichem, läppischem Wesen, besonders beim Abklingen der Störung. Das Auftreten von Kindheitsszenen in den mehr deliranten Zuständen ist nicht selten; sie bilden den Uebergang zu den Reminiszenzdelirien. Für manche Fälle wird man Stern zugeben können, dass der Krankheitswunsch nicht nur durch die gleichzeitig wirksamen und zweifellos oft mächtigen Affekte erweckt wird, sondern infolgedessen auch die geeignete Disposition zur Verwirklichung findet; es tritt so gleichsam die Flucht in die Krankheit ein. Ich glaube aber, dass man den Wunschfaktor gerade für diese Fälle, die so ausgeprägt einheitlich sind, und immerhin doch tiefgehende Störungen des Bewusstseins zeigen, nicht so hoch veranschlagen darf; jedenfalls tritt er gegenüber den starken Affektwirkungen sehr zurück; von grösserer Bedeutung ist er für die weiter unter zu besprechenden Fälle. Zur Illustrierung möchte ich einige Fälle eigener Beobachtung anführen. ${ }^{1}$ )

Fall 1. W. R., 15 Jahre, Schmiedelehrling, unehelich geboren; Mutter +; Vater im Kriege. Wegen drohender sittlicher Verwahrlosung seinem Vater entzogen und der Waisenfürsorge 1909 übergeben. Betragen nicht zufriedenstellend; durch und durch verlogen, diebisch, bestahl seine Stubenbrïder. Faul, zuletzt gebessert. Nach einigen Nonaten lautet der Bericht: Zu Klagen kein Anlass mehr; verschlossenes Wesen, vielleicht infolge Stimmungen, über welch letztere der Junge selbst nicht recht klar ist. Verträglich. Keine Diebstähle. 1911 in Pflege. Bericht der Pflegeeitern: Ungezogen, leichtsinnig; zu viel Untugenden. Ansatz zor Besserung. Hilft sonst mit. 1914: Kräftiger, geistig gut begabter Jingè. Verhalten vielfach tadelnswert. Neigt zur Faulheit, Unwahrhaftigkeit und Lngehorsam. Streng zu halten. Auch Jehrer klagen. Besserung nur vorübergehend, 1915: Etwas nachlässig in seiner Kleidung, sonst anstellig zufriedenstellend, intelligent und geschickt. Brauchbarer Bursehe; Pflegerater hofft aus ihm einen tüchtigen Schmied zu macben. 1916: Strenge Zucht nötig; sonst zufrieden. Juni 1916: Betragen viel besser als früher; macht gute Fortschritte.

Am 7. 7. 1916 wird er ins Krankenhaus aufgenommen. Bericht des Krankenhauses:

Der Junge wird von seinem Meister am Nachmittag des 7. 7. in die Klinik gebracht, er soll bis jetzt stets ein braver, fleissiger Junge gewesen sein. Pat. ist ein Waisenkind, über Eltern und Geschwister nichts bekannt. Pat. soll am Montag, den 3. 7., in einer Allee Kirschen gestohlen haben und wurde von einem Wachtmeister deshalb scharf angefahren. Der Junge kam infolgedessen ganz eingeschïchtert nach Hause, erzählte noch dieses Frlebnis, und dann entwickelte sich in 1-2 Tagen (am 5. hätte er noch gearbeitet) - seit dem 6. - der jetzige Zustand, wegen dessen er ins Krankenhaus gebracht wird.

Pat. ist ein für sein Alter dürftig ertwickelter, noch ziemlich kleiner und.

1) Fall 1 und 9 konnte ich in der Leipziger Klinik beobachten. Für Ueberlassung der Krankengeschichten bin ich Herrn Geh. Rat Prof. Flechsig zu Dank verpilichtet. 
etwas inferior aussehender Junge. Ausgesprochener stuporöser Zustand. Pat. reagiert meist auf kein Anrufen, steht regungslos still am Bett oder liegt mit offenen Augen regungslos da, ausgesprochene katatonische Störung, der erhobene Arm bleibt in der Luft, das erhobene Bein dagegen fällt schlaff zurück. Von Zeit zu Zeit offenbar halb halluzinatorische Störung, Pat. greift in die Luft oder nach der Hand und steckt dann den anscheinend ergriffenen Gegenstand in den Mund (Kirschen?). Dexartige Halluzinationen können ihm auch verbaliter oder durch Zeichen leicht suggeriert werden. Ebenso kann man ihn mit einigem Zureden zu kleinen Handlungen bringen, Schreiben, Kleiderabbürsten $u$. dg]. Doch tritt bald wieder der gewöbnliche Stupor ein, nur ganz vereinzelt stösst Pat. plötzlich ein lantes Wort hervor, z. B. Lump.

Auf Zureden hat Pat. allein gegessen, hat nachts geschlafen, Harn und StuhI ins Bett entleert. Kein Fieber. Innerer Organbefund o. B.

Am 10. 7. 1916 der Klinik überwiesen. Nach Bericht des Pflegevaters hat der Knabe auf der Schule schlecht gelernt, hörte nicht, war ungezogen. Seit anderthalb Jahren bei dem Neister, sonst gesund; war ein fleissiger, aufmerksamer Junge; aber etwas schwächlich. War aber ein grosser Lügner; man konnte ihm nichts glauben. Vor etwa einer Woche Kirschen vom Baum gepflückt. Der Obstzüchter, der ihn erwischte, brachte die Sache zur Anzeige. Soll dem Wachtmeister gegenüber unwahre Angaben gemacht haben (es seien mehrere Täter gewesen usw.), wisse wohl nun nicht mehr aus noch ein: seit 8 Tagen psychisch verändert, sass sinnend und schweigend da. Hörte schliesslich auf zu arbeiten; stand starr da, auf einem Fleck, sah stier drein. Ass dann nichts mehr; blieb im Bett. Status: Weite Pupillen; offener Mund, den er zeitweise auf- und zuklappt, begleitend mit unartikulierten Lanten. Aengstlich gespannter Gesichtsausdruck; starre Haltung. Lässt sich allsziehen und ins Bett bringen. Tiefe Nadelstiche fast ohne Reaktionen; Faradisieren entlockt ihm nur einige Schmerzenslaute. Halluziniert; ruft: „Der Dieb ist getötet... der Mörder ist getötet... Kirschen... ach Gott, ach Gott, ach Gott. Keine Soldaten mehr... Habe alle erschossen." Finger werden meist richtig gezählt. Andere Angaben werden auf Befragen nicht gemacht. Macht die Bewegungen des Arztes nach; spricht als Antwort auf gestellte Fragen Worte - sie stets in monotoner Weise wiederholend - nach, die ein anderer Katatoniker gerade ausspricht. Andeutung von flexibilitas cerea. Umarmt den Arzt mit den Worten: „Mein Jieber guter Papa." Die Frage, ob er gestohlen hätte, bejaht er; bezichtigt sich als Mörder. Angst verneint er, ebenso Furcht vor dem Pflegevater. Unrein mit Kot und Urin. 11. 7. Sobald er den Arzt sieht, ruft er dauernd: „Komm, guter Papa." 12. 7. Liegt meist ängstlich gespannt mit offenem Munde da. Leichte flexibilitas cerea. Glieder werden anch in unbequemer Lage eine Zeitlang gehalten, dieses Symptom aber nicht immer vorhanden. Starke Echolalie; befolgt Befehle, sie wiederholend, in etwas automatischer Weise. Bei der Aufforderung, sich wieder ins Bett zn legen, legt er sich mit Kopf und Rumpf quer über das Bett, ist aber nicht imstande, sich ohne Anweisung allein richtig ins Bett zu legen. Zuweilen einzelne Worte und Sätze, wie „Mörder ..." Stürzt sich gierig aufs Essen, geht mit Fingern in die Suppe. Muss abgeführt werden. Bei Nadelstichen ins Septum Schmerzreaktion. Zeitweise Vorbeireden (wie alt bist du?) tot, (wer bin ich?) Null. 
16. 7. Seit heute Bewusstsein etwas aufgehellt. Erkennt den Arzt als solchen. Auf die Frage, weshalb er hier sei: ,Ich habe alles gestohlen, alles geraubt, die ganze Welt habe ich gemanst, alle Soldaten getötet." 25. 7. Schrieb gestern an seinen Pflegevater einen kurzen, aber geordneten Brief, bittet un dessen Besuch. Beim Essen etwas langsam. Bezichtigt sich weiterer Schlechtigkeiten, Schule schlecht golernt, die Leute beloger, gibt an, Eier gestohlen zu haben; verwickelt sich dabei in Widersprüche, nimmt die Selbstbezichtigung wieder zurück. Auf Befragen erklärt er, er habe Angst; hier werde er für seine Taten getötet, die er nicht gestanden, sondern vor Gericht abgeleugnet habe. Fängt dabei ängstlich zu weinen an. - Behauptet einmal, hier sei das Gericht, daun wieder Gefängnis, mit der Begründung, dass die Fenster doch vergittert seien. Werde mit dem Bajonett erstochen (zeigt dabei aufs Herz), oder mit dem Revolver erschossen. Sei erst etwa 4 Wochen hier (recte 14 'Tage), gibt den Ort seines sonstigen Aufenthaltes richtig an. Begrüsst heute morgen in freier Weise den Referenten mit Herrn Dr. Bei weiterer Exploration zusehends befangen. Weint, er werde hier geschlachtet, behauptet auf Befragen, der Referent sei der Gerichtsvollzieher. Als er jetzt etwas angefahren wird, dass er nicht lügen und ob man von der Hinrichtung Abstand nehmen solle, verspricht er ängstlich weinend Besserung. 27. 7. Zunehmend klarer. Erkennt den Arzt, behauptet aber, noch vor Gericht oder im Zuchthaus zu sein. Als ihm bedeutet wird, Aerzte seien doch nicht im Znchthaus, gibt er richtig Nervenklinik an. 30. 7. Bei der Visite Klagen über Kopfschmerzen. Bei Besuch seines Pflegevaters und Meisters läuft er ihm weinend in die Arme mit den Worten: „Lieber Meister, nehmen Sie mich mit, ich will wieder arbeiten." Die Frage, ob er noch Angst hat, verneint er. 1. 8. Kommt spontan auf den Arzt zu und bittet gesund geschrieben zu werden, danit er bei seinem Meister wieder arbeiten kann. 2. 8. Die Frage, ob er sich darauf besinnen könne, dass er Mörder gerufen, in dem Glauben, getötet zu werden, dass er den Arzt als Papa bezeichnet habe, bejaht er. Weiss aber angeblich nicht, dass ex vorher in einem anderen Krankenhaus gewesen ist. Beim Versuch einer näheren Exploration über seinen kranken Zustand, wird er stumm, ängstlich, die Augen füllen sich mit Tränen; flüstert nur noch mit leiser Stimme, bleibt schliesslich die Antwort schuldig. Hatte gestern einen zwar unbeholfenen, aber geordneten Brief an seinen Meister geschrieben, worin er ihm sein Tagewerk hier schildert. Die Intelligenzprüfung entspricht dem Durchschnitt.

4. 8. Gibt sein Alter auf 16 statt 15 an, behauptet, es sei jetzt 1917 , bleibt auf wiederholtem Vorhalt dabei. Müsse heute Nachmittag von 6 bis 7 zur Fortbildungsschule gehen. Bekäme Keile, sei ausgerissen. Behauptet auf wiederholtes Befragen, es sei 1915. 5. 8. Erzählt ausführlich und genau, wie er die Kirschen vom Baum gepflückt und dabei ertappt worden ist. Erzählt auch spontan, dass er falsche Angaben gemacht hat. In der Schmiede habe er nichts erzählt. Ein Tag später erfuhr es der Meister; dieser sagte, er wolle ihn nicht länger behalten, leiste ihm nicht genug. Er habe auch öfter kleine Eisenstücke im Werte von 5-10 Pfennig verkauft, ohne dem Meister das Geld zu geben. Habe dafür manchmal tüchtige Haue bekommen. Sich fürs Geld Sonntags Zigaretten gekauft. Bringt allerlei Kindereien vor, die er mit anderen getrieben habe. Am Mittwoch habe er nicht mehr gearbeitet; hatte keine Last mehr. Bücher (Räuberschwarten) gelesen. Im 
Garten herumgelaufen. Wieviel Tage er noch zu Hause gewesen sei, wüsste er nicht. Der Meister habe ihn in das Krankenhaus gebracht; erst zu Fuss gegangen, damn mit der Elektrischen gefahren. Im Krankenhaus 14 Tage im Bett gelegen (recte 3 Tage).

(Wo bist du jetzt?) in der Schule. Wird dann wieder bei der Exploration ängstlich verlegen, gespannt. Fasst die Fragen schwer auf, beantwortet sie mühsam. Ab und zu Vorbeireden. Zeigt sich im übrigen - soweit seine Affäre nicht ins Spiel kommt - orientiert, macht sachliche und detaillierte Angaben; auf der Station tätig und behilflich. 8. 8. Bei der Exploration wieder etwas fassungslos; zuerst Vorbeireden. Antwortete dann etwas besser; den Unterschied zwischen Lüge und Irrtum bringt er trotzdem nicht zustande. 14. 8. Apathisch stumpf; nimmt jetzt wenig Interesse an der Umgebung, beschäftigt sich jetzt auch nicht. Eigentümliche Monotonie der Stimme. 15. 8. Dass er im Krankenhaus gewesen sei, wisse er nicht, habe es von anderen erfahren. (Datum?) 4. August, (Tag?) Sonnabend (recte Donnerstag), (warum?) weil heute rein gemacht worden sei. Die Länge seines hiesigen Aufenthaltes gibt er richtig an. 21. 8. Versuchsweise gebessert entlassen. Darïber aufgeräumt und lebhaft. 1. 9. Stellt sich dem Arzt wieder vor; ist munter, frisch und aufgeweckt. Dem Arzt gegenüber nicht sonderlich verlegen. 1. 11. Nochmaliger Besuch beim Arzt; ist dabei munter und guter Dinge. Auf Befragen erzählt er in freier Weise: Sei ,;in den Kirschen" gewesen, dabei ertappt worden; sollte bestraft werden; glaubte ins Zuchthaus zu kommen. Habe sich das in den Kopf gesetzt, konnte nicht mehr arbeiten, sei deswegen nach hier gekommen. Die Amnesie für seinen damaligen Zustand im übrigen unverändert. Den Unterschied zwischen Lüge und Irrtum weiss er jetzt zutreffender anzugeben: Lüge sei schlimmer, wird bestraft, Irrtum könne jedem passieren. Sənsibilität ungestört. Bemerkenswert ist die etwas niedrige Stirn und ein doppelter linker Caninus.

Ein 15 jähriger Junge war, zum Teil infolge unehelicher Geburt und verwahrloster Erziehung, in seinen früheren Jahren ein Tunichtgut, besserte sich aber später intellektuell und moralisch und wurde ein brauchbarer Lehrling. Nur über Lügenhaftigkeit hatte der Meister noch zu klagen. Dieser Knabe wird eines Tages beim Kirschenpflüeken ertappt (hatte dies früher sehon öfter getan, war aber bisher nur geprügelt worden). Sucht sich erst mit Lügen herauszureden, gelingt ihm aber nieht. Ausserdem erfährt der Meister davon und droht, ihn fortzuschicken. Nun packt den Jungen doppelt Angst und Schreck, er fürchtet, ins Zuchthaus zu kommen, ausserdem hatte er bei dem Meister manches noch auf dem Kerbholz. Diesem starken Affekt ist die noch unreife Psyche nicht gewachsen, eine akute Insuffizienz tritt ein, die sich zuerst als zunehmende Hemmung äussert und schliesslich einem katatonischen Stupor gleicht. Dazu treten Sinnestäuschung und phantastische Selbstbeschuldigungen unter Bewusstseinstrübung, mit Verkennung der Cmgebung und Personen: Eine Situationsverschiebung im Sinne seiner. schlimmsten Befürchtung. Er glaubt, im Gefängnis zu sein und getötet zu werden für die unmöglichsten Schandtaten. Dass seine auch sonst an- 
scheinend lebhafte Phantasie hier unter der Chokwirkung derartige Dimensionen angenommen und so einen grösseren Anteil an dem hysterischen Delir trägt, ist wohl sicher. Interessant ist dabei auch, wie er sich in seiner Angst und Furcht zu Vatern zu flüchten sucht und in anderen Personen seinen Vater sieht, dem er doch schon seit Jahren völlig fremd ist. Eín Beweis, wie echt und stark der Affekt ist. Auch nach Abklingen der deliranten Phase bleibt noch eine gewisse Hemmung, die sich bei Explorationen bis zur Fassungslosigkeit steigert. Auch sein Vorbeireden ist sicher zum Teil auf seine Fassungslosigkeit zurückzuführen. Es ist überhaupt fraglich, ob der Krankheitswunsch eine nennenswerte Rolle spielt; wurde ihm doch bedeutet, dass seine von ihm immer geforderte Entlassung erst dann stattfinden würde, wenn er ordentliche Antworten gebe. Zum Teile findet eine missverständliche Auffassung der Frage statt, die die falsche Antwort erklärt. Es kommen wohl auch noch andere Momente in Betracht. So erklärt er einmal, sich in der Schule zu befinden, nachdem er kurz zuvor gesagt hatte, er müsse zur Schule. - Einige Monate später zeigt er nicht nur völlige Krankheitseinsicht, sondern vermag spontan eine Erklärung für seine Erkrankung abzugeben, wie sich überhaupt seine Intelligenz als dem Durchschnitt entsprechend erweist. Auch sein Benehmen dem Arzt gegenüber ist jetzt tadellos, ohne jede grössere Befangenheit. Von hysterischen Andezedenzien finden wir nur eine starke Lügenhaftigkeit; möglich, dass sich dahinter ein Ansatz zur Pseudologia phantastica verbirgt. Die redizidivierende fassungslose Hemmung, wie sie gerade bei Kindern unter dem Einfluss von Affekten häufiger auftritt, gehört möglicherweise auch zur Eigenart dieses Knaben und mag zum Auftritt des Stupors beigetragen haben. Durch einen starken Affektchok entstand dann die seelische Gleichgewichtsstörung unter dem äusserlichen Bilde eines Stupors, die dann den geeigneten Boden für das Wuchern der starken Phantasie abgab. Die Wirkung des affektiven Erlebnisses ist eine derartig exzessive und bei emeuten Explorationen so nach dem Typ der psychogenen Fassungslosigkeit rezidivierend, dass schon aus diesem Grunde die Diagnose auf Katatonie wenig wahrscheinlich ist. - Trotz alledem ist uns diese Erkrankung in ihrer Eigenart so noch nicht genügend verständlich. Vielmehr müssen wir hier annehmen, dass die Erscheinung der Situationsverschiebung als spezielle Affektwirkung auf eine individuelle Tendenz zurückzuführen ist, die bei einer akuten psychischen Insuffizienz zutage tritt. Nicht zu vergessen ist die Pubertät als ätiologischer Faktor. Es ist also eine Kombination innerer und äusserer Faktoren, die zu dieser hysterischen Situationspsychose geführt haben. Die übrigen katatonen Züge von Unreinigkeit, Echolalie werden wohl als Effekte der ängstliehen Verwirrung aufzufassen sein. Ein Krankheitswunsch scheint nicht vorgelegen zu haben. 
Fall 2. E. M., 1885 geboren, ledig, evangelisch, Mechaniker, zurzeit Heizer bei der Marine. Vater Trinker, an Nierenleiden gestorben. 3 Brüder gesund. Angeblich auf der Schule gut gelernt, immer gesund gewesen. Lues, Alkohol negiert. Im Zivil nicht vorbestraft; während der aktiven dreijährigen Dienstzeit 26 mal mit Strafexerzieren, mittlerem und strengem Arrest von 3 bis 28 Tagen, und zwar wegen Schlägerei, unpassenden Benehmens, Drückerei vom Dienst, unerlaubte Entfernung, Achtungsverletzung, Ungehorsam, unmilitärischer Haltung, Belügen eines Vorgesetzten, Wachvergehens, leichtfertjge Beschwerdeführung. Bei einer Reservistenübung 14 Tage strengen Arrestes wegen Achtungsverletzung und Ungehorsam. Seit der Mobilmachung 20 mal bestraft wegen ähnlicher Delikte und militärischën Diebstahls, darunter eine Höchststrafe von 9 Monaten 14 Tagen Gefängnis. Nach Begehen einer neuen Achtungsverletzung Zweifel an seiner Zurechnungsfähigkeit. M. macht den Eindruck eines verstörten Menschen, wird von Vorgesetzten und Kameraden als übergeschnappt bezeichnet, will sich des Vorfalls angeblich nicht exinnern können. Kommt ins Lazarett. Der dortige Bericht: Psychisch: Vermag nicht die einfachsten Fragen $z \mathfrak{l}$ beantworten und die allerleichtesten Rechenaufgaben zu lösen. $(3 \times 3) 18,(1 \times 1) 3$. Weiss nicht, wann der Krieg erklärt ist, ist über Zeit nicht orientiert. Gibt an, leicht aufgeregt zu sein. Zu ihm kam jemand vorige Nacht, ihn zu wecken; er sollte aufstehen, Alarm blasen. Das war der Sanitätsgast. Sei danach aufgestanden, die ganze Nacht angezogen gesessen. Hat die Empfindung, dass alle anderen über ihn lachen. Grimassiert, faucht, puff, püff, weiss nichts davon. Gebückte Haltung, traurige, unbewegte Miene, wenig Bewegung des Körpers und der Glieder, stumpfer Ausdruck, Schädel nicht empfindlich. Starker Tremor der Hände. Wassermann negativ. In nächster Zeit keine Vexänderung des Zustandes. Schwingt in der Ecke den Taktstock. Halluziniert offenbar. Habe ein Orchester; es fehlten ihm nur noch einige Instrumente. An dem Ohr eines vorübergehenden Kameraden macht ex püff, püff, spuckt beinah, verzieht dabei keine Miene. Läuft 9 Uhr abends in den Garten im Hemd, gibt an; Grossfürst Nikolaus habe ihm sein Brot gestohlen. Liess sich ruhig hineinführen; das Brot lag auf dem Nachttisch. Im marineärztlichen Gutachten wird ausgesprochen: das Bild eines fortgeschrittenen geistigen Verfalls; Sinnestäuschung, Wahnideen, Manieren, Grimassieren, auffallende Stumpfheit im Gesichtsausdruck. Typisch für die Art der Geistesstörung die Häufigkeit der Delikte im nüchternen Zustande, ferner ihr durchweg negativer Charakter. Jahrelang bestehende Erkrankung infolgedessen wahrscheinlich (weit vorgeschrittene Verblödung). Der Negativismus pathognomonisch für Dementia praecox. Möglichkeit der Simulation auszuschliessen. Wird am 14. 12. 1915 nach der Kieler Universitätsklinik überführt. Pat. ist ruhig. Oertlich und zeitlich nicht orientiert. Sei jetzt Frühling. Auch sonst ganz verkehrte Antworten (Wieviel Erdteile?) Einen: Deutschland. Glaubt hier im Gesandtschaftsgebäude in Moskau zu sein, schimpft auf den Grossfürsten, nennt ihn Mordbuben. Fr habe ihn mit seinen Kameraden bei Brunsbiittel verhaftet, mitgebracht und werde hier den "Mordbuben von Serajewo" an den Pranger stellen. Dieser habe seine Heimat vernichtet, seiner Mutter Haus abgebrannt; sie müsse nun auf der Strasse liegen. Zeigt bei dieser Erzählung wenig Affekt. Kräftiger Knochenbau, guter Emährungszustand, vierschrötiges Gesicht mit starkem, hervor- 
tretendem Unterkiefer, niedrige Stirn, Ohrmuscheln abstehend, Ohrläppchen angewachsen. Am nächsten Tage noch ganz verkehrte Antworten; bezeichnet den draussen liegenden Schnee als Staub, luält vier Finger für zwei. Es macht allerdings den Eindruck, als ob er sich dumm stellt; eine Hemmung oder Trübung des Bewusstseins scheint nicht vorzuljegen. Am folgenden Tage nach Faradisieren völlig geordnet, rechnet auch schwierigere Aufgaben aus, weiss, wer Bismarck und Luther waren. Gibt die Hauptstädte richtig an. Unter Gerechtigkeit versteht er, wenn man jeden gleich, nach Verdienst behandeJt. - Er sei als Heizer bei der Marine gewesen und wollte sich von seinen Vorgesetzten bei seiner Arbeit nicht dareinreden lassen. Im Lazarett hätte er Stimmen gehört, jetzt nicht mehr. Auch keine Angstzustände mehr, fühle sich ganz frisch. In den nächsten Tagen zeigt er zur Arbeit sehr wenig Lust, beschäitigt sich ungern, schimpit oft über Essen und Behandlung, regt sich manchmal über Kleinigkeiten auf, vermag angeblich kein Unrecht zu sehen. Als Motiv scheint Langeweile vorzuliegen; widersetzt sich der Verlegung in eine andere Station. Mit der Zeit ruhiger, völlig geordnet. Als geheilt am ó. 2. 1916 entlassen.

M. ist von Haus aus ein ethisch minderwertiger und geistig stumpfer Mensch mit körperlichen Degenerationszeichen, der, wie viele minderwertige Individuen, unter der militärischen Disziplin versagt, während er im ZivilIeben sozial unauffällig ist. Es häufen sich nun mit der Länge des Dienstes Straftat auf Straftat, da ihm der Militärdienst nicht in den Kram passt, wie man aus seinen Aeusserungen in der Klinik schliessen darf. Die fortgesetzten Bestrafungen und Zusammenstösse mit den Vorgesetzten, wahrscheinlich auch die wenig zusagende Behandlung der ihn kaum achtenden Kameraden brachten ihn schliesslich aus dem seelischen Gleichgewicht, wobei wohl auch die Furcht vor den immer länger und strenger werdenden Strafen wesentlich mitsprach. Das Bild, das er im Lazarett zeigte, entspricht am ehesten einem Dämmerzustande unter dem Bilde des Puerilismus. Dieser Zustand war bei Ueberführung nach der Klinik wohl schon im Abklingen begriffen, die Symptome wurden von ihm absichtlich beibehalten Durch die faradische Behandlung wird er veranlasst, sein Gebahren aufzugeben; ist noch eine Zeitlang gereizt, wird aber schliesslich ruhiger, nachdem er den militärischen Druck schon längere Zeit nicht mehr gespürt hat. Seinen Angaben, dass er im Lazarett Stimmen gehört und Angstzustände gehabt hat, wird man Glauben schenken. Der ganze Habitus des Mannes spricht für eine allgemeine Minderwertigkeit, mehr auf ethischem, als auf intellektuellem Gebiete; besondere hysterische Antezedenzien sind nicht nachweisbar. Möglicherweise spricht hier ein Krankheitswunsch bis zu einem gewissen Grade von vornherein mit, um den weiteren eventuellen Bestrafungen zu entgehen. Auch hier hat man den Eindruck, dass die hysterische Umsetzung bei diesem minderwertigen Individuum eine individuelle Tendenz darstellt, die unter ungünstigen Umständę̣ als reaktives, psychi- 
sches Insuffizienzphänomen in die Erscheinung tritt. - Hier wieder ein Zusammentreffen verschiedener ätiologischer Faktoren: Der Druck der militärischen Disziplin auf ein von Haus aus ninderwertiges Subjekt, die vorangegangenen Bestrafungen und Reibereien, die Furcht vor weiteren strengeren Strafen, der Wunsch vom Militär loszukommen usw.

Fall 3. Kurz möchte ich noch auf einen Fall hinweisen, den Stern bereits in seiner Arbeit aufgeführt hat (Fall 15). Damals hatte der Kranke auf nicht nachweisbarem, psychopathischem Boden im Gefängnis wohl infolge Furreht vor disziplinarer Bestrafung und Aufregung über ein neues drohendes Strafverfahren eine hysterische Psychose durchgemacht (1911), beginnend mit einen Suicidversueh, im Anscbluss daran ein deliröses Stadium, ausgezeichnet durch die eintretende „Verkindlichung des gesamten Benehmens" (plumpe Bewegung, kindliche Sprechweise, kindliches Betasten, Ergreifen, Wegschleppen und nicht Wiederhergebenwollen aller Gegenstände); die nur kurze deliröse, puerilistische Phase wich dann mehr einer stuperösen Bewusstseinstrübung mit angedeutetem Vorbeireden. War vom 2. bis 9. 11. 1911 in der Klinik; hat dann im Gefängnis seine Strafe verbüsst. - Dieser Mann war im Jahre 1914 noch 2 mal in der Klinik. Entpuppte sich als ein sehr jähzorniger, zu tobsuichtigen Erregungszuständen neigender Mensch, der seine Ehefrau misshandelt. Auch war wieder eine Verhandlung wegen Diebstahl im Gange. Am 25. 8. 1914 von der Polizei eingeliefert, weil er Familie mit Dolch und Revolver bedroht und mit geladenem Tesching auf seine Frau eingeschlagen hatte. War stark eifersüchtig, soll bei jeder Kleinigkeit auf seine Frau eingeschlagen haben (diese neigt jedoch bei ihren Angaben zu Uebertreibungen). Da er tobte und sich zur Wehr setzte, wurde er von der Feuerwehr überwältigt und im Krankenwagen zur Klinik befördert. Zeigt zum zweitenmal hier eine Situationsverschiebung im Sinue einer Verkindlichung des ganzen Habitus: jammert, heult wie ein kleines Kind, schlägt die Hände zusammen, läuft mit einem Schuh im Arm hin und her, stellt sich läppiseh in eine Ecke. Auf alle Fragen unverständliches Murmeln, zappelt mit den Beinen. Nach 3 Tagen klar. - Ein psychopathischer Zug scheint demnach doch vorhanden zu sein; dafür spricht seine krankhafte Reizbarkeit und Gewalttätigkeit. Der rezidivierende Puerilismus, der im starken Kontrast zu dem sonst so gewalttätigen Menschen steht, lässt in Analogie zu den beiden frïheren Fällen vermuten, dass hier ebenfalls eine sonst nicht manifeste Tendenz vorliegt. Völlig ist jedoch die Ursache für den erneuten psychotischen Ausbruch nicht sicherzustellen: Zum Teil werden es eheliche Zwistigkeiten gewesen sein, zum Teil hat er noch manches auf dem Kerbholz; dann soll er aber nach Angaben der Frau einige Tage vorher abends durchs Fenster verschwunden und morgens erst wiedergekommen sein. Wo er gewesen, wusste die Frau nicht. Möglicherweise liegt hier vielleicht ein wiehtiger Faktor, von dem wir nichts Näheres mehr wissen.

Fall 4. K. F., etwa 28 Jahre alt. Aus gesunder Familie; als Kind Lungenentzündung und Masern. In der Schule schlecht gelernt. Von 3 Klassen nur 2 absolviert, wurde Maschinenschlosser. Als Geselle tätig bis 1913. Dann in H. ein Delikatessengeschäft betrieben bis Kriegsausbruch. Dann eingezogen. Im Zivil nicht bestraft. Während der aktiven Militärzeit mit 3 Wochen Arrest wegen mili- 
tärischem Diebstahls (Wein ans dem Offizierskasino), eigenmächtiger Entfernung 5 Tage Mittelarrest, Achtungsverletzung und Trunkenheit anch je 5 Tage. Machte sich jetzt der Urlaubsüberschreitung schuldig; hatte dabei aber anscheinend im guten Glauben gehandelt, weil er den durch die Post übermittelten Befehl nicht erhalten hat. Kam gleich in Arrest und die Angelegenheit vors Kriegsgericht. Wurde nach 3 Stunden wieder freigelassen. Musste aber als Strafe dauernd Dienst tun. Infolgedessen sehr erregt und vor Schwäche umgefallen: Schwindelanfälle, schlaflos, Erbrechen. Dabei stiegen ihm „Hlusionen“ in den Kopf, die Sache ,liess ihm keine Ruhe“. Nach 14 Tagen (10. 2. 1916) warde F. ins Lazarett gebracht. Gespannter Gesichtsausdruck, grosse stierende Augen, Klagen über Magenschmerzen, starker Geruch nach Azeton. Ausgesprochen negativistisch, stark deprimiert; am 16. 2. Gerichtsverhandlung, danach verwirrt. ,Infolge des ihm drohenden Strafverfahrens ist er so deprimiert, dass er keine Lust mehr am Leben hat und jede Nahrungsaufnahme verweigert." Am 28. 2. nach der Klinik überführt. Erzählt hier, wie er nachts eine Person gesehen, die ihn mit einem Messer habe stechen wollen. Nehrere Nächte habe diese Person mit einem langen Bart vor inm gestanden; wenn er deswegen Licht machte, war sie verschwunden. Keine körperlichen Degenerationszeichen. Reflexe und Sensibilität intakt. Isst nicht; Sondenfütterung. 29. 2. Sondenfütterung. Er werde morgen zum Tode verurteilt. Sprang nachts plötzlich aus dem Bett, schlug mit der Faust gegen Fenster und Türen und schrie, man solle ihn hinauslassen.

1. 3. Verlangt seine Kleider, damit er den Transport zur Türkei erreiche. 2. 3. Nachts plötzlich erregt, zitterte am ganzen Körper, wollte die Scheiben durchschlagen. Wollte nicht eingesperrt werden und nach Sibirien kommen. Ein Transport mit einem Unteroffizier und zwei Mann sei zur AbhoJung hier gewesen.

4. 3. Behauptet, das Essen sei vergiftet, isst das Brot unter der Decke. 7. 3. Aeussert noch Vergiftungsideen: Habe 2 Milliarden geerbt, deshalb wolle man ihn hier vergiften. 8. 3. Isst das Brot unter der Decke. Seine Hinrichtung sei angeordnet. 9. 3. Die 2 Milliarden, die er geerbt, habe er dem Roten Kreuz vermacht. Beim Kaiser habe er seine Erschiessung beantragt, da er nicht mehr weiterleben wolle. 10. 3. Mein Geschäft ist dahin, meine Gesundheit auch, ich will nicht mehr weiterleben. 13. 3. Verlangt Senf, um die schwarzen Ratten zu töten, die nachts an sein Bett kommen. 17. 3. Sehe nachts eine Gerichtsverhandlung, einen alten Kriegsrat, höre die Verhandlung, dass er seine Tat mit Willen begangen habe und dass er zu 6 Monaten bestraft werde. Schlangen, Mäuse, Schwaben, Käfer sähe er nachts im Wachen. Sie kriechen in Hals, Mund und Ohren hinein. Wenn die Sinne klar sind, versehwinden die Tiere. Sehe anch den Bureaufeldwebel nachts, der an seinem Unglïck schuld sei. 21. 3. Aeussert noch in der gleichen Weise Lebensüberdruss. Heute Nacht seinen Schwager gesehen, der ihm geraten habe, zu dem Kaiser zu gehen. Traumhaft benommenes, zeitweise gespanntes Wesen. 22. 3. Wieder eime Kriegsgerichtsverhandlung nachts mitgemacht. 23. 3. Etwas freier. Zeitweise zugänglich; unterhält sich, liest die Zeitung. 3. 4. Soll nachts zweimal im Schlaf gerufen haben: "Mein Feldwebel ist draussen." Hat noch die gleichen nächtlichen Erlebnisse. 9. 4. Noch mürrisch und verstimmt. Bezüglich der gerichtlichen Affäre für alle Vorschläge unzugänglich. Wie er auf den Gedanken komme, dass 
er 2 Milliarden geerbt habe, wisse er nicht. War 1910-13 in einem Goldminenwerk tätig; vielleicht sei er dadurch auf den Gedanken der Erbschaft gekommen. 20. 4. Sei immer lebhaft und lustig gewesen, keine Sorgen, Vater hat Geld. Sei krank geworden, weil er sich die Sache so zu Herzen nahm. Weiss angeblich nicht, dass er Sondenfütterung bekommen habe; vermag sich überhaupt nicht auf den Anfang zu besinnen, auch nicht auf die Erscheinung von Mäusen, Ratten usw. Nur dass er den Feldwebel gesehen habe, wisse er, glaube, dass dieser hier gewesen sei und ihn weiter hineinreissen wolle. Möglich, dass es eine Sinnestäuschung war. Die Gerichtsverhandlung sehe er nachts noch vor sich, debattiere dabei laut. In Kamerun sei er Lokomotivfïhrer gewesen, aber niemals in einem Goldbergwerk tätig. Wie er auf die Lüge gekommen sei, wisse er nicht. 25. 5. Wechselnd; oft mürrisch, verdrossen und unfreundlich. 12.6. Sei nicht verhandlungsfähig, wolle lieber in die Irrenanstalt (hofft auf diese Weise die Sache aus der Welt zu schaffen). 13. 6. Eines Besseren belehrt, erklärte sich für verhandlungsfähig. Am 16. 6. abgeholt. Weiteres über das Schicksal des Mannes war nicht zu erfahren.

Charakteristisch ist, dass wir hier die Situationsverschiebung nach beiden Richtungen hin finden. Er ist Besitzer von 2 Milliarden, andererseits wird über ihn zu Gericht gesessen. Die Situationsverschiebung beruht hier auf nächtlichen Halluzinationen, die er am Tage einfach reproduziert, deren Einfluss aber auf seine Stimmung und überhaupt den ganzen psychisehen Zustand unerkennbar ist. Der Inhalt der Halluzinationen und Träume entstamm. seinen Wünschen und Befürchtungen. Dabei ist in der ersten Zeit eine gewisse Benommenheit mit nachfolgender Amnesie vorhanden. Die Umgebung wird nicht verkannt, aber ebenfalls eine Zeitl9ng mit in die Situationsverschiebung einbezogen. Hier wird man dem Krankheitswansch eine Rolle zuerkennen müssen; das Bild ist nicht so einheitlich geschlossen wie in Fall 1. Er zeigte sich suggestiv beeinflussbar. Die Wahnideen und Sinnestäuschung wurden anscheinend später mit bewusster Absicht und Uebertreibung vorgebracht. Jedoch macht es den Eindruck, als ob F. in der Tat von seiner Unschuld überzeugt ist. Der Affekt, der durch die Angst vor einer zu Unrecht zu erfolgenden Freiheitsstrafe ausgelöst und durch sein gerade in Konkurs geratenes Geschäft verstärkt worden ist, kommt in erster Linie für den Ausbruch der Seelenstörung ursächlich in Betracht. Eine degenerative Anlage ist nicht nachweisbar, eine stärkere kriminelle Betätigung liegt ebenfalls nicht vor. Dass aber auch hier während des psychotischen Zustandes eine krankhafte Phantasiebetätigung vorlag, geht aus seiner Erzählung von seiner Beschäftigung im Goldbergwerk hervor, die er später selbst als falsch widerrief, ohne einen Grund für die damaligen unwahren Angaben zu wissen.

Der Stupor macht differenzialdiagnostisch die grössten Schwierigkeiten gegenüber der Katatonie; jedoch auch Zustände von traumhafter und deliröser Benommenheit können katatone Züge zeigen. ,,Das Fortwirken affektbetonter Vorstellungen im Stupor genügt allein nicht, um die Erkrankung 
als eine psychogene aufzufassen. Das gleiche gilt von solchen Aenderungen des Verhaltens, die einen gekünstelten Eindruck hervorrufen und von hysteriseh erscheinenden Krämpfen." Allerdings, meint Stern, wird bei katatonischen Stuporen durch die Versetzung in häusliche Verhältnisse keine Heilung, sondern nur ein Nachlassen und eine Aenderung bestimmter Krankheitsäusserungen erzielt, während bei Situationspsychosen die Beeinflussbarkeit des Krankheitsprozesses durch äussere Faktoren darmn bestehen sollen, dass die Wirkung schnell erfolgt und einen erheblichen Grad erreicht. Aber auch dieser Umstand trifft nach unseren Erfahrungen nicht durchgehend zu. Dass die sogenannten katatonen Symptome auch bei hysterischen Stuporen nicht selten sind, wurde bereits von vielen Autoren bestätigt: Negativismus Befehlsautomatie, Echopraxie, Echolalie, Manieren, Gimassieren, Stereotypien usw. kommen zur Beobachtung, selbst Stuporen, die sich über viele Nonate erstreckten, wurden beobachtet (Kutner); im allgeneinen sind sie jedoch kurzdauernd und erstrecken sich nur über Tage eventuell Wochen. Dabei kommen alle Intensitätsgrade vor, von leichter Hemmung, eventuell mit Mutismus, bis zur völligen Starre und Sperrung. Gegen Katatonie und für Situationspsychosen sprechen nach Stern neben Beeinflussbarkeit durch äussere Umstände und dem akuten Beginn mit tobsüchtiger Erregung oder zuweilen halluzinatorischer Verwirrtheit, theatralische oder affektierte Färbung des Zustandsbildes, Fehlen von Störungen des Allgemeinbefindens; für hysterischen Stupor im speziellen sprechen ausserdem das Erhaltenbleiben des Sinnes für Bequemlichkeit (Vermeidung unbequemer Lage), der charakteristische stupide oder kummervolle Gesichtsausdruck, eventuell das Festhalten affektbetonter Vorstelllungen der Erinnerungen, die sogar als Reminiszenzdelirien auftreten können. Fernerhin ist die tiefe Amnesie nach $\mathrm{Ab}$ lauf der akuten Erscheinungen bemerkenswert. Dazu komme der Gesamteindruck (Hey, Stern); das Verhalten der stupurösen Kranken habe nicht das automatisch Triebhafte wie das der Katatoniker. Doch meint Sterm schliesslich resigniert, wenn man auch in der Praxis aus der Gesamtsumme der Krankheitserscheinungen und der Verlaufsform in vielen Fällen wird bestimmte Schlüsse ziehen können, so gibt es doch kaum pathognomonische Symptome, vielleicht mit Ausnahme eines objektiv schwer zu schildernden, besonders theatralisch-affektierten Benebmens, das die Diagnose des Stupors erleichtern kann." Noch weiter gehen newerdings Raecke und Meyer. „Die Abtrennung degenerativer Gerstesstörungen von der Katatonie gelingt da am besten, wo uns ein klinisch gut charakterisiertes Bild entgegentritt, wie eben das einer gut ausgeprägten hysterischen Psyche. In allen zweifelhaften Fällen wird man abwarten müssen ... Gerade aus diesem Gesichtspunkt ist die Einführung der Situationspsychose durch Siemerling und Stern wertvoll, weil solehe Bezeichnung nichts präjudiziert. Es ist 
falsch, zu behaupten, dass die Abhängigkeit einer Geistesstörung in ihrem Verlaufe von der Situation allein ausschlaggebend sei für die spezielle Diagnose... Es kann sich um eine unmerklich chronisch entwickelte Geisteskrankheit handeln, deren manifeste Schübe durch die Situatıon verursacht werden. Wahrscheinlicher ist es freilich, dass nur ein transitoriseher Ausnahmezustand vorliegt, wie er am häufigsten bei Hysterikern ist ... Jedenfalls bedarf der Name Situationspsychose stets emes näher erläuternden Prädikats, soll er eine wirkliche Diagnose bedeuten. Wir haben zu unterscheiden: eine hysterische und katatonische Situationspsychose. Im Verlauf einer Dementia praecox können wie bei der Hysterie exquisit psychogen entstandene Symptomkomplexe auftreten, die allein durch die Situation geschaffen und erhalten zu sein scheinen und demgemäss mit derselben zunächst verschwinden. Da die differenzialdiagnostische Abgrenzung allein nach dem Verlauf somit lange Zeit auf Schwierigkeiten stossen kann, sollte man wieder mehr bestrebt sein, durch Vertiefung unserer Kenntnis von der Symptomatologie des Zustandsbildes weiterzukommen. Die zu allgemein gehaltene Bezeichnung, Degenerationspsychose für psychogene Hafterkrankung ist unzweckmässig, weil sie den möglichen Versehiedenheiten der klinischen Bilder ungenügend Rechnung trägt." Meyer schliesst sich den Ausführungen Raecke's an: „Die Differenzialdiagnose der psychogenen Reaktion des Psychopathen gegenüber ähnlichen Bildern der Dementia praecox aus dem Nachweis eines stark affektbetonten Erlebnisses einer Situation ist nicht angängig; denn im gewöhnlichen Verlauf sonst durehaus verschiedener Krankheitsarten können sich längere oder kürzere Zustandsbilder einschieben, die in ihrer Entstehung an eine Situation, ein mit starkem Affekt einhergehendes Erlebnıs, gebunden sind. In Friedenszeiten seien diese Schwierigkeiten nur auf bestimmte Gebiete, vor allem die sogenannten Haftpsychosen beschränkt. Im Kriege spielen aber schon bei der Zivilbevölkerung psychische Momente vielfach mit; ganz unbegrenzt sind aber diese bei den Kriegsteilnehmern." „Und nun kommen unausgesetzt Fälle mit stuporösen und verwandten Zuständen, Bilder mit Verworlenheit, Perseveration, monotone Reden und Bewegungen

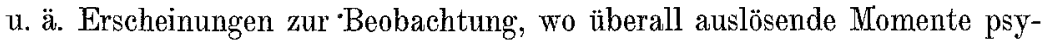
chischer Art sehr möglich oder direkt nachweisbar sind, wie soll uns da das stark affektbetonte Erlebnis, die Situation zur Diagnose verhelfen; nur das klinische Bild vermag uns Aufschluss über die Grundkrankheit zu geben, wenn wir auch vielleicht von serologischen Untersuchungen (Abderhalden) und solchen des Blutes und elektrischer Art Unterstützung erwarten können."

Man wird den Ausführungen Meyer's und Raecke's insoweit zustimmen können, als psychogene Symptomkomplexe, die einer bestimmten Situation ihre Entstehung verdanken und eventuell mit ihr verschwinden, im Verlauf anderer Psychosen vorkommen. Hier ist aber der Begriff der Situation 
im engsten Sinne gefasst, als affektbetontes Erlebnis. Wir fassen aber ihn im Sinne des reaktiven Zustandes überhaupt, den das Individuum durchlebt, und da ist er nicht nur von dem affektiven Erlebnis abhängig, sondern noch von verschiedenen anderen Faktoren. Wir könmen uns daher den Ansichten Raecke's über den Sinn und die Bezeichnung Situationspsychosen nicht anschliessen. Würcle doch gerade dadurch dasjenige Moment verwischt, dass wir als charakteristisch hervorhoben; dass es Psychosen transitorischen Charakters gibt, die sowohl in ihrer Entstehung und ihrem Verlauf sozusagen von einer zufälligen Kombination von Umständen abhängen, in ihrer Symptomatik nach dieser jeweiligen Kombination differieren und - was das wichtigste ist - nur durch diese ermöglicht werden, also nicht im Bereich der vorwiegend auf einer degenerativen Anlage beruhenden endogen funktionellen Psychose zuzurechnen, ebensowenig aber durch die zu allgemein gehaltene Bezeichuung der psychogenen Reaktion ausreichend gekennzeichnet sind.

Da diese Kombination ätiologischer Faktoren am besten durch den erweiterten Begriff der Situation gekennzeichnet ist, wird man die Bezeichnung der Situationspsychosen eben auf diese transitorische Störung beschränken und nicht auf die Phasen eines Krankheitsprozesses anwenden. Gewiss kann im Beginn einer Dementia praecox eine psychogene Reaktion so stark hervortreten, dass ein diagnostiseher Irrtum sehr wohl möglich ist. Diese Schwierigkeit gilt aber für Diagnostik von Zustandsbildern überhaupt. Eine Paralyse kann im Beginn das Zustandsbild einer reinen Depression bieten usw. Es ist auch noch gar nicht gewiss, ob wir jemals bei Verfeinerung und Vertiefung unserer Kenntnis der Symptomkomplexe imstande sein werden, aus Zustandsbildern allein a uch in schwierigen Fällen die Diagnose zu stellen. Aber selbst die besten Kenntnisse nützen uns wenig in den Fällen, in denen wir sie nicht anwenden können, weil eine genügende Exploration nicht möglich ist. Hinzu kommt dabei noch für manche Fälle die ungeklärte Frage, wieweit sich auf dem Boden einer degenerativen Anlage, speziell Hysterie, die Dementia praecox entwickelt. Bei Bejahung dieser Frage könnte es sehr wohl - wie aus einem Falle Raecke's - möglich sein, dass die später ausbrechende Dementia praecox in keinem direkten Zusammenhang mit den vorausgegangenen psychogenen Reaktionen steht. Bei Verneinung dieser Frage bleibt die Möglichkeit bestehen, dass die Dementía praeeox als fortschreitender Krankheitsprozess sich sozusagen als etwas Neues der Individualität aufpfropft, ganz unabhängig von der Vergangenheit und dem bisherigen Schicksal des Individuums. Die diagnostischen Schwierigkeiten werden allerdings dadureh nicht beseitigt. Wenn auch die Katatonie auf psychopathischem Boden erwachsen kann, so bieten anamnestische Angaben über eine eventuell degenerative Anlage (Homburger), sowie die Berück- 
sichtigung der gesamten Persönlichkeit (Raecke) keine ausreichende Sicherheit. Diese Fälle sind aber unverhältnismässig selten; eine volle Berücksichtigung der Persönlichkeit findet ja auch erst da statt, wo man den weiteren Lebensgang des Individuums verfolgen kann. Gelingt zudem eine ausreichende Analyse des Zustandes unter Berücksichtigung der von uns genannten ätiologischen Faktoren und Beachtung des weiteren Verlaufs der Krankheit, so werden die Fälle noch seltener, die diagnostische Irrtümer zu erzeugen geeignet sind. Wo man die individuelle Einstellung, die hier die Form der Situationsverschiebung hat und meist mehr oder weniger ausgesprochen ist, genügend aufzuklären vermag, wird man auch bei Bestehen verschiedenster katatoner Symptome zu einer Entscheidung kommen. Neben der Situationsverschiebung mit all ihrem affektiven und theatralischen Beiwerk - die eben mehr ist als eine blosse Affektfixation und qualitativ etwas anderes darstellt als einen Komplex bei der Dementia praecox - ist noch charakteristisch der damit in Zusammenhang stehende Gesamteindruck, der das AutomatischTriebhafte vermissen lässt, und die zurückbleibende Amnesie. Gelingt es nicht bei einem länger dauernden Stupor - sei es während dieser Zeit oder nachher - einen genügenden Einblick in das Seelenleben zu gewinnen und hat man keine sonstigen Anhaltspunkte für eine bestehende Hysterie oder einen degenerativen Charakter, so wird man in erster Linie an Katatonie denken. Man muss dann eben das weitere Schicksal des Patienten abwarten, um die Bedeutung der durchgemachten Psychose würdigen zu können. Dieser diagnostisch-prognostisehe Mangel kommt bei anderen wohldefinierten Krankheiten auch vor: bei einer akuten Paranoia, Depression und Manie ist die Prognosenstellung sehr oft unsicher, zuweilen sogar die Diagnose falsch.

Ganz allgemein wird man also annehmen können, dass ausserdem eine hysterische Situationsspyhcose, wenn sie sich bei einem nicht hysterischen Individuum entwickelt und dabei in der Symptomatik ein einheitliches Gepräge bewahrt, z. B. als Stupor, Dämmerzustand oder Delirium, ohne weiteres nicht unter dem Einfluss eines Krankheitswunsches zu stehen braucht. Das Hinzutreten anderer Symptome und vor allem ein Wechsel im Symptombild spricht mehr für den Einfluss eines Krankheitswunsches. Auch die Oberflächlichkeit und Beeinflussbarkeit der Symptome ist hier viel auffälliger. Bei typischen Hysterikern kann sich schliesslich die Krankheit in eine „Kette von Einzelphasen“ (Stern) auflösen, in denen Erregungszustände, Stupor, läppisches Wesen, Ganserzustand usw. abwechseln. Hier werden auch die Ansichten zu Recht bestehen, wonach sich diese Bilder bei dem betreffenden Individuum aus kleineren Zufällen (Zänkereien, Zornausbrüche, Nahrungsverweigerung), die sie wohl noch hätten unterdrücken können, allmählich entwickelt haben, bis die Handlungen einen mehr automatisehen Charakter erhalten und die Kranken sich nicht mehr Halt gebieten 
können (Janet). Hier hätten wir bereits die Uebergänge zu den gewöhnlichen hysterischen Psychosen.

Die Verhältnisse komplizieren sich nun aber dadurch, dass auch hier nicht nur Hysterische diese Zweckpsychosen (Raimann) zeigen, sondern auch andere degenerierte Individuen, namentlich Schwachsinnige und sonstige erblich Belastete oder durch Alkohol usw. Geschädigte. Die Jan et'sche Ansicht wird hier nicht überall Geltung haben; die pathologische Wirkung des Wunsches ist daher hier noch undurchsichtiger. Möge auch die Autosuggestion mitspielen, namentlich wenn stürmische Affekte die Fixation pathologischer Zustände wie Schreck, Verwirrung, Hemmung zu fördern imstande sind, so dass schliesslich ein Stupor oder Verwirrtheitszustand resultiert. Jung namentlich hat zu zeigen versucht, wie aus abnormen Affektnachwirkungen und dadurch bedingten hysterischen Automatismen sich viele Simulationsfälle erklären. Abgesehen davon, worauf Raecke und Stern aufmerksam machen, dass auch bei krankhaften Störungen noch normale Gedankengänge auf das Handeln Einfluss gewinnen können und dass gerade der Wunsch, als geisteskrank zu gelten, bei gehemmten oder schwer besinnlichen Personen viel leichter zur Wirkung kommt, was namentlich bei Vorbeireden eine Rolle spielt, macht sich bei „Schwachsinnigen die geistige Inferiorität besonders bemerkbar und zwar gerade bei bestimmten Situationen, welche an die Anpassungsfähigkeit grössere Ansprüche stellen und unter Umständen eine weitere Schädigung setzen, wie bei Haft und Militär. Das sind auch die äusseren Umstände, unter deren Einfluss eine Geisteskrankheit bei den Schwachsinnigen leicht ausbricht. Die Hauptschwierigkeit wird hier oft die Erkennung einer möglichen Simulation sein bei Störungen, die infolge ihres Wechsels oft den Eindruck des Gekünstelten haben und zwar gerade bei Kriminellen und dauernd in Konflikt mit den Gesetzen stehenden Individuen ... Ein Geisteszustand, der ein so merkwürdiges Gemisch von Geisteskrankheit, Geistesgesundheit und dazu oft genug noch von Simulation der ersteren darstellt. Hier sei oft nur ein Wahrscheinlichkeitsschluss möglich" (Siemerling). Neben der Heredität müsse man bei den Gewohnheitsverbrechern noch die nervösen Schädigungen die erworbene neuro- und psychopathische Disposition berücksichtigen, ausserdem sind Alkoholmissbrauch, die Unterernährung, unstetes Leben und eventuell Kopfverletzung bei den Gewohnheitsverbrechern als ätiologische Faktoren anzuführen. Auch Leppmann meint, dass sich bei Erregungszuständen der Schwachsinnigen und auch phantastisch Minderwertigen und Hysterischen unter dem Drucke der Haft atypische Geisteskrankheiten entwickeln können (wahnhafte Einfälle und Widersprüche; dabei einsichtslos, blindes Wüten). Ja Leppmann spricht sogar von einem Grenzgebiet zwischen Vortäuschungen und wirklichen Geistesstörungen. Er macht die Annahme, ,dass bei erblich 
Belasteten, labilen und degenerierten Personen starke seelische Erregungen einen Zustand der Fassungslosigkeit hervorrufen, in welchem sie ihre Lage als unerträglich empfinden, ohne rechte Ueberlegung ziellos wirre Reden führen und unverständliche Handlungen begehen, für die sie möglicherweise nachher eine getrübte Erinnerung haben." - Wahrscheinlich gäbe es einen allmählichen Uebergang zu den Ganserzuständen.

Die Simulation wird durch die krankhaften Züge der Hysterie erleichtert; diese Erleichterung kann sogar soweit gehen, dass diese Automatismen oder wie wir sonst uns theoretisch die hysterischen Mechanismen vorstellen wollen, vorübergehend das Krankheitsbild beherrschen oder, anders ausgedrückt, dass der Schauspieler vorübergehend imstande ist, sich mit seiner Rolle zu indentifizieren. Das mag die Differenzierungen erschweren; aber die Beobachtung des ganzen Verlaufs zeigt denn doch, wie sehr das gesamte Krankheitsbild von der bewussten Willkür regiert wird als Folge einer beabsichtigten und durchgeführten Reaktion: es kann mit einem Schlage bei passender Gelegenheit schwinden. Ein gewöhnlicher hysterischer Dämmerzustand oder hysterisches Delirium - mag es auch ein theatraliseh-dramatisches Gepräge tragen - macht auf den Beobachter nicht so den Eindruck des Willkürlichen, wie er bei den durch Simulation regierten Fällen sich einzustellen pflegt, es schimmert doch immer eine stärkere Krankhaftigkeit der Reaktion durch; sie pflegt auch mehr allmählich abzuklingen. Sodann ist der Krankheitswille der Hysterischen bekanntlich auch nicht identisch mit Simulationsabsichten. Dem Hysterischen mag das Kranksein unter gewissen Umständen ein Bedürfnis sein; seine seelische Unzulänglichkeit mag auf diesem Wege das durch das affektbetonte Erlebnis umgeworfene Gleichgewicht sozusagen instinktiv wiederherzustellen suchen; die Flucht in die Krankheit wäre dann aber immer noch eine krankhafte Reaktion. Anders beim Simulanten, der sich sozusagen die Art der zu produzierenden Störung, wenn auch nicht immer in klarer Weise auswählt oder irgendeiner unklaren Eingebung stattgibt, um sie dann je nach den Mitteln seiner Eigenart und krankhaften Züge durchzuführen. Wie vereinzelte, deutlich simulierte Symptome bei einem Hysterischen nichts für die Annahme einer Simulation beweisen, so dürfen umgekehrt vereinzelte hysterische Symptome und sogar rasch vorübergehende hysterische Bewusstseinsstörungen noch nicht gegen die Annahme einer mit Simulation einhergehenden Reaktion sprechen. Uebergänge sind natürlich möglich und machen die Entscheidung schwierig. Auch unter Berücksichtigung der sonstigen persönlichen pathologischen Eigentümlichkeiten dürfen wir in solchen Fällen jedoch nicht vergessen, dass der Psychopath zugleich Simulant ist.

Selbst wenn nach Jung eine abnorme Affektwirkung das unterstützende Anfangsmoment bildet (, sie verfallen in einen Zustand von. Stupidität, in 
welchem ... sich bewusste Uebertreibung, halbbewusste Schauspielerei und hysterische Automatismen zu einem unergründlichen Gemenge vereinigen können, ähnlich dem Bilde einer traumatisehen Neurose, wo Simuliertes und Hysterisches untrennbar zusammenhängen"). Die Kombination von Simulation und Hysterie ist mannigfaltig, die Simulation pflegt um so stärker hervorzutreten, je länger der Verlauf dauert, teils, weil die bisherigen krankhaften Symptome willkürlich festgehalten, teils, weil ähnliche oder andersartige neu produziert werden. Es können sich sogar, wie Birnbaum gezeigt hat, den akuten Reaktionen, wie z. B. Dämmerzuständen, derartige Bilder anschliessen, die sich über längere Zeit erstrecken und einen schwankenden 'Verlauf nehmen. Gerade die Bewrusstseinstrübung mit eventuellen Ilusionen und Halluzinationen scheint einen günstigen Boden für Einfälle und Phantasieerfindung abzugeben, die einer weiteren Abkehr von der eigentlichen Situation günstig sind. Vereinzeltes Auftreten krankhafter Ideen im Sinne der Situationsverschiebung wird keine wesentliche Modifikation des Krankheitsbildes darstellen. Die Ideen können aber stärker hervortreten, nicht nur im Stupor oder Dämmerzustand, sondern auch über ihn hinaus. In demselben Masse kann sich dabei die zugrunde liegende Einstellung des Individuums ändem: nicht mehr eine blosse Situationsverschiebung und -verkennung, sondern ein Umdeuten der gegenwärtigen Lage. Die objektive Sachlage bleibt erhalten, es wird ihr aber eine andere Ursache und Erklärung untergeschoben, die meistens das eigene Verschulden auszuschalten sucht. „Eine scharfe Trennung nach dem Bewusstseinszustande ist nicht möglich, vielmehr existieren fliessende Uebergänge zu den hysterischen Dämmerzuständen, man kann in einzelnen Fällen degenerativer Wahnbildung von einer Art protrahierten Dämmerzustandes sprechen" (Birnbaum). Es kann aber auch die Bewusstseinstrübung fehlen und das Individuum plötzlich mit Wahnideen hervortreten.

In diesen nur uneigentlich zu nennenden paranoiden Zuständen haben wir demnach kaum mehr als Erfindungen, Einfälle und bewusste Uebertreibungen zu sehen - mögen es nun phantastische Grössen- oder Beeinträchtigungsideen sein - , die den Kranken ein willkommenes Mittel in die Hand geben, sich über die objektive Lage hinwegzusetzen: eine innige Verbindung von Hysterie und Simulation. Sie macht aueh meistens den Eindruck, dass es sich um bewusst ausgebaute, wenn auch nicht immer bewusst entstandene Mittel zu einem bewussten Zweck handelt. Daraus erklärt sich ihre genügend bekannte Eigenart, die sie von den eigentlichen paranoiden Zuständen trennt. Wenn nun auch eine gewisse Bewusstseinstrübung oder Autosuggestibilität und krankhafte Phantasie und Lügenhaftigkeit das Individuum zeitweilig selbst an die vorgebrachten Ideen glauben lassen, so bleiben sie doch immer Mittel zum Zweck, über die der Situation entsprechend das 
Individuum verfügt. Treten sie dann in Aktion, so stützen sie die vom Șubjekt umgedeutete Situation in dem Masse, dass sie selbst der Realität dieser untergeschobenen Situation teilhaftig werden können. Die Bedeutung dieser Ideen wird so aus der Reaktionsanomalie und der durch sie geschaffenen Situation verständlich. Birnbaum nennt diese Gebilde wahnhafte Einnbildungen, führt sie aber auf die erhöhte Labilität zurück, die ein schnelles Uebergehen vom psychischen Grundzustand in einen eigentlichen Krankheitszustand ermöglicht. - Bei echten Wahnideen steht das Individuum. unter der Herrschaft der krankhaften Vorstellungen, denen es sich nicht entziehen kann; hier lässt es sich höchstens von seinen Ideen beeinflussen, ohne die Herrschaft über sie zu verlieren. Das Paranoische bleibt auf das Rollenspiel beschränkt, das das Individuum auf eine gewisse Zeitdauer übernommen hat, ohne sein Ich damit völlig zu identifizieren. Wenn man-bei manchen Vorstellungen, die vorgebracht werden, nach Birnbaum den Eindruck hat, dass sie nur die Lust am Fabulieren, der Freude am eigenen Phantasiespiel entsprungen sind, dass auf diese Weise die eigentlíche Wahnfabel fast unterdrückt wird, dass diese Ausmalungen und Ausschmückungen gewissermassen um ihrer selbst willen da sind, so wird man dem insofern zustimmen können, als man in diesen ebenso wie in den Konfabulationen indifferenten Inhaltes (die z. T. auf Erinnerungsfälschungen beruhen und ebenfalls oft keine Beziehung zur angeblichen Wahnfabel haben) nur die Tendenz zu erblicken hat, sich der objektiven Lage durch alle Mittel zu entziehen; gleichgültig ob dadurch Widersprüche usw. in Erscheinung treten. So entstehen sinnlose, durch den Hass diktierte Anschuldigungen gegen die Träger - der Rechtsprechung und des Rechtsvollzuges. Aeusserungen werden produziert, die umgekehrt den innersten Wünschen entspringen: habe sein Strafe zu Ende verbüsst bzw. sei begnadigt worden, man müsste ihn jetzt frei lassen. Es wird sozusagen das ganze Seelenleben unter eine bestimmte Determination oder Zielvorstellung gesetzt, die die Umdeutung der objektiven Wirklichkeit bezweckt. Diese Zielvorstellung beherrseht das Bewusstsein, auch wenn sie nicht immer klar gedacht wird. Von „Umdeutung k" können wir deshalb sprechen, weil die wirkliche Lage nicht einfach ignoriert zu werden pflegt - deren Wirksamkeit vermag sich der Kranke auf die Dauer doch nicht zu entziehen (das unterscheidet diese Gebilde von den akuten Zuständen mit vereinzelten Wahnideen), sondern dass er ihr einen anderen Sinn unterzulegen sucht, dass er überhaupt unschuldig sei oder dass er seine Strafe schon verbüsst habe, dass man ihn um seiner hohen Abkunft willen derart verfolge oder dass man seine Enthüllung auf diese Weise zu unterdrücken suche usw. Die gesamte Persönlichkeit mit all ihren Eigenschaften stellt sich so in den Dienst dieser Tendenz. Die Labilität des Persönlichkeitsbewusstseins, die ,darin besteht, die Erinnerungsreihe des wirklichen Lebens gegenüber 
Phantasievorstellungen, wie sie dem Kinde in seinem unreifen Bewusstsein eigen sind, unterbewusst werden zu lassen", wird man übereinstimmend mit Bonhöffer als Grundlage für diese Umdeutung mit heranziehen können. Allerdings wendet Bonhöffer diese Erklärung nur auf die Wahmideen selbst, also die sekundären Merkmale an, während es doch wahrscheinlich ist, dass diese von ihm als allgemeines Degenerationssymptom hingestellte Kennzeichen tiefer als allgemeine Labilität in die seelischen Schichteu hineinreicht und das gesamte reaktive Verhalten von vornherein bestimmt und die Reaktionsanomalie bilden hilft. So deutet es auch Birnbaum, wenn er mir auch darin zu weit zu gehen scheint. Wie in den früheren Fällen, so wird auch hier dieses Moment nicht der einzige und auch nicht immer vorhandene Faktor sein. Neben der Qualität der äusseren Reize werden auch andere seelische Faktoren mit im Spiele sein. Von äusseren Reizen werden diejenigen eine beträchtliche Rolle spielen, die einer illusionären und halluzinatorischen Verarbeitung günstig sind. Das Verhalten der Umgebung kann geradezu ausschlaggebend wirken, wie die Heilung nach Ueberführung aus einer Strafanstalt in die andere bzw. Irrenanstalt beweist; solche Kranke saugen sozusagen beständig neue Nahrung für ihr pathologisches Verhalten aus einer sie unzweckmässig behandelnden Umgebung. Sie sind vielleicht mangels endogener Faktoren auf ständige äussere Beeinflussung angewiesen, um sich in ihrer Situation halten zu können. - Frühere Lebensschicksale, wenu sie als unverschuldetes Unglück erscheinen, lassen das Subjekt in seinen eigenen Augen um so eher als gekränkte und verfolgte Unschuld erscheinen. Oder Erinnerungen an frühere Erlebnisse, Wünsche und Hoffnungen bringen die Kranken auf Einfälle, die bei starker Autosuggestion vorübergehend überwertigen Vorstellungen sich nähern können. Auf die autosuggestive Realisierung lustvoller Wünsche und die ebenso bedingte Unterdrückung unlustvoller Erlebnisse, wie der Straftaten usw., hat Birnbaum aufmerksam gemacht. Ein weiterer Faktor, auf den mamentlich Wilmanns hingewiesen hat, ist, dass die von ihm sogenannten epileptoid Entarteten (aber auch andere) unter den erzwungenen Verhältnissen der Straf- und Irrenanstalten, ebenso beim Militär ihren psychischen Habitus sozusagen ändern. Es treten krankhafte Zïge, wie Verstimmung, Querulieren usw. und asoziale Tendenzen auf, die die Kranken im freien Reden weniger oder gar nicht zeigen. Dieser Punkt wurde bereits in der Einleitung von uns erörtert. Wie mannigfach nun im einzelnen die psychologisehe Genese des Zustandsbildes ist, wie stark es von der Eigenart der jeweiligen Persönlichkeit abhängig ist, es bleibt im Grunde nur der Ausfluss einer für alle Individuen typischen Reaktionsanomalie, die durch das Bestreben hervorgerufen wird, sich einer anhaltenden unlustbetonten Situation irgendwie zu entziehen. Aus der gemeinsamen Grundlage heraus erklärt es sich, warum allen diesen Zustandsbildern charak- 
teristische Merkmale gemeinsam sind, die sie von eigentlichen psychotischen Prozessen der Dementia praceox und Paranoia unterscheiden; namentlich Bonhöffer und Birnbaum haben darauf hingewiesen: die in mehr oder weniger hohem Grade vorhandene Oberflächlichkeit und Beeinflussbarkeit sowohl der einzelnen Symptome wie des Zustandsbildes, das Episodische der ganzen Krankheit und eventuell schwankendes Rezidivieren unter ähnlichen Umständen, die nachherige völlige oder partielle Krankheitseinsicht je nach dem geistigen Niveau.

Hierbei ist nun noch gegenüber Birnbaum zu betonen, dass die Simulation nicht, wie er meint, von völlig untergeordneter Bedeutung ist. Nach ihm liegt wohl in diesen Fällen ursprünglich die Absicht der Simulation vor, die psychotische Folgeerscheinung entwickelt sich aber sozusagen automatisch, ohne bewussten Willen als Ausfluss der Labilität und Autosuggestibilität. Das Vorliegen der Simulation erscheint doch mehr als Anzeichen einer veränderten Stellungnahme des Kranken selbst, die auch im psychotischen Zustand zum Ausdruck kommt: Ausreden, Lügen, aus der Rolle fallen, wobei unter Umständen jede Veränderung in der Umgebung das Individuum zur Aenderung seines Verhaltens veranlasst, sofern er glaubt, dadurch seinem Zweck am besten zu dienen; namentlich das Hin- und Herpendeln zwischen wahnhafter Verkennung und sachlicher Auffassung, je nachdem es gerade das Interesse erheischt, müssen als deutliche Symptome einer mitspielenden Simulation gelten. Diese pseudoparanoiden Situationspsychosen sind also gekennzeichnet durch das Umdeuten der objektiven Lage; möge dieses Umdeuten sich nur in der Annahme einer ungerechten Behandlung oder Verurteilung äussern oder sich bis zum Grössenoder Erfinderwahn steigern. Wir haben diese Zustände, die Birnbaum uns unter dem Titel: Wahnbildung und wahnhafte Einbildung bei Degenerierten beschrieben hat (wenigstens ein Teil seiner Fälle gehört hierher), in Beziehung zu den hysterischen Situationspsychosen gebracht, weil ihnen eine gewisse Verwandtschaft zukommt; wenn auch der hysterisehe Grundcharakter nicht überall zu konstatieren ist, so findet man doch oft Zeichen einer verwandten krankhaften Anlage. Angesichts der dominierenden Rolle, die hier die Simulation spielt und zu unechten Wahngebilden führt, erscheint es berechtigt, vom pseudoparanoiden Situationspsychosen zu sprechen. Zu ihnen gehören die von Birnbaum als wahnhafte Einbildung beschriebenen Fälle; ähnliche schildert Bonhöffer in seiner dritten Gruppe der Degenerationspsychosen.

Fall 5. B. K., geboren 1883 , ledig, evangelisch, ohne Beruf, gute Schulbildung, höhere Bürgerschule, bis zum 16. Lebensjahre im Elternhause, von der Mutter verwöhnt. Arbeitet nicht, zeitweise Kellner. Mit 19 Jahren wegen Sittlichkeitsverbrechen bestraft. Im ganzen 6 mal vorbestraft wegen Sittlichkeitsver- 
brechen und mehrerer Diebstähle, zuletzt mit Zuchthaus 2 Jabr 4 Monate. Schon 1905 ärztlicherseits als hysteriseh bezeichnet, 1907 lautet der ärztliche Befund: Würge- und Bindehautreflex fehlen; Herabsetzung der Schmerzempfindung am Rumpfe und an den Armen; am Oberarm lässt er sich die Nadel quer durch eine Hautfalte stechen, ohne Schmerzäusserung. Führung in den Strafanstalten schlecht. Weihnachten 1913 deprimiert. Januar 1914, zu Kaisers Geburtstag, plötzlich in der Kirche gerufen: "Gott beschütze den Kaiser und König." Stand auf, wollte mit einer Hand taktieren. Nächsten Tag fortwährend eine Choralstrophe gesungen. Isoliert, zieht sich nackt aus. In nächsten Tagen behauptet er, sein Vater sei in seiner Zelle, der Arzt sehe ihn nicht, weil er keinen Glauben habe; singt wieder die Choralstrophe. Nach der Irrenabteilung des Strafgefängnisses M. verlegt: nur mangelhaft orientiert, unruhig rastlos, aggressiv, uriniert zum Fenster hinaus. Stimmung wechselud, sinnlos heiter, tobsüchtig erregt oder auch - allerdings seltener - traurig und weinerlich. Gedankenablauf beschleunigt, gelegentlich durch Depression gehemmt. Stört durch Trommeln, Pfeifen und Singen. Er könne im Dunkeln so gut sehen wie im Hellen: „Ich kann alles seben. Der Kopf geht fortwâhrond hin und her, ich bin die lebendige Sprechmaschine, das ist gar nicht mehr menschlich. Das Schaukeln kommt vom lieben Gott, ich sollte Kaiser Wilhelm werden, das habe ich aber nicht beachtet. Ich hörte die Stimme Gottes, welche sagte, du sollst Kaiser Wilhelm werden, du sollst für Kaiser Wilhelm regieren, da musst du aber erst knien und beten. lch bin jetzt selost Jesus und werde die ganze Welt regieren, die ganze Welt gehört mir, ihr habt mir alle zu gehorchen oder ich mache euch alle kaput." Wegen manisch depressiven Irreseins September 1914 nach der Kieler Klinik. Macht klare und geordnete Angaben. Sei unschuldig verurteilt, in der Haft dauernd schikaniert rom Personal. In Einzelhaft von den Aufsehern in der gemeinsten Weise gepeinigt. Sei sehr aufgeregt gewesen. In der Kirche zu Kaisers Geburtstag von einer göttlichen Macht plötzlich emporgerissen worden. Diese Macht hatte ihn völlig in der Gewalt. In seiner Zelle vor Freude Choräle gesungen. Gott habe sich ihm offenbart, weil er unschuldig leide. Er gebe ihm Gedanken ein, die mit den seinigen nicht übereinstimmten. Eine Nacht habe er mit Gott im Schlaf gerungen, dabei am Himmel Morgenröte. Sich in der Zelle nackt ausgezogen, weil göttliche Macht dies ihm eingab. Nähere Angaben über Angehörige kann er nicht machen; habe sich um sie nicht gekünmert, weil das Gefühl gehabt, als ob er nicht hineingehöre. Wollte Güterverwalter bei dem Grafen L. werden, mit dem er von Kind an befreundet sei, und der auch Schulgeld für ihn bezahlt habe. Fin andermal erklärt er wieder, Hoteldirektor in Bonn werden zu wollen. Im selben Monat erklärt er schriftlich, daß er seit 4 Monaten durch Gnadenakt des Kaisers kein Gefangener mehr sei. Macht öfters geheimnisvolle Angaben über seine Beziehungen zu dem Grafen L., ohne sich auf-nähere Einzelheiten einzulassen. Benehmen geordnet, Stimmung meist heiter. Im Oktober gebessert nach Irrenanstalt Neustadt überführt. Sei nicht krank, unschuldig verurteilt. Gespreiztes Wesen, Selbstüberschätzung, gewählte Sprache, renommiert fortgesetzt mit seinen vornehmen Beziehungen und was für ein guter Mensch er sei. In den Strafanstalten sei er miserabel behandelt worden, habe in seiner Verzweiflung lauter mit seinem Gott geredet als es üblich sei. Das übrige leugnet er. 
Hier keinerlei Anzeichen von Sinnestäusehung, beschäftigt sich. Seine Beschuldigung gegen das Gefängnispersonal hält er aufrecht. Gibt zu, dass er frïher Erscheinungen in einer wohl nicht gewöhnlicheu Anfregung gehabt habe, jetzt nicht mehr. Das Renommistische tritt immer wieder hervor, hält sich für besser als die andern. Sonst keine Wahnideen. Februar 1915 von der Haftpsychose als geheilt entlassen.

Fin anamnestisch durch hysterische Stigmata ausgezeichneter Gewohnheitsverbrecher fühlt sich in der Strafanstalt miserabel behandelt, er soll sich auch frech und faul benommen haben, Nach leichten Vorboten bricht plötzlich an Kaisers Geburtstag ein verwirrter Zustand aus mit sinnlosen Grössenideen, eine vorwiegend aufs religiöse Gebiet sich erstreckende Situationsverschiebung. Es ist immerhin denkbar und nicht unwahrscheinlich, dass die Geburtstagsfeier als solche zum auslösenden affektiven Moment wurde. Charakteristisch dabei ist der Wunsch nach möglichster Erhöhung der eigenen Persönlichkeit unter Betonung seiner Unschuld. Gott habe sich offenbart, weil er unschuldig leide, so begründet er dies auch noch später. Stellt sich als Kaiser Wilhelm und den Heiland hin, dem alle gehorehen müssten. Nach Abklingen der akuten Störung zeigt sich seine Renommiersucht und Selbstüberschätzung in allerhand Plänen und Einfällen. Beschränkt sich dabei aber nur auf Andeutung, abgesehen von der vermeintlichen Begnadigung. Zusammenhängende Wahngedanken werden nicht produziert. Er begnügt sich damit, als die verfolgte und misshandelte Cnschuld zu erscheinen, wobei er wohl anch z. T. bewusst falsche Angaben benutzt. Die Ansatzpunkte für einen weiteren Ausbau, dass er einerseits zu Grossem bestimmt, andererseits hier unschuldig leiden muss, liegen also vor. Sie fallen in eine abklingende Phase, nachdem eine hysterische Situationspsychose vorangegangen war. Ein hysterischer Charakter mit einer hysterischen Situationspsychose und nachfolgendem Ansatz zu pseudoparanoiden Gebilden.

Fall 6. H. H., uneheliches Kind, 1894 geboren. Im Jahre 1912 der Fürsorge überwiesen, weil er 2 mal wegen Unterschlagung bestraft mit 4 Wochen und mit 9 Monaten Gefängnis. Ferner weil er sich der Kontrolle seines Vormundes völlig entzogen. Mittelmässiger Schüler. Nach der Konfirmation an versehiedenen Stellen als Arbeitsbursche tätig gewesen. Aus der Fürsorgeerziehung wiederholt entwichen und wieder zurücktransportiert. Wegen Anzëigen von Geistesstörung, die er Anfang Mai 1914 zeigte, ins Krankenhaus S. überführt. Schreibt dort in seinem Lebenslauf, habe 3 Väter und 3 Mütter, komme nächstens als Kutscher zum Kaiser. Schreiben an den Kaiser: Empfiehlt sich selbst als zuverlässigen. Menschen. Bittet um Anstellung als Kutscher, Diener, Leibgardist oder Gesandter. Sei zwar vorbestrafter Verbrecher, aber auf dem besten Wege, ein nützliches, Mitglied der menschlichen Gesellschaft zu werden. Im Fall der Ablehnung fordert er den Kaiser zum Duell. Nach Angabe des Fürsorgepersonals habe H. etwa 3 Tage vor seiner Einlieferung aufgehört zu essen, und behauptet, das Essen sei vergiftet; packte mit dem Bett herum. ${ }_{L}^{i}$ Mitte Juli nach der Kieler Klinik überführt. Kleine, mangelhaft diveren- 
zierte Ohren, angewachsene Ohrläppchen. Gespaltenes Zäpichen. Ueber seine Ideen befragt, meinte er lachend, da glaube er nicht mehr daran, auch nicht, dass er vergiftet werden sollte. Habe sich gänzlich in den Gedanken hineingelegt, er miïsse Kutscher bei dem Kaiser werden. Schon früher habe er diesen Gedanken gehabt, doch sei ihm dieser Gedanke verschwunden, um ab und zu mal aufzutauchen. Ein Aufseher habe ihm gesagt, der Kaiser sei in $R$. und habe ihm rote Grütze geschickt zum Essen, da habe er fest gemeint, es sei Gift. Namentlich, da ein Anfseher meinte, es sei nicht schade, wenn er stürbe, habe er dies so aufgefasst, als ob die Absicht bestünde, ihn zu töten. Am Essen selbst habe er nichts bemerkt. Gibt noch an, dass er oft den Drang habe, fortzulanfen, sei leicht reizbar und prügele dann drauflos. Schreibt später einen unverschämten und drohenden Brief an seine Eltern. Entschuldigt sich nachträglich bei dem Arzt: es sei so über ihn gekommen, als er über sein Leben nachdachte. Eine Intelligenzprüfung fiel gut aus. Nach zweimonatlicher Behandlung im September 1914 wieder der Fürsorge zngeführt. Bericht vom 1. 3. 1915: H. sei aus der Fürsorgeerziehung entlassen, als gerettet anzusehen und hätte als Hausdiener eine Stellung gefunden.

Bei einem unehelichen Kinde entwickelt sich vielleicht im Zusammenhang mit einer Neigung zum triebartigen Davonlaufen zur Zeit der Pubertät ein unstetes, haltloses Wesen, dass schliesslich zu Delikten führt. Der harten Zueht in der Fürsorge versucht er vergeblich durch Entweichen zu entgehen. Als Aequivalent vertieft er ssch in dem - von Kindern häufig und auch von ihm bereits früher geäusserten -- Wunsch, kaiserlicher Kutscher zu werden. All seine Hoffnung, namentlich den Wunsch, aus dem Fürsorgehaus herauszukommen, knüpft er an diese Lieblingsvorstellung so innig, dass sich der blosse Kinderwunsch zu einem sein Gemütsleben völlig ausfüllenden Komplex entwickelt, der ihm dazu verhilft, die Vorkommnisse seiner Umgebung im entsprechenden Sinne umzudeuten, wozu auch das ihn hänselnde und aufiziehende Personal stark beiträgt. Er legt sich die Dinge im Sinne seines Lieblingswunsches zurecht; eine direkte wahnhafte Auffassung und Verarbeitung der Erlebnisse besteht dabei nicht. Es erfolgt dann auch nach kurzer Zeit ein Abklingen der Störung mit völliger Krankheitseinsicht. Ob beim Ausbinch der Störung ein leichter Verwirrtheitszustand - worauf das Umherpacken mit dem Bett hindeutet - bestanden hat, ist wohl möglich. Der Aerger über die missglückten Entweichungen und vielleicht auch über die Behandlung seitens des Personals summierten sich zu den übrigen infolge des Zwanges - ungünstig wirkenden Umständen und lösten diesen pseudoparanoiden Zustand bei einem intellektuell mittelmässigen, aber moralisch defekten zwanzigjährigen Menschen aus. Eine leichte epileptoide Entartung mag immerhin vorliegen. Bezeichnend ist die ganze kindliche Art seines Briefes, in dem er den Kaiser zum Duell fordert.

Fall 7. W. C., geboren 1889, ledig, evangeliseb, Schlosser. Ehelich, schlecht gelernt, aus der 3. Klasse konfirmiert, unstetes Leben, bereits mit 12 Jahren wegen 
Diebstahls, bestraft. Will als Schüler mit einem Hammer von seiner Stiefmutter anf den Kopf geschlagen worden sein. Kinmal seinen Vater mit einem Messer bedroht, wird Gewohnheitsdieb mit vielen Gefängnis- und 2 Zuchthausstrafen. Zuletzt 3 Jahre 1 Monat Zuchthaus. Erkrankte in der Haft, nachdem er sich schon ungebührlich benommen hatte und fortgesetzt Zänkereien hatte. Behauptet am 28. 11. $1913 \mathrm{im}$ Gefängnislazarett, wohin er wegen Lungenkatarrh gekommen war, man wolle ihm seine Million wegnehmen, er habe einen Doppeimord begangen, verlangt rom. Staatsanwalt Bestrafung. Dezember 1913 nach der Irrenanstalt $H$. transportiert. Dort in gehobener Stimmung. Bei ärztlichen Besuchen Leidensmiene, äussert, möglichst bald hingerichtet zu werden. Wenn unbeachtet, lustig, zu läp]ischen. Spielereien aufgelegt. Bei einer Fxploration produziert er absichtlichen Unsinn. Auf seine Mordbezientigung sề er gekommen, nachdem ihn der transportierende Wachtmeister danach gefragt hatte. Mai 1914 nach der Kieler Klinik überführt. Dort eines Nachts sehr erregt, meinte, eine Frauensperson ging spazieren am Fenster, fing laut an, auf sie zu schimpien, drohte ihr mit der Hand, sprach unanständiges Zeug. Erwies sich als Päderast. Renommierte mit angeblich guten_Faten: Einen Menschen gerettet, sei einem Pferd in die Zügel gefallen; ganz I. und A habe einen Hass auf ihn und Neid, weil er so klug sei und es nicht nötig habe, zu arbeiten. Habe mit den Zähnen einen halben Zentner hochgerissen, in der Arena gerungen, den Todesring auf dem Rad gemacht. Wird als einsichtsloser Sträfling charakterisiert. Späterhin arbeitet er fleissig mit. Im Juli 1914 unverändert nach der Irrenanstalt $N$. überführt. Habe seine Anschuldigung nux im Scherz erzählt, behanptet jedoch damals in seiner Zelle, Kriminalbeamte und Staatsanwalt gesehen zu haben, später nicht mehr. Hat dauernde Wünsche, neigt zum Querulieren und zu Beschwerden, prügelt hilflose Patienten, macht schwachsinnigen Eindruck, ist frech. Zunehmende Krankheitseinsicht, wird auch sonst verständiger in den späteren Monaten. November 1915 geheilt in Strafvolluug entlassen.

Ein etwas schwachsinniger, nicht nachweisbar belasteter Gewohnheitsdieb, mit renommistischen Neigungen, zeigt sich zunehmend aufsässig gegen die Anstaltsordnung, schreibt plötzlich Briefe an die Staatsanwaltschaft, in denen er sich des Mordes bezichtigt und um Bestrafung bittet. Auf die Mordaffäre ist er - nach seinen eigenen Angaben - durch diesbezügliche Fragen anderer gekommen. Daneben behauptete el, man wolle ihm seine Million wegnehmen. Auch nächtliche Halluzinationen stellten sich anscheinend ein. Sein weiteres Verhaiten zeugt von einer starken Phantasie und krankhaitter Renommiersucht, dazu Unaufrichtigkeit. Bei seiner Selbstbezichtigung hat wahrscheinlich seine Renommiersueht eine gewisse Rolle gespielt. Er, der Gewohnheitsdieb, gefiel sich darin, auch mal als Mörder auftreten zu können. Die ganze Art, wie er sich über die Misere der Zuchthaushaft hinwegzutrösten suchte - indem er sich dort als Verbrecher ganz anderer Art, gewissermassen grösseren Stils, hinstellen möchte - trägt den Stempel des Schwachsinns. Er erlangt jedoch völlige Krankheitseinsicht. 
Die Summation von Reizen bei längeren Gefängnis- und Zuchthausstrafen kann versehiedene Wirkung entfalten. Es treten interkurrente Ereignisse auf, die von einer unmittelbaren krankhaften Reaktion gefolgt sind: eine erneute Anklage oder Verurteilung, eine disziplinarische Anstaltsmassnahme führen den psychotischen Ausbruch herbei; insofern können dann diese Störungen unter Umständen den bisher betrachteten akuten gleichen, namentlich wenn ein affektives Moment, wie die Angst, von dominierendem Einfluss ist. Sie entfernen sich jedoch von ihnen in dem Masse, in dem die Reize eine länger dauernde Wirkung und Schädigung zuvor enthalten können. Die akuten Reaktionen bilden dann oft die Initialstadien anderer Bilder. Die Reize bekommen nicht nur Zeit zu einer ausreichenden psychischen Verarbeitung, sondern sie werden sogar überwertig, insofern anderweitige Erlebnisse, die eine Ablenkung bringen könnten, in Wegfall kommen. Daraus resultiert eine unzweckmässige gedankliche Verarbeitung, die den besten Boden für paranoide Zustände abgibt. Die affektive Beeinflussung geht nicht mehr wie bei den akuten Fällen auf das ganze Bewusstsein, sondern verbleibt den dominierenden Vorstellungskomplexen, ihnen so eine Ueberwertigkeit verleihend. Phantasie, Träumerei, Grübelei, Misstrauen und sonstige dem Individuum eigentümliche krankhafte Züge finden reichliche Nahrung. Sie verhelfen ihm dazu, sich in eine wahnhaft verkannte Situation hineinzuleben, die sich von der Wirklichkeit mehr oder weniger weit entfernen kann. Es resultieren paranoide Zustände mannigfacher Art: querulatorische und persekutorisehe Komplexe, Erfinder- und Grössenwahn, Begnadigungswahn, Unschuldswahn usw., die ohne scharfe Grenzen in die pseudoparanoiden Zustände übergehen, bzw. sich untereinander mischen können. Hier wird die Verschiedenheit der eventuell degenerativen Anlage am ehesten das Zustandsbild nach Art und Richtung der Wahnbildung beeinflussen können: ein lügenhafter, den Augenblickseinflüssen unterliegender Phantast wird eher Einfälle, Ausreden, Lügen, Einbildungen produzieren, deren Realitätswert für das Subjekt selbst oft nur ein momentaner ist; ein querulatoriseher und misstrauischer Charakter oder ein erethischer Imbeziller wird mehr den echten Wahnideen nahestehende Phänomene aufweisen. Echte und unechte Wahnideen können so vereinigt vorkommen und ein sehwer analysierbares Konglomerat darstellen. Das Gebiet der Situationspsychosen hat hier seine Grenze und fïhrt einerseits zu Formen, die eine Intensitätssteigerung des Habitualzustandes bilden, wie bei vielen schwer degenerativen Gewohnheitsverbrechern, oder als weitere Entwicklung der krankhaften Persönlichkeit aufzufassen sind. Die letzte Form ist noch wenig durchforscht. Den Rest bilden die jetzt zu besprechenden paranoiden Situationspsychosen, die gerade in längerer Haft ausbrechen, aber auch in der Freiheit entstehen können. Sie stellen wie die bisherigen transitorischen Erkrankungen Episoden mit 
Ausgang in Heilung dar, knüpfen an ein bestimmtes, meist aussergewöhnliches Erlebnis an, das auch zumeist den ausschliesslichen Gegenstand des Wahnes bildet; mit dem Abklingen des Erlebnisses, bzw. mit dem Wechsel der Umgebung kommt der Wahnkomplex, der vielleicht nur zum Teil oder gar nicht korrigiert wird, in Fortfall; er hat keinen Einfluss mehr, kann diesen jedoch wiedererlangen, sobald das Individuum wie bei den Haftpsychosen wieder in die gleiche Umgebung kommt. Fine eigentliche degenerative Anlage kann fehlen, zum mindesten ist eine starke psychopathische Konstitution oft nicht nachweisbar; die Charakteranomalien brauchen nicht stärker ausgeprägt zu sein, als bei anderen gesund bleibenden Individuen. Speziell das Fehlen der paranoiden Denkart ist oft auffällig, worauf $u$. a. auch B ir n ba u m hinweist. Er meint, der Druck der Haft könne für degenerative Individuen bei einem Milieu, das so leicht Mlissdeutung ausgesetzt ist, die genügende Ursache bilden. Homburger meint ähnlich, daß man bei hochreaktiven Psychopathen paranoide Entgleisung in der Haft selten vermissen wird.

Als Fälle des freien Lebens möchte ich Friedmann's ,,milde Paranoirformen" anführen: nach ihm kommt es ,,nicht gerade häufig zu einer paranoischen Wahnbildung im Sinne des Beeinträchtigungswahnes bei Personen, welche zwar von Charakter sensibel, eigensinnig und exaltiert sind - abnorme Charaktere, die aber bis dahin noch nie psychisch krank waren, - welche normale Intelligenz besitzen und bei denen weder Alkoholismus, noch Senium, noch eine ausgeprägte Form der psychischen Degeneration, kurz irgend eine spezifische Aetiologie vorliegt. In der Mehrzahl sind es Frauen und Mädchen in dem Alter zwischen 30-40 Jahren. Geraten diese unter einen stärkeren äusseren Konflikt oder erleiden sie eine Enttäuschung oder Sehädigung stärkeren Grades, wird eine erwartete Heirat vereitelt, einer des Verrates an seinen Arbeitsgenossen fälschlich und öffentlich bezichtigt, erleidet eine Dame ohne ihr Vorwissen bei einer Operation den Verlust der Ovarien und damit der Konzeptionsfähigkeit, so entwickelt sich im Laufe einer Reihe von Monaten oder auch noch langsamer ein Wahnsystem, das sich mit den Ursachen oder den Folgen jener Schädigungen beschäftigt und bei welchen bestimmte Personen beschuldigt werden, welche sich aber ausschliesslich bei dieser einzigen Gedankenkette begrenzt. Was allein noch hinzutritt, das ist ein ebenso beschränkter Beobachtungswahn, Halluzinationen fehlen, die Besomnenheit bleibt völlig gewahrt, der Wahn wird mit gutem logischen Zusammenhang gebildet, die Personen geraten in einen leidenschaftlichen Affekt, der aber weder manische, noch depressive Färbung besitzt. Nach 1-2 Jahren verblasst der Affekt, die Patienten werden wieder ruhig und sprechen nicht mehr von der ganzen Sache, wenn auch meistens keine Korrektur eintritt. Sie sind praktisch geheilt, der ganze Verlauf beansprucht meistens $21 / 2$ Jahre. Ausser dieser als impulsiver und Beziehungswahn gekennzeichneten Form 
unterscheidet Friedmann eine weitere als logiseh affektive Urteilstrübung, die symptomatisch nur durch das Fehlen eines Beziehungswahns von der ersteren differiert.

Vielleicht werden auch so manche leichte Fälle von Eifersucht, Erfinderund Querulantenwahn des freien Lebens hierher zu rechnen sein. Die querulatorischen Formen, die so häufig in der länger dauernden Strafhaft ausbrechen, werden allerdings von Wilmanns der Paranoia Kraepelins zugerechnet (dieser selbst trennt den Querulantenwahn neuerdings als psychogene Geistesstörung von der Paranoia); es handele sich in beiden Fällen um ein langsam sich entwickelndes, dauerndes, unerschütterliches Wahnsystem bei vollkommener Erhaltung der Klarheit wie der Ordnung im Denken, Wollen und Handeln. Die verschiedene Prognose, die Unheilbarkeit der chronischen Paranoia, das Abblassen der durch die Strafhaft ausgelösten Formen nach dem Milieuwechsel sei kein genügender Grund zur Abgrenzung. Die Form des freien Lebens und die der Strafhaft sind seines Erachtens völlig gleichwertig; jene allerdings weit schwerere Grade der Entartung als diese, die das Resultat der Entartung und eines äusseren entfernbaren Momentes sind. Dieser Querulantenwahn sei der milden Paranoia Friedmann's und dem Querulantenwahn Kraepelin's gleichzustellen. Nun betont Wilmanns selbst , die überraschend häufige Verbindung des Querulantenwahnsinns nit anderen Zeichen der Entartung insbesondere mit hysterischen Symptomen, sei es, dass Lähmungen, Ganserzustände usw. anamnestisch vorliegen oder interkurrent als akute Haftpsychosen auftreten. Daraus erklärte sich auch das Auftreten der Erkrankung bei Unfallverletzten, Rentenjägern und als Folge psychischer Infektion." - Diese Eigenheit spricht doch gerade dafür, dass sie nicht den Typus der endogenen Paralloia im Sinne Kraepelin's zuzusprechen sind, sondern zu den degenerativen Formen rechnen, bei denen eine vielfältige Kombination pathologischer Züge nichts Seltenes ist. Nun kommt noch hinzu, dass nach Wilmanns zu dem Querulantenwahn in der Haft wie auch zu den übrigen ehronischen Haftpsychosen sich über längere Zeit hinziehende ängstliche Erregungen mit massenhaften Halluzinationen des Gehörs (Schimpfworte, Beschuldigungen, Drohungen) hinzugesellen. Auch dies entspricht nicht der Kraepelin'schen Paranoia. Dureh den Wechsel der Omgebung tritt Stillstand in der Krankheitsentwicklung und Einsicht für die stürmisehen Aeusserungen der Psychose ein (den Halluzinationen und Wahnideen). Nur die sich langsam entwickelnden Wahnideen werden festgehalten, namentlich dann, wenn die Beeinträchtigungsideen sich in derselben Richtung bewegen, wie die Ansiehten, die bei tiefstehenden Verbrechern über das Wesen des Strafvollzugs und ihre Stellung zu der Gesellschaft verbreitet sind.

Weitere hierher gehörige Bilder beschreibt Bonhoeffer: Zustände, die 
ebenfalls auf dem Boden der Entartung entstehen, wobei aber die Psychose keine ejgentliche psychologische Kontinuität mit der ursprünglichen Persönlichkeit zeigt: er bezeichnet sie als paranoide Erkrankung oder akute Paranoia auf dem Boden von Entartungszuständen, die der erethischen Debilität nahestehen. Hereditäre Belastung und frühzeitige Asozialität sind meist vorhänden. Bei erhaltener Besonnnenheit und äusserer Orientierung, Entwicklung von Beziehungswahn und Erklärungswahnideen, die einen durch das Gefängnismilieu gegebenen Inhalt haben. Dauer einige Monate bis zu 2 Jahren. Die Wahnbildung schreitet nur kurze Zeit fort, es kommt in keinem Fall zu einer retrospektiven Veränderung des Bewusstseinsinhaltes, der Wahnbildungsprozess bleibt versehieden lang stationär und klingt endlich unter Entwicklung von Krankheitseinsicht ab, ohne eine Veränderung der urspringlichen Persönlichkeit zu hinterlassen. Die Beeinflussbarkeit der Erscheinung durch das Milieu, die aus Angstträumen entnommene Konfabulation von Geschlagen- und Gewürgtwerden erinnert wohl an Hysterie. Dagegen lässt die Einförmigkeit des ängstlichen Beziehungswahns und der vereinzelten Phoneme, der im ganzen gleichmässige adäquate paranoische Affekt, die erhaltene Besonnenheit, das Massvolle des Erklärungswahns ganz den hysterischen Charakter vermissen. Die degenerative Anlage drückt sich während der geordneten paranoischen Wahnbildung nur in dem antisozialen Charakter und in der Neigung zu Hetzereien und Disziplinwidrigkeiten aus; das ursprüngliche Temperament lässt eine paranoische Denkrichtung ganz vermissen: also keine Steigerung einer vorher bestehenden paranoischen Anlage, sondern die Psychose steht unvermittelt der ursprünglichen Persönlichkeit gegenüber.

Vielleicht wird man ferner auch die Fälle Rüdin's hierher zählen, die er als eine Form akuten halluzinatorischen Verfolgungswahnes in der Haft ohne spätere Weiterbildung des Wahnes und ohne Korrektur bezeichnet. Dass hier die Halluzinationen hervortreten, wird man wohl zum Teil auf die Isolierhaft zurückführen können; die Psychose entwickelte sich in akuter Weise bei drei abnorm veranlagten Gewohnheitsverbrechern nach 2-3jähriger Haft mit Sinnestäuschungen, vornehmlich des Gehörs. Auf ihnen im Verein mit den Wünschen, Hoffnungen, Befürchtungen und anderweitigen Wahrnehmungen baut sich ein, wenn auch nicht ausgedehnter systematischer Verfolgungswahn auf. Das Gefühl, die klare Ueberzeugung, in ihrer Existenz bedroht zu sein, die beunruhigenden nervösen und körperlichen Allgemeinerscheinungen, welche meist als direkte und indirekte Folge der Mordpläne aufgefasst werden, versetzen den Gefangenen in äusserste Gereiztheit, Misstrauen und Angst, ein hervorstechender Zug des Bildes. Im übrigen völlig korrektes Benehmen. Eine Weiterbildung des hauptsächlich auf Halluzinationen gegründeten und mit ihnen einhergehenden Wahnes begrenzter 
und bestimmter Verfolgung hört mit dem Verschwinden der akuten Symptome, oft auch früher auf. Dauer einige Monate bis 1 Jahr. Eine Korrektur soll nicht eintreten, nach Meinung Leppmann's jedoch noch in der Freiheit. Die Erinnerung war erhalten, hysterische Symptome fehlten. Rüdin lässt es dahingestellt, ob die Psychose nur bei Verbrechern in der Haft vorkomme oder auch bei Unbescholtenen. Leppmann bekennt sich in einem Nachwort zur letzteren Ansicht; in einem vollwertigen Seelenleben entstehe sie durch den Dauereinfluss der Haft und werde durch die Aenderung der Haftbedingungen günstig beeinflusst; in der Freiheit können ähnliche Symptomkomplexe unter ähnlichen Bedingungen entstehen.

Zwei Fälle, von denen der zweite der eigenen Beobachtung entsiammt, mögen hier ausführlicher Erwähnung finden.

Fall 8. J. H., geboren 1883, evangelisch, Händler. Vater etwas merkwürdig, später geistes- und nerrenkrank. Die übrige Familie gesund. In der Schule angeblich gut gelernt, aus der ersten Klasse konfirmiert. Dann Bäcker und Hausdiener gewesen; beim Militär gute Führung. Dann erst kriminell. Mit Gefängnis bestraft wegen versuchter Erpressung, Körperverletzung und Zuhälterei. Auch wegen Bettelns und Obdachlosigkeit mit Haftstrafen belegt. Hatte mit mehreren männlichen Personen gegenseitige Onanie getrieben und dann Erpressungsversuche gemacht. Wegen Verdacht auf paranoide Geistesstörung musste Strafzeit unterbrochen werden. Behauptete in monotoner Redewendung und schwachsinniger Weise, alle hätten sich vor Gericht gegen ihn verschworen, der Verteidiger hätte für den Gegner Partei ergriffen, der Gerichtsvorsitzende sei bestochen worden. Seine Gegner müssten auch auf die Leute im Gefängnis eingewirkt haben, um ihn za vernichten, die Angehörigen seien gegen ihn aufgereizt. Glanbt von anderen Leuten, dass sie verrückt seien. Will sich mit seinem Gegner duellieren, im Traum Duelle. Werde verfolgt von den Gefangenenanfsehern, die ihn verspotteten. Schulkenntniisse äusserst mässig. Nach der Irrenanstalt M. überführt. Dort von 1909 bis 1913. Hört seine Gegner sprechen; belästigen und beschimpfen ihn, rufen Schweinereien zu. Sollte hier vernichtet werden, sei nicht krank. Deutliche Verifikation von Träumen. Findet sich in seinen Straftaten nicht zurecht. Verfolgungsideen nehmen zu, breiten sich gegen die Irrenanstalt aus. Reibereien und Schlägereien mit anderen Kranken, beschwert sich über die Wärter. Produziert auch Grössenideen und unterschreibt einen Brief mit Grafen Waldeck. Ins Gefängnis zurück, beleidigend und drohend, störend. Sei unschuldig, fühlt sich danernd zurückgesetzt. Beschuldigt Wärter und Kranke. Mnsste deshalb wieder zurück in die Irrenanstalt. Queruliert, zeigt süssliches, weiches, schlappes Wesen, Mangel an Urteilsfähigkeit, Vernunftgründen nicht zugänglick. Direktor und Aerzte steckten mit dem Staatsanwalt unter einer Decke. Behauptet aber jetzt von seinem Gegner im Erpressungsprozess, er habe sich als Kavalier gezeigt. Allmählich ruhig, macht keine Schwierigkeiten mehr, kommt gebessert April 1913 ins Strafgefängnis Ne. April 1914 wurde er wieder, zwecks Beobachtung, nach der Kieler Klinik überführt. Aeussert die früheren Ideen, schimpft, scheint zu halluzinieren. Diagnose: Imbezillität mit 
Neigung zu Wahnbildungen und Erregungen. Mai 1914 ungeheilt nach Anstalt N. Dort ebenfalls zurückhaltend, häufig hysterische Anfälle, die sehr gewollt und gemacht aussehen. Später beschäftigt er sich etwas ruhiger. Einmal zwei hysterische Anfälle mit Erregungszuständen, droht Scheiben einzuschlagen, Streit mit anderen Kranken. Bestreitet jetzt, im Gefängnis verfolgt worden zu sein. Wird zuletzt ruhiger $_{\text {: }}$ und verständiger. Oktober 1914 gebessert entlassen.

Ein Gewohnheitsverbrecher, der verhältnismässig spät kriminell wird, deutlich hysterische Symptome, Einsichtslosigkeit und Beschränktheit, die man schon als Schwachsinn bezeichnen kann, aufweist, erkrankt, nachdem er bereits mehrere Strafen anscheinend gut überstanden hat, in der letzten Strafhaft unter den Zeichen nächtlicher Halluzinationen und sich gegen seine Umgebung immer mehr ausbreitenden Beeinträchtigungsideen. Zwischendurch erscheinen auch Grössenideen, die aber wieder zurücktreten: so die Unterschrift eines Briefes mit Graf Waldeck; keine eigentliche Wahnvorstellung, sondern ein flüchtiges Phantasieprodukt, das bei stärkerem Hervortreten zur vorigen Gruppe zu rechnen wäre. Bei seinen Beeinträchtigungen und Verfolgungsideen liegen jedoch die Dinge anders. Hier begünstigt der Schwachsinn eine verkehrte Auffassung seiner Lage und wahnhafte Verarbeitung der Erlebnisse mit Hilfe nächtlicher Halluzinationen und trifft sich mit seinem Wunsche, möglichst als unschuldig zu gelten; dazwischen treten halluzinatorische Verwirrtheits- und Erregungszustände auf, später, im Stadium der Besserung und zum Sehluss nur noch hysterische Anfälle, die wir wohl als durch die Haft bedingte Intensitätssteigerung seiner krankhaften Artung betrachten dürfen: Nach etwas längerem Verlauf treten aber auch die Wahnideen völlig zurück. Er bestreitet sogar seine früheren Verfolgungsideen, was man allerdings nicht als Zeichen einer Krankheitseinsicht verwerten kann. Die paranoide Episode dürf́en wir vornehmlich als Produkt einer schwachsinnigen Verbrecherpsyche betrachten, das unter dem Druck der sich wiederholenden längeren Haft entstanden, durch Wunsch, Phantasie und halluzinatorische Erlebnisse begünstigt wurde. Ist es doch bekannt, dass selbst bei den geistesgesunden Verbrechern abergläubische Vorstellungen ganz abstruser Natur häufig sind (Wilmanns). Hier summieren sich also Hysterie und Schwachsinn und führen durch die Ungunst der Umstände wie z. B. die Aussicht auf die gegen früher länger dauernde Gefängnisstrafe zu einer wahnhaften Auffassung und Verarbeitung der Ereignisse. Der Zustand verläuft langsam und intermittierend, kommt aber schliesslich unter der veränderten Umgebung zum Abklingen.

Fall 9. R., 27jähriger Monteur, Vater Trinker, Mutter angeblich hysterisch, mangelhafte Erziehung. Wurde von der Mutter zum Betrügen angehalten, mit 15 Jahren bereits wegen Betrugs mit Gefängnis bestraft. Ging dann aufs Technikum, zum Monteur ausgebildet. Drei Jahre in einem Hüttenwerk gearbeitet, in der 
Zwischenzeit nicht bestraft, dann Differenzen mit seinem Betriebschef, den er wegen Uebervorteilung verklagte, aber abgewiesen wurde ( $R$. hat angeblich in England, wohin er auf Kosten der Hütte geschickt wurde, ein neves Härteverfahren kennen gelernt, das dann sein Betriebschef, ohne ihn seinem Versprechen gemäss zu entschädigen, verwertete). Zu derselben Zeit auf Kosten des Arbeitgebers in einem Sanatorium: Arzt konstatierte Wahnideen und hystero-epileptische Anfälle. Ging dort weg, seitdem unstet, Kautionsschwindeleien in kleinen Beträgen bis 30 Mark. Auf Veranlassung seiner Braut stellte er sich später der Polizei, kam wegen hysterischen Anfällen in die psychiatrische Klinik M.; simulierte dort auf Anraten eines untergebrachten Gewohnheitsverbrechers Verrücktheit: Sei der grösste Verbrecher der Welt, hätte sämtliche Morde auf dem Gewissen, sei der ewige Jude, wolle gekreuzigt werden, oder er verpuppe sich und werde mit Gestank zum Himmel fahren (eigenes Geständnis, weil ihn ein anderer Verbrecher auf die Folgen der Internierung aufmerksam machte). (Diagnose: hysterischer Psychopath.) Auf freiem Fuss 8 Monate gearbeitet, machte dann einen Teil seiner Strafe ab. Kurz nach der Entlassung aus dem Gefängnis neue Fahndung zwecks Gerichtsverhandlung - dadurch erregt; Renkontre mit der Polizei, tobsüchtige Erregung, kam dann in die Heilanstalt K., von dort nach 4 Monaten als geheilt entlassen. Fahndung wieder erneuert, floh jetat; in einer sechswöehentlichen Reise will er etwa 40 Kautionsschwindeleien gemacht haben, wovon 15 zur Kenntnis der Polizei gelangten. Stellte sich in Nürnberg wieder der Polizei, kam ins Krankenhaus, trat dort zum erstenmal mit Wahnideen hervar: Beschuldigte seinen früheren Betriebschef als den ,geistigen Urheber" der krimminellen Handlungen. Er quäle ihn durch elektrisehe Strahlung und Fernwirkung; bekommt fast täglich Anfälle. (Wie er auf die Wahnideen von damals gekommen sei, wisse er nicht, vielleicht eine aus „Not und Verzweiflung geborene, aber unbewusste Simulation", es wirkte ihm wohltuend, wenn der Arzt auf seine Ideen einging.) Widerrief später die Wahnideen der elektrischen Beeinflussung und hielt die anderen aufrecht, bekam weiterhin hysterische Anfälle. Diagnose: Psychopath mit Wahnbildung eines Degenerierten, vermindert zurechnungsfähig. Diagnose und Gutachten des Gerichtsarztes: Halbwahnideen eines Degenerierten. 3 Monate Gefängnis. Um weiteren schwebenden Strafverfahren zu entgehen, fliichtete er nach Belgien. 11/2 Jahre als Elektriker dortselbst gearbeitet, ohne sich etwas zuschulden kommen zu lassen. Interniert bei Kriegsausbruch (behauptet, bewusst die Paranoia simuliert zu haben), wurde nach der belgischen Irrenanstalt T. gebracht. Von Deutschen befreit, wurde er zur Truppe eingestellt, aber später wegen der schwebenden Fahndung der Gerichtsbehörde ausgeliefert. Auf Anordnung der Staatsanwaltschaft von neuem in der Klinik M. beobachtet. Dort keine Anfälle oder erwähnenswerter körperlicher Befund. Gibt an, dass Oberingenieur $\mathrm{K}$. ihn schon einige Jahre zu schädigen und zu beseitigen versucht. Alles, was anders lief, als ihm genehm oder günstig war, bringt er in Verbindung mit den Machenschaften eines Feindes; Missempfindungen irgendwelcher Art, welche ihn befallen, führt er anf diesen zurïck; auch in der Anstalt bemerkt er die Hand K.'s, ein Pfleger wurde von diesem bestochen, bedeckte sein Bett mit Chloroform, so dass er bewusstlos wurde, er wollte aufstehen und brachte dies nicht fertig; ein anderer Explorand hatte es auf sein Leben abgesehen. Unwahrscheinlichkeiten, Unmöglich- 
keiten gibt es in diesen Punkten nicht für ihn, irgendwie kann K. immer Wege und Mittel finden, gegen ihn zu wirken; die Ursache von K.'s Verfolgungen liegt darin, dass derselbe, so lange er lebe, Erfindungen nicht verwerten kann, die zum 'Teil die seinigen sind. Auch in seinen Straftaten wollte er wie früher, den Effekt K.'scher Einwirkung sehen; einen wirklichen Vorteil wollte er von seinen Betrügereien nicht gehabt haben.

Diagnose: Paranoische Seelenstörung auf hysterisch degenerativer Grundlage. - Seine Straftaten unter Einfluss der Wahnideen, daher nicht verantwortlich.

Nach Pflegeanstalt H. überführt im Dezember 1915. Da er sich 1913 mit Lues infiziert hatte, bekam eine Schmierkur mit Salvarsan. 22. 3.1916 nach einer schmerzhaften Salvarsaninjektion tobsuchtsartiger Erregungszustand mit üngstlicher Färbung. Am nächsten Tage wieder klar. Bestreitet im übrigen, eine Paranoia zu haben, wechselnde Stimmung, entweder manisch gehoben oder gedrückt, Wahnideen bis auf die Uebervorteilung des $K$. werden nicht vorgebracht. Verfasst eine etwas phantastische, aber nicht paranoische Eingabe an die Staatsanwaltschaft, wo er um Aburteilung bittet. Entwichen am 1. 4. 1915. 3 Monate gearbeitet, als die Polizei ihn entdeckte, wieder geflohen, macht neue Betrügereien in verschiedenen Städten, wird schliesslich in I. ergriffen.

Im Polizeigefängnis Krämpfe und Tobsuchtsanfälle, kommt deswegen nach der Klinik. Hier ruhig und geordnet. Stellt sich als Opfer des Milius und mangelhafter Erziehung nebst krankhafter Veranlagung dar. Er macht den typischen Eindruck eines hysterischen Schwindlers. Seine Betrügereien, die er mit Raffinesse ausführte, gibt er zu, den letzten Betrug in L. begangen, stellt er in Abrede; ebenso seine Verhaftung. Von Krampfanfällen and Untersuchung durch den Polizeiarzt weiss er angeblich nichts. Er bezeichnet einen gewissen Oberingenieur $\mathrm{K}$. als grossen Feind, der Polizei und Staatsanwaltschaft hinter ihm herhetze. Derselbe bediene sich elektrisch-chemischer Wellen, womit er ihn überall beeinflusse, er glaube, die körperlichen, eigenartigen Empfindungen darauf zurückführen zu müssen. Mit dem Apparat, der Adrenalin enthalten soll, könne K. auf biologischem Wege alle Lebewesen töten. Er beeinflusse damit anch Polizei und Staatsanwaltschaft. Er glaube, man benutze ihn als ein psychiatrisches Experiment; er müsse dabei zugrunde gehen. Wechselnde Stimmung (wenn gehoben, bekritelt er selbst. die krankhaften Beschuldigungen).

13. 8. Sucht durch phantastische Erzählung die Pfleger zu bestechen, um zu entfliehen und Geldbeträge leihen zu können. Komplottiert und hetzt das Personal gegeneinander.

16. 8. Die Sache mit $\mathrm{K}$. sei keine Idee, sondern innere Ueberzeugung. Diese trete immer auf, wenn er sich verfolgt. In der Zeit, wo er ruhig zwei Monate gearbeitet, ebenso während seines Aufenthaltes in der belgischen Irrenanstalt habe er gar nicht daran gedacht.

4. 9. Dem Arzt gegenüber freier und offener; äussert sich über Spiritismus, Aberglauben und Hysterie in vollkommen richtiger Weise. Seine Wahnideen produziert er nicht mehr, will seine Straftaten alle abbüssen, um von der Polizei loszukommen und ein geordnetes Leben führen zu können.

10. 11. Lenkbar und beeinflussbar. Ist sehr tätig auf der Station, verrichtet Archiv 1. Psychiatrie. Bd. 58. 
alle grossen Arbeiten. Seine krankhaften Beschuldigungen werden ron ihm in ruhigen Zeiten einsichtig und kritisch beurteilt.

Sobald ihm aber etwas schief geht, tauchen immer wieder dieselben Beschuldigungen auf, ohne Progression. Erklärt immer, dass die Arbeit ihn gesund mache. Wenn er untätig sei, komme er wieder durch Grübeln in alte Gedanken. Seine unwahren Angaben erscheinen zurzeit durch ein ungenaues Gedächtnis mit bedingt zu sein.

1. 10. Sei aus H. deswegen entwichen, weil or den Arzt verdächtigte, dass er mit ihm lebensgefährliche Experimente mache. Habe diese Idee in der Freiheit wieder verloren; halte sie jetzt für absurd. Wenn er auf der Flucht sei, kämen die Gedanken und werden immer grösser und stärker. Vor der Entweichung hinfällig krank, habe sich in der Anstalt selbst krank gefüblt, schon auf der Ilucht fühlte er sich gesund. Während der Flucht sei er von einem glühenden Menschenhass begleitet, er begehe seine Betrügereien nur an solchen Menschen, die finanziellen Rückhalt haben. Seine, geistige Konstitution" müsse in jenen Zeiten eine andere sein. Benutze das Geld nur, um wieder weiterhasten zu können, esse nichts; seine Erinnerung an jene Betrugsperioden seien in ganzen vollständig, jedoch ähnem sie der Erinnerung eines Tranmes.

Kommt als nicht geisteskrank in Untersuchungshaft, wird vom Gericht entlassen, führt jetzt ein arbeitsames Leben und verlobte sich.

Ein wohl erblich belasteter, zu Unredlichkeiten erzogener Junge begeht in seinem 15. Lebensjahr Betrügereien, für die er bestraft wird. Hält sich dann eine Zeitlang sozial, ergreift einen Beruf, in dem er auch anscheinend Tüchtiges leistet; er gerät in Differenzen und Rechtsstreitigkeiten mit seinem Vorgesetzten, kommt infolgedessen in ein Sanatorium, wo der Arzt bereits von Wahnideen spricht. Nach den späteren Angaben des Kranken hat es sich wohl mehr um affektive Entgleisungen und hysterische Anfälle gehandelt. Verliert seine Stellung, gerät dadurch anscheinend in Not und begeht eine Reihe Kautionsschwindeleien und wird damit zugleich auch unstet. Die weiteren Lebensschicksale und psychiatrischen Beobachtungen zeigen einen ausgésprochenen Hysteriker mit Neigung zu Pseudologia phantastica, starker Beeinflussbarkeit und Labilität der Stimmung; namentlich eine Tendenz zu tageweiser Verstimmung und Bewusstseinsstörung nach stark affektiven Erlebnissen macht sich geltend. Kompliziert wird diese vielfältige degenerative Anlage noch durch eine paranoide Tendenz, die manifest wird, wenn er sich im Druck befindet und in eine depressive Stimmung gerät: eine typische Situations-Paranoia. Zuerst trat diese Tendenz einige Jahre nach. seinem Prozess mit dem Vorgesetzten auf; er war der Ueberzeugung, dass dieser sein Unglüick bezwecke, an allem schuld sei und Staatsanwalt und Polizei gegen ihn mobil mache und in seinem Sinne beeinflusse. Diese Ueberzuugung machte sich auch später bei ihm geltend jedesmal, wenn er seine Freiheit verlor; allerdings wird seine lebhafte Phantasie und autosuggestive. 
Fähigkeit mit zu dieser Ueberzeugung beigetragen haben. Ein Gutachter kam schliesslich zur Ueberzeugung, es liege ein umschriebenes, aber unerschütterliches Wahnsystem vor. Dass dies nicht der Fall ist, beweist nicht nur der weitere Verlauf, sondern auch die Tatsache, dass er unter ungünstigen Umständen auch gegen andere zu wahnhaften Verdächtigungen kommt: als Ursache seiner Flucht aus der Anstalt H. gibt er später seine Furcht an, der Arzt mache mit ihm absichtlich lebensgefährliche Experimente, wiewohl er doch selbst auf die Injektion gedrungen hatte. Diese Ansicht hatte er dann bald wieder korrigiert. Seine Wahnideen enstammen also affektiv bedingten Urteilstrübungen. Darauf deutet auch der Umstand hin, dass er sich auf der Flucht immer verfolgt glaubt, weil er in jedem Menschen einen Kriminalbeamten fürchtet. Dazu kommt als verstärkendes Moment eine lebhafte Phantasie, die bei einer depressiven Verfassung sich ebenfalls in einer Richtung bewegt, die sein Unglück leicht als die Schuld und Schlechtigkeit anderer erscheinen lässt. - R. besitzt eine für seinen Bildungsgang ungewöhnlich scharfe Selbstbeobachtung und Selbstkritik in ruhigen Zeiten. Das macht den Fall zu einem so lehrreichen. Nach seinem bisherigen Lebensgang wird man ihn vielleicht als Frühkriminellen, dabei aber nicht als Gewohnheitsverbrecher bezeichnen können. In seinen Stellungen zeigt er sich völlig sozial und auch geistig gesund.

All die gezeichneten Bilder zeigen mancherlei Verschiedenheiten. Es kann eine gewisse paranoische Denkrichtung, ein leicht paranoischer Charakter bestehen, in anderen Füllen wird derartiges vermisst; dafür können aber hysterische, epileptoide und andere Züge als Zeichen der degenerativen Anlage vorhanden sein; schliesslich können diese Momente auch fehlen. Ebenso kann der Ausgang der Krankheit mit völliger oder teilweiser Krankheitseinsicht - wie meistens - vor sich gehen, aber auch Fälle ohne Korrektur kommen vor. Während in der Freiheit die Halluzinationen gegenüber den Beeinträchtigungs- und Erklärungswahnideen zurücktreten, gibt die Haft einen günstigen Boden für zahlreiche Halluzinationen ab. Die sonstigen Verschiedenheiten sind zum Teil auf die vielfach vorhandene differente degenerative Anlage, zum Teil auf die jeweilig wirksamen Erlebnisse und dabei bestehende Konstellation, nicht zum wenigsten auch auf persönliche Momente zurückzuführen. Dass gerade - wie bei Friedmann - Männer in gereiftem Alter und alternde Mädchen und Frauen in der Nähe des Klimakterium erkranken, kann darauf hinweisen, dass eben zu dieser Zeit, wo sich der ausgesprochene paranoische Charakter zu zeigen pflegt, auch leicht und sonst gar nicht manifest paranoisch Veranlagte durch entsprechende, stark affektbetonte Erlebnisse zu einer episodenhaften Wahnbildung veranlasst werden können. Ebensogut ist es vielleicht aber auch denkbar, dass ein Mensch ohne paranoide Denkart unter besonders ungünstigen, seinem viel- 
leicht berechtigten Misstrauen immer neue Nahrung gebenden Cmständen in eine affektiv bedingte paranoide Phase geraten kann. Auch bei sonst gesunden Menschen kann ja ein von starken Affekten gewecktes und getragenes Misstraueiı zu abenteuerlichen Vermutungen führen.

Gemeinsam ist allen diesen Bildern, dass sie nur eine vorübergehende Phase im Leben des Individuums darstellen, hervorgerufen durch bestimmte Erlebnisse, an ihnen sich entwickelnd, auf sie sich beschränkend und mit ihnen auch abllingend, eventuell rezidivierend. Wir können sie daher zweckmässig und mit Recht als Situationspsychosen bezeichnen, und zwar bilden sie eine besondere Gruppe, die als die paranoide zu charakterisieren wäre, da im Vordergrunde krankhafte Vorstellungen von Charakter der Wahnideen stehen und zu einer Situationsverfälschung führen. Diese mögen in verschiedenen Fällen eine verschiedene Genese haben, einmal mehr nach Art der überwertigen Ideen gebildet werden, ein andermal mehr nit Hilfe von Halluzinationen und Illusionen sich Geltung verschaffen, schliesslich auch vielleicht im Sinne der echten Paranoia Kraepelin's auf logisch deduktivem Wege sich entwickeln; die Folge ist überall eine wahnhafte Verfälschung zirkumskripter, mit den auslösenden Erlebnissen in Beziehung stehender Vorgänge.

Zum Schluss hätten wir noch kurz die Frage zu streifen, ob die Situationspsychosen unter Umständen nicht doch in chronische und damit andere Formen übergehen können. Diese Frage steht mit dem Problem, ob die H. $\mathrm{ft}$ als solche eine chronisch verlaufende spezifische Psychose zu erzeugen imstande ist, in einem inneren Zusammenhang. Man wird sich dem gegenüber nicht prinzipiell verneinend verhalten können. Schliesslich kann wohl auch eine akute psychische Infuffizienz chronisch und irreparabel werden, wenn die schädigenden Momente nicht in Wegfall kommen. Aber das werden Ausnahmefälle sein. Im übrigen werden wir festhalten können: es gibt psychotische Zustände sowohl in der Freiheit wie in der Haft, die allein einer sozusagen zufälligen Kombination innerer und äusserer Momente ihre Entstehung verdanken und nur eine Episode im Leben und Schicksal der Persönlichkeit darstellen. Sie verdienen daher zu einer gemeinsamen Gruppe der Situationspsychosen zusammengefasst zu werden, die im übrigen verschiedene Bilder der Symptomatik und Pathogenese, den jeweiligen Umständen und der Individualität entsprechend, aufweisen, wenn auch im allgemeinen die Anzahl leicht Degenerierter überwiegt. Als Untergruppen haben wir die emotionellen, hysterischen mit den ihnen nahestehenden pseudoparanoiden, und die paranoiden situationspsychosen abgrenzen können; kenntlich sind sie an den verschiedenen Situationsformen: der Situationsfixierung, der Situationsverse hiebung,der Situationsumdeutung und der Situationsverfälschung. 
Bei ihnen haben wir es demnach nicht mit Erkrankungen zu tun, die nach inneren Gesetzen wie die endogenen Psyehosen Verlauf und Ausgang nehmen, sondern mit vorübergehenden Zuständen, die durch ein zufälliges Zusammentreffen von Faktoren, wie degenerative Anlage, individuelle Eigenschaften, Lebensschicksale, Milieu, psychophysische Konstellation und emotionelle Ereignisse hervorgerufen, mit dem Fortfall dieser Kombination auch ihren Abschluss finden. Mit der Bezeichnung ,degeneratives Irresein“ oder „Hysterie" wird man also der tatsächlichen Mannigfaltigkeit nicht gerecht. Gibt es doch Individuen, die weder vorher noch nachher die Zeichen einer degenerativen oder speziellen hysterischen Anlage aufweisen, bzw. bei denen die psychopathische Konstitution nicht derart ist, dass sie die hinreichende Aetiologie abgibt. Man wird den Satz, dass die psychogene Reaktion als solche Kennzeichen einer degenerativen Anlage sei, wie früher Birnbaum und auch Bonhöffer meinten, nicht in seiner Allgemeinheit anerkennen. Auch die Kriegserfahrungen mancher Psychiater sprechen dagegen. Man wird vielmehr - allgemein ausgedrückt - die Frage, ob gesunde Individuen infolge einer unglücklichen Verkettung von Umständen transitorisch erkranken können, einer weiteren Diskussion unterziehen müssen. Vielleicht werden uns hier die Erfahrungen des jetzigen Krieges weiterhelfen.

\section{Literaturverzeichnis.}

Alzheimer, Die diagnostischen Schwierigkeiten in der Psychiatrie. Zeitschr. f. d. ges. Psych. u. Neur. 1910. Bd. 1.

Binswanger, Hyster-somatische Krankheitserscheinungen bei der Kriegshysterie. Monatsschr. f. Psych. u. Neurol. Bd. XXXVIII.

Birnbaum, Psychosen mit Wahnbildung und wahnhafte Einbildungen bei Degenerierten. 1908. Halle, Marhold. - Zur Lehre von den degenerativen Wahnbildungen. Allgem. Zeitschr. f. Psych. Bd. 66. H. 1. - Simulation und vorübergehende Krankheitszustände auf degenerativem Boden. Aerztl. Sachverst.-Ztg.1909. Nr. 3. - Zur Frage der psychogenen Krankheitszustände. Zeitschr. f. d. ges. Psych. u. Neurol. Bd. 7. S. 404. - Psychopathische Verbrecher. Berlin 1914. Kriegsneurosen und Psychosen. Zeitschr. f. d. ges. Psych. n. Neurol. Bd. XII.

Bonhöffer, Klinische Beiträge zur Lehre von den Degenerationspsychosen.

Samml. zwangl. Abhandl. Bd. 1. H. 6. - Wieweit kommen psychogene Krankheitsprozesse vor, die nicht der Hysterie zuzurechnen. sind. Allgem. Zeitschr. f. Psych. Bd. 43.

Friedmann, Beiträge zu der Lehre von der Paranoia. Monatsschr. f. Psych. u. Neurol. Bd. 17.

Ganser, Ueber einen eigenartigen hysterischen Dämmerzustand. Archiv f. $Y_{\text {sych. }}$ Bd. 30. H. 2. - Zur Lehre rom hysterischen Dämmerzustand. Archiv f. Psych. Bd. 38. S. 34. 
Henneberg, Ueber das Gansersymptom. Allgem. Zeitschr. f. Psych. 1904. Homburger, Lebensschicksale geisteskranker Strafgefangener. Berlin 1912. Jan et, Der Geisteszustand der Hysterischen. Tebers. v. Kahane. 1894.

Jung, Ueber Simulation von Geistesstörung. Journ. f. Psych. u. Neurol. 1902. Ein Fall von hysterischem Stupor bei einer Untersuchungsgefangenen. Journ. f. Psych. u. Neurol. 1902. H. 3.

Kirn, Die Psychosen der Strafhaft. Allgem. Zeitschr. f. Psych. Bd. 45.

Kraepelin, Lehrbuch der Psych. 8. Aufl.

Kutner, Ueber katatonische Zustandsbilder bei Degenerierten. Allgem. Zeitschr. f. Psych. Bd. 67.

F. Leppmann, Simulation von Geisteskrankheit. (Simulation von Krankheiten und ihre Bedeutung. Leipzig 1908.)

Löwenstein, Beitrag zur Differentialdiagnose des katatonen und hysterischen Stupors. Allgem. Zeitschr. f. Psych. Bd. 65 .

Meyer, Bemerkungen zur Differentialdiagnose der psychogenen Reaktionen, mit besonderer Berïcksichtigung der im Kriege beobachteten psychischen Störungen. Archiv f. Psych. u. Nervenkrankh. Bd. 56.

Michaelis, Zur Kenntnis der psychischen Erkrankungen bei Kriegsteilnehmern u. Klinik für psychische und nervöse Krankheiten. Bd. IX. H. 4.

Nitsche u. Wilmanns, Die Geschichte der Haftpsychose. Zeitschr. f. d. ges. Neurol. u. Psych. 1911. Bd. III.

Raecke, Beiträge zur Kenntnis der hysterischen Dämmerzustände. Allgem. Zeitschr. f. Psych. Bd. 58. S. 115́. - Hysterischer Stupor bei Strafgefangenen. Allgem. Zeitschr. f. Psych. Bd. 58. S. 408. - Hysterisches Irresein. Berliner klin. Wochenschr. 1907. Nr. 10. - Ueber hysterische und katatonische Situationspsychosen. Archiv f. Psych. u. Nervenkankh. Bd.55. Raimann, Die hysterischen Geistesstörungen. Wien-Leipzig 1904.

Reich, Ueber akute Seelenstörung in Gefangenschaft. Allgem. Zeitschr. f. Psych. 1871.

Rüđin, Klinische Formen der Gefüngnispsychosen. Allgem. Zeitschr. f. Psych. Bd. 58. S. 447.

Schuster, Entstehen die traumatischen Neurosen somatogen oder psychogen?

Neurologiseh. Zentralblatt. 1916. Nr. 12.

Siefert, Ueber die Geistesstörungen der Strafhaft. Halle, Marhold. 1907.

Siemerling, Strittige geistige Krankheit. Schmidtmann, Handb. d. ges.

Med. Bd. 3. - Simulation und Geisteskrankheit bei Untersuchungsgefange-

nen. Berliner klin. Wochenschr. 1905. Nr. 48.

Skliar, Ueber Gefängnispsychosen. Monatsschr. f. Psych. u. Neurol. Bd. 16.

Stern, Beiträge zur Klinik. Hysterische Situationspsychosen. Archiv f. Psych.

u. Nervenkrankh. Bd. 50.

Sträussler, Beiträge zur Kenntnis der hysterischen Dämmerzustände.

Karl Willmanns, Ueber Gefängnispsychosen. Samml. zwangl. Abhandl. 1908. H. 1. Wollenberg, Ueber die Wirkung der Granaterschütterung. Archiv f. Psych. u. Nervenkrankh. Bd. 56. 